University of Louisville

ThinkIR: The University of Louisville's Institutional Repository

Electronic Theses and Dissertations

8-2018

\title{
EGFR signaling from the early endosome.
}

Julie A. Gosney

University of Louisville

Follow this and additional works at: https://ir.library.louisville.edu/etd

Part of the Biochemistry Commons, Cancer Biology Commons, Cell Biology Commons, and the Pharmacology Commons

\section{Recommended Citation}

Gosney, Julie A., "EGFR signaling from the early endosome." (2018). Electronic Theses and Dissertations. Paper 3007.

https://doi.org/10.18297/etd/3007

This Doctoral Dissertation is brought to you for free and open access by ThinkIR: The University of Louisville's Institutional Repository. It has been accepted for inclusion in Electronic Theses and Dissertations by an authorized administrator of ThinkIR: The University of Louisville's Institutional Repository. This title appears here courtesy of the author, who has retained all other copyrights. For more information, please contact thinkir@louisville.edu. 


\title{
EGFR SIGNALING FROM THE EARLY ENDOSOME
}

\section{By}

\author{
Julie A. Gosney \\ B.A., Anderson University, 2012 \\ M.S., University of Louisville, 2016
}

\begin{abstract}
A Dissertation
Submitted to the Faculty of the

School of Medicine of the University of Louisville

In Partial Fulfillment of the Requirements

for the Degree of
\end{abstract}

Doctor of Philosophy in Pharmacology and Toxicology

Department of Pharmacology and Toxicology

University of Louisville

Louisville, KY

August 2018 
Copyright 2018 by Julie Gosney

All Rights Reserved 

EGFR SIGNALING FROM THE EARLY ENDOSOME

By

Julie A. Gosney

B.A., Anderson University, 2012

M.S., University of Louisville

Dissertation Approved on

June 6, 2018

By the following Dissertation Committee:

Brian P. Ceresa, Ph.D.

Joshua Hood, M.D., Ph.D.

Levi Beverly, Ph.D.

Michael Merchant, Ph.D.

Geoffrey Clark, Ph.D. 


\section{ACKNOWLEDGMENTS}

There are several people to whom I owe a great debt of gratitude; I would not have made it here without them. First, to my family, especially my sister Jessica--I am deeply thankful for your love, support, guidance, and encouragement over these last four years. They have been the hardest years for me so far, and every single one of you played an integral role in getting me through each one. To my nephew Kolton and my niece Oakley--thank you for reminding me that getting a $\mathrm{PhD}$ is not the most important thing in this world!

To my mentor, Dr. Brian Ceresa, thank you for your patience, advice, and openness to brainstorming new ideas with me. I am grateful for the independence you were willing to give me, and for allowing me the freedom to test my own ideas and hypotheses. Also, to my committee members, thank you for your dedication of time, resources, ideas, and encouragement.

I would particularly like to thank all the friends I have made in the Pharmacology and Toxicology department. It has been so helpful to commiserate together! I wish you all the best of luck in research and in life, and a speedy graduation to those who are still working toward their $\mathrm{PhD}$. In the words of a good friend and confidante, "If I can do it, you can do it." Hang in there!

Lastly, I want to point out that I would not be here if it weren't for a loving and patient Higher Power. This endeavor I undertook four years ago would have 
never come to completion if it weren't for His guidance and love carrying me through the entire experience. I am so grateful. 


\section{ABSTRACT \\ EGFR SIGNALING FROM THE EARLY ENDOSOME \\ Julie Ann Gosney \\ June 6, 2018}

The epidermal growth factor receptor (EGFR) is a receptor tyrosine kinase that is an integral component of proliferative signaling. When activated by a ligand at the plasma membrane, EGFR dimerizes with another ErbB family receptor, leading to kinase domain activation and transphosphorylation of Cterminus tyrosine residues. These phosphotyrosines act as crucial regulators of EGFR signaling as effector proteins dock to the receptor at these sites. The receptor undergoes clathrin-mediated endocytosis into early endosomes, where it can then be trafficked to a lysosome for degradation. However, the kinase domain of EGFR retains its activity during trafficking, suggesting that EGFR can continue to elicit signaling cascades after internalization. Unfortunately, there is no consensus as to how EGFR spatial regulation affects its signaling or interaction with downstream effectors. We hypothesize that EGFR localization in early endosomes permits unique interactions with downstream effectors. In an effort to identify proteins that uniquely associate with the internalized EGFR, we have developed a strategy for isolating early endosomes and analyzed the protein make-up of these compartments. HeLa cells were stimulated with and without EGF, and the post-nuclear supernatant (PNS) was loaded onto a $17 \%$ 
Percoll gradient which separates endosomes based on density. The gradient was fractionated, and fractions containing early endosomes were pooled and immunoisolated with an EEA1 monoclonal antibody. The morphology of isolated compartments was monitored using transmission electron microscopy.

Endosomes were also subjected to liquid chromatography/tandem mass spectrometry (LC-MS/MS) for proteomic analysis. The isolation method precipitates early endosome marker proteins, but not marker proteins specific to other organelles. Electron microscopy revealed that the isolated vesicles are intact and have an average diameter of $68.63 \pm 26.74 \mathrm{~nm}$. More than 900 proteins were isolated with the early endosome, and five proteins were detected in endosomes in a ligand-dependent manner: EGFR, RUFY1, STOML2, PTPN23, and CCDC51. RNAi was used to knock down RUFY1 and PTPN23 in HeLa cells to monitor changes in the trafficking of EGFR. Knock-down studies revealed that loss of PTPN23 leads to endocytic accumulation of EGFR and decreased degradation of the ligand:receptor complex. Loss of RUFY1 resulted in a significant increase in cell growth as well as a resistance to cell death.

We have developed a rapid and high-throughput isolation technique to collect early endosomes from HeLa cells that can be analyzed by LC-MS/MS to detect a distinct proteome. The purification protocol yields a highly enriched population of early endosomes, as evidenced by immunoblot and LC-MS/MS analyses. The isolated vesicles are also intact and exhibit morphology and size distribution similar to early endosomes. These data provide evidence that endocytic trafficking of the activated EGFR changes the protein composition and 
signaling potential of the early endosome. 


\section{TABLE OF CONTENTS}

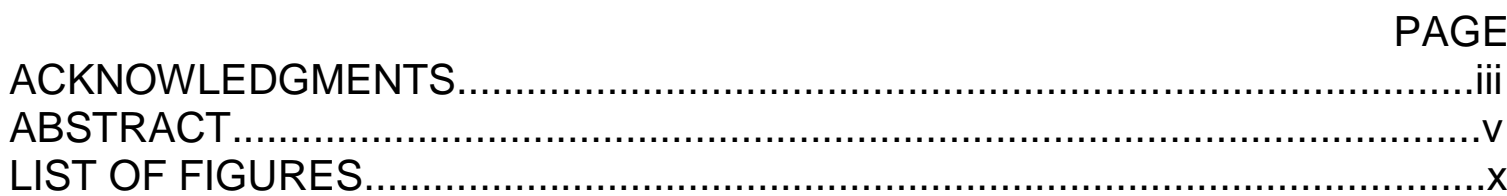

\section{CHAPTERS}

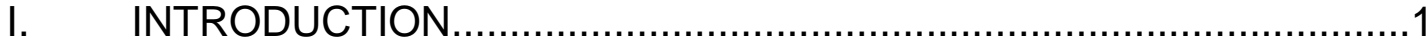

a. Epidermal Growth Factor Receptor...........................................

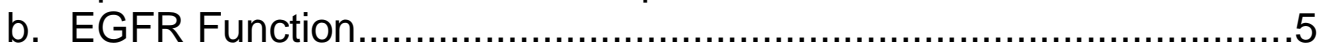

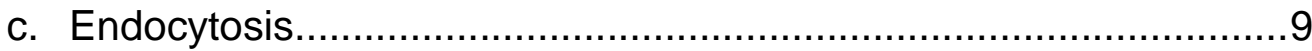

d. Significance and Statement of Specific Aims.............................17

II. MATERIALS AND METHODS..................................................21

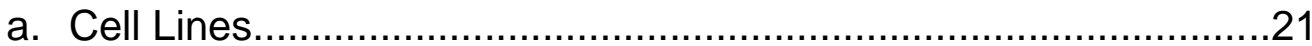

b. Post-Nuclear Supernatant Preparation........................................21

c. Percoll Gradient Fractionation...................................................22

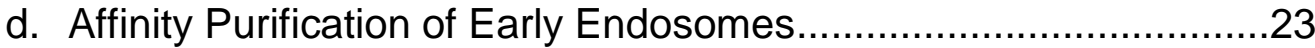

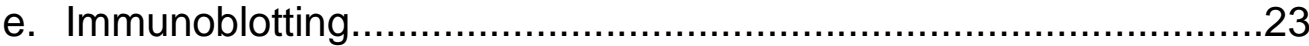

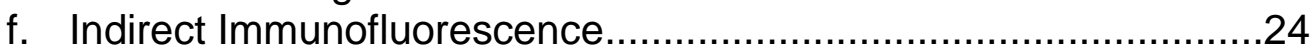

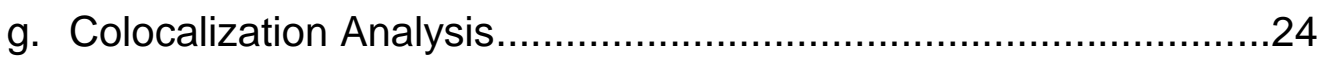

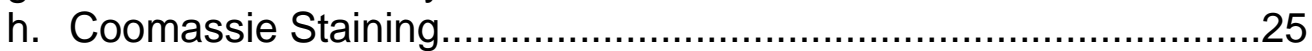

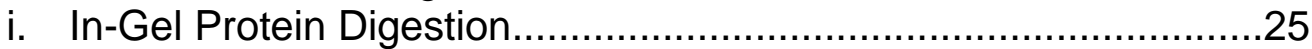

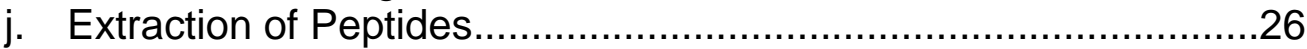

k. Liquid Chromatography/Tandem Mass Spectrometry (LC-

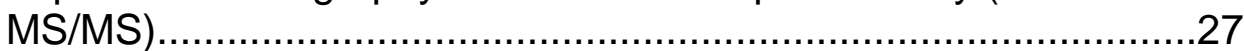

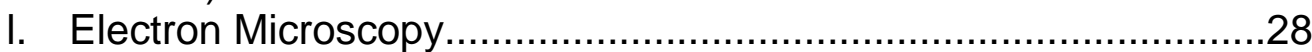

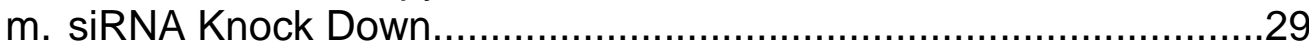

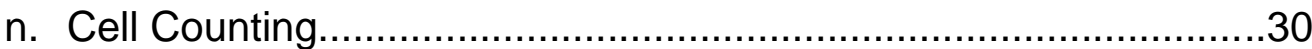

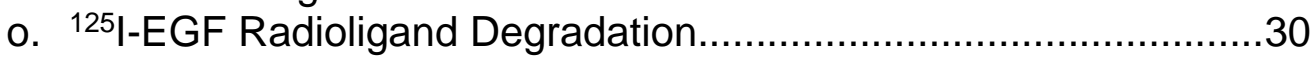

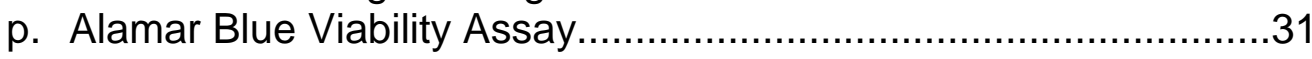

q. Inhibition of EGFR Phosphorylation via AG1478 .........................31

r. Statistical Analyses...........................................................32

III. ISOLATION OF EGFR-CONTAINING EARLY ENDOSOMES............33

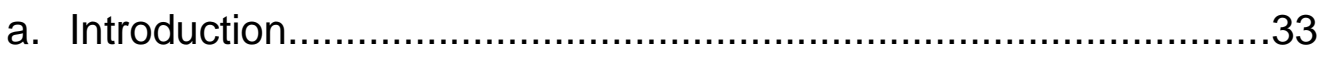

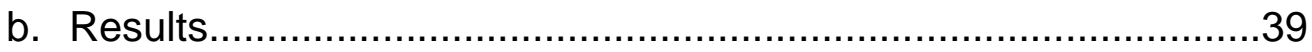

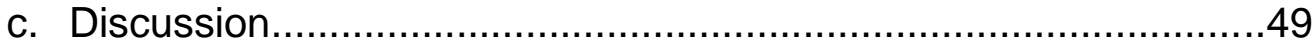

IV. THE RELATIONSHIP OF RUFY1 AND PTPN23 WITH EARLY

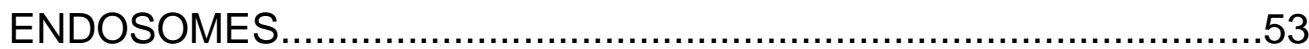

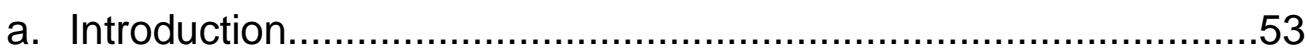

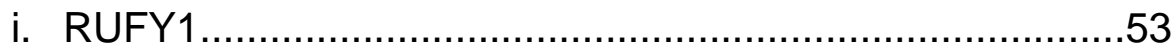




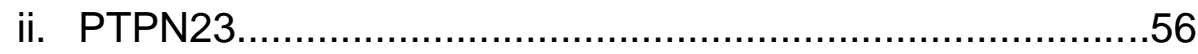

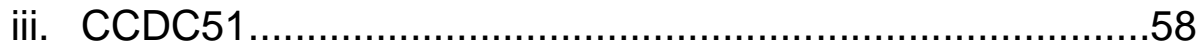

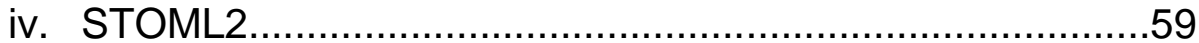

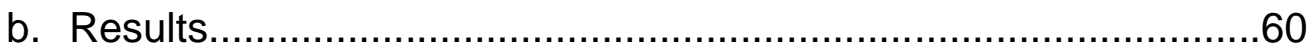

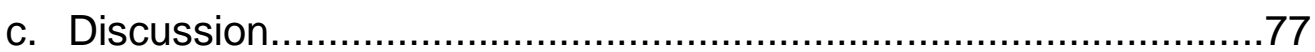

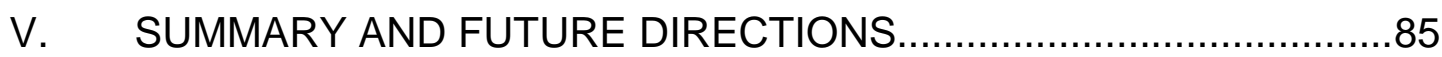

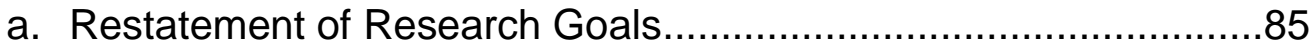

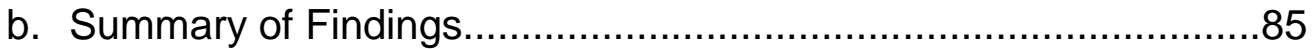

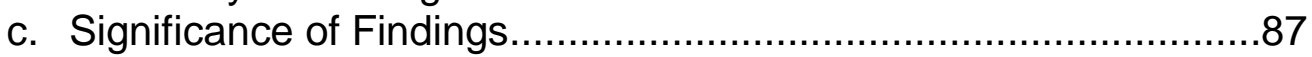

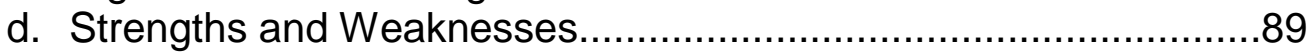

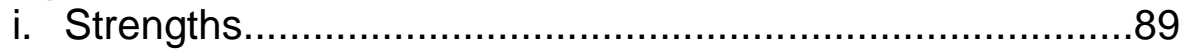

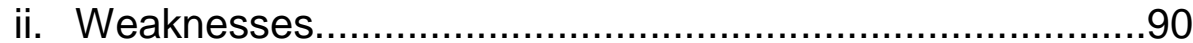

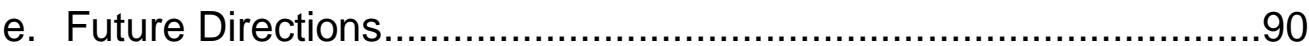

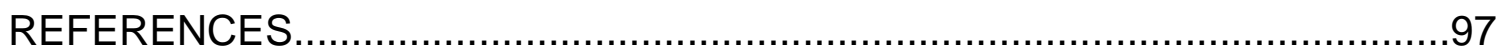

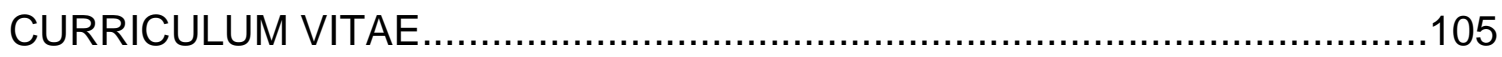




\section{LIST OF FIGURES}

FIGURE

PAGE

1.1 Epidermal Growth Factor Receptor structure .........................................

1.2 The effects of EGFR knockout on craniofacial development in mice..............6

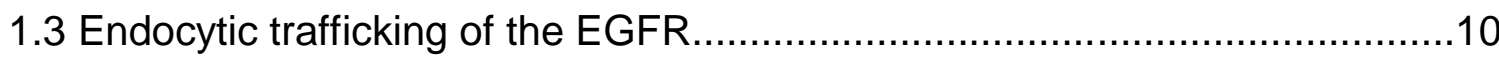

3.1 EGF colocalization with EEA1-positive vesicles.......................................41

3.2 Total and phosphorylated EGFR colocalize with early endosomal markers following isotonic Percoll gradient fractionation..............................................42

3.3 Schematic of the Percoll Gradient purification protocol...............................44

3.4 Affinity purification of early endosomes from Percoll gradient fractions.........46

3.5 Early endosome and membrane trafficking proteins.................................48

3.6 Receptors detected in early endosomes and proteins that associate with the early endosome in an EGF-dependent manner...........................................50

4.1 Secondary protein structure of RUFY1 and PTPN23................................55

4.2 Receptors detected in early endosomes and proteins that associate with the early endosome in an EGF-dependent manner..........................................61

4.3 RUFY1, STOML2, and PTPN23 colocalize with early endosomes and internalized EGF. 63

4.4 EGF and EGFR colocalization with EEA1 in siCON, RUFY1 KD, and PTPN23

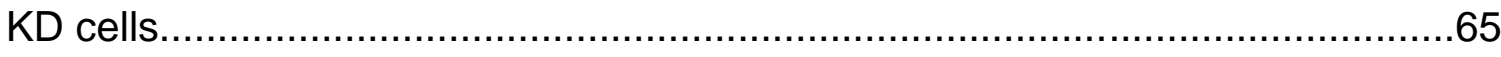

$4.5^{125}$ I-EGF radioligand trafficking in RUFY1 KD and PTPN23 KD cells...........68 
4.6 Cell number of siCON, RUFY1 KD, and PTPN23 KD HeLa cells under

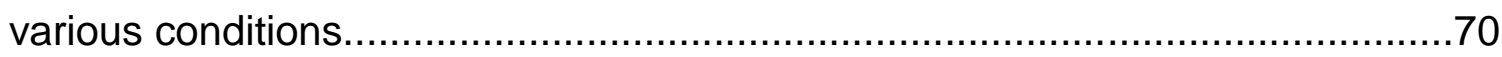

4.7 Cell morphology of HeLa cells transfected with siCON, RUFY1, and PTPN23 siRNA, and treated with AG1478

4.8 PARP-cleavage induction in RUFY1 KD and PTPN23 KD cells..................75 4.9 Cell viability in siCON, RUFY1 KD, and PTPN23 KD cells under various

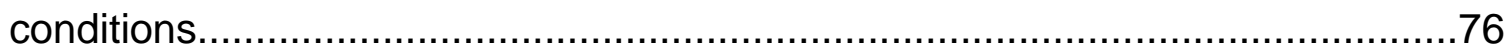

5.1 A schematic representation of a signaling pathway permitting Etk to drive cell

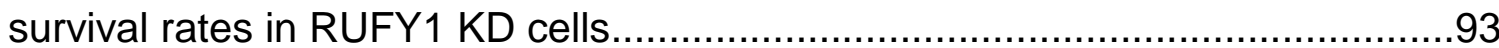




\section{CHAPTER I \\ INTRODUCTION}

\section{A. Epidermal Growth Factor Receptor}

The study of growth factors and their receptors is a rapidly growing field of research that began in the 1960s when Stanley Cohen and Rita Levi-Montalcini discovered the first growth factors: Nerve Growth Factor (NGF) and Epidermal Growth Factor (EGF) [1, 2]. NGF and EGF are small proteins that stimulate the growth of nerve and epithelial cells, respectively. Before the discovery of growth factors, scientists knew that cells could signal for growth and proliferation, particularly during development—-but they didn't understand how this phenomenon occurred [1]. The identification of NGF and EGF was pivotal, as these proteins could now be studied directly in order to elucidate their functions in cellular and organ physiology [3]. These discoveries were a major scientific breakthrough that earned Cohen and Levi-Montalcini a shared Nobel Prize in 1986 [4].

Upon Levi-Montalcini's discovery of NGF, she and Cohen worked diligently to understand its function. Because NGF was discovered in the submaxillary glands of mice, they continued using these extracts to study its effects on neuronal growth [5]. However, injecting mouse salivary gland extracts into newborn pups ended up yielding other, unexpected phenotypes. Cohen noted that these new changes were not due to the induction of nerve growth, but 
due to changes in epithelial tissues [2]. During Cohen's original experiments characterizing his novel epithelial tissue-specific growth factor, he referred to the protein as the "tooth-lid factor" [2]. While the title was only temporary until he coined the name EGF, the "tooth-lid factor" was so named because it directly described the effects he saw in mice injected with EGF: it increased the rates of tooth growth and eyelid opening in newborn pups [2].

The discovery and characterization of growth factors led to another essential discovery—growth factor receptors. Once Cohen had discovered EGF, he immediately began working to isolate and identify its receptor. In 1982 Cohen successfully isolated and characterized EGF's cognate receptor from A431 cells and mouse livers $[3,6]$. In this work, the receptor was identified as a $170 \mathrm{kDa}$ glycoprotein with intrinsic tyrosine kinase activity. Over the next three decades, the EGF-receptor was studied extensively, leading to the most current understandings of the signaling, trafficking, regulation, and physiologic implications of this protein.

The epidermal growth factor receptor (EGFR) is a membrane spanning receptor tyrosine kinase (RTK) that is an integral component of proliferative signaling. Part of the ErbB family of receptors, EGFR is also referred to as ErbB1 or Her1 (human ErbB1). The other ErbB family members include ErbB2 or Her2, ErbB3, and ErbB4. Structurally, EGFR and the ErbB receptors are made up of three domains: 1) the extracellular ligand binding domain, 2) the transmembrane alpha helices, and 3) the intracellular domain which contains the kinase domain and multiple tyrosine residues on the C-terminus (Figure 1.1). The extracellular 
domain contains two ligand-binding regions that alternate with two cysteine-rich regions. Binding of one of EGFR's seven endogenous ligands-epidermal growth factor (EGF), heparin-binding EGF-like growth factor (HBE), epiregulin (EPR), epigen, transforming growth factor alpha (TGFa), amphiregulin (AR), and betacellulin (BTC) - to the extracellular region induces a conformational change in which the ligand binding regions directly interact with the ligand [7]. This structural change exposes the two cysteine-rich domains, allowing the receptor to associate with the exposed cysteine-rich domains of another ligand-bound EGFR or ErbB family RTK monomer to form a dimer [7].

The binding of two ligand-bound receptors causes the formation of a dimer, which is required for receptor activation [8]. The dimer pair interaction structurally induces the activation of the kinase domains. The kinase domain of one receptor then phosphorylates the C-terminal tyrosine residues of its dimer partner (transphosphorylation) [8]. The cytosolic phosphorylated tyrosine residues of the EGFR serve as docking sites for effector molecules that contain phosphotyrosine binding (PTB) or src homology 2 (SH2) domains [9]. Proteins that dock to the phosphorylated tyrosine residues of an activated EGFR will recruit and/or activate other proteins, thus inducing a signaling cascade. For example, at the plasma membrane, an activated EGFR dimer will recruit the scaffolding proteins Shc and Grb2 to bind to phosphotyrosines and the EGFR kinase domains phosphorylate these proteins [9]. Activation of Grb2 leads to the recruitment of SOS and induction of the Ras-ERK pathway which is known to activate cell proliferation [9]. Activation of Shc leads to induction of the JNK 


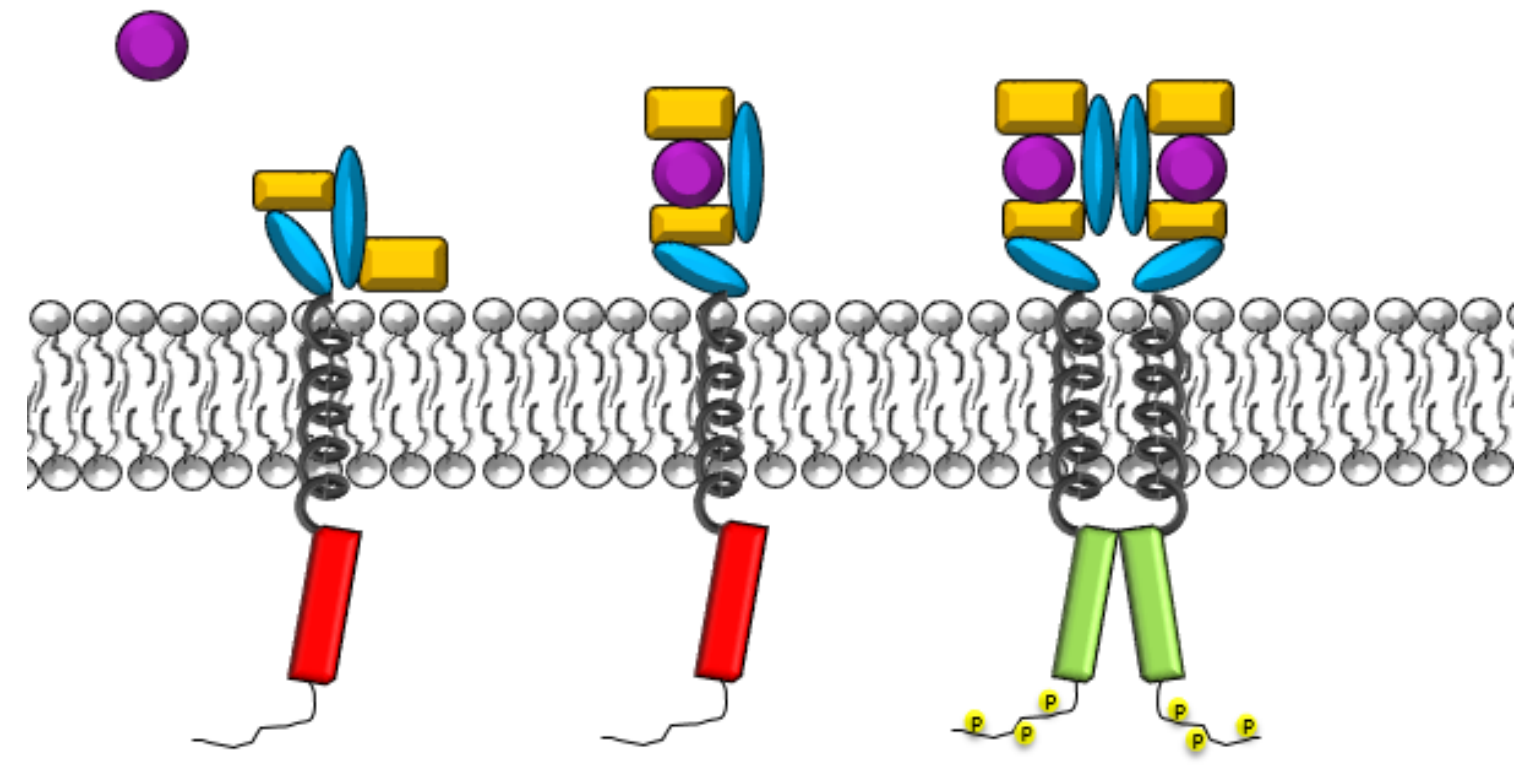

Figure 1.1 Epidermal Growth Factor Receptor structure. When unbound by a ligand, the receptor is often found in a "closed" conformation in which the cysteine-rich regions of the extracellular region interact. When a ligand is introduced it binds to the two ligand binding domains and a conformational change occurs, exposing a cysteine-rich region which can then interact with an exposed cysteine-rich region of another ligand-bound ErbB family receptor. Red=inactive kinase domain; green=active kinase domain; orange=ligand binding domains; blue=cysteine-rich domains. 
pathway which is also known to be involved in the induction of cell proliferation via the activation of nuclear transcription factors [9].

\section{B. EGFR Function}

EGFR signaling plays critical roles in cell proliferation, migration, differentiation, wound healing, development, and tissue homeostasis. Growth factors are mitogens, and the EGFR is an important mitogenic signal transducer. In fact, the EGFR is an essential component of cellular physiology and is critical for proper tissue development. In 1995, Miettinen et al. produced a line of EGFR knockout mice to determine the physiologic importance of the receptor in development [10]. They found that their line of knockout (-/-) pups only survived for eight days after birth. The mice also had significant developmental impairments in multiple epithelial tissues and organs including the lungs, skin, and gastrointestinal tract [10]. In 1999 Miettinen also documented that EGFR (-/-) pups have compromised craniofacial development (Figure 1.2) [11]. EGFR is clearly a crucial component for normal tissue development and homeostasis throughout the body.

While the absence or reduction of EGFR signaling unquestionably causes severe developmental impairments, excessive EGFR signaling also has detrimental effects. It has been well documented that the receptor is often overexpressed and/or over-activated in many different cancer types, including non-small cell lung cancer, breast, pancreatic, cervical, head and neck, and colorectal cancer among others [12-17]. Glioblastoma multiforme (GBM) was 


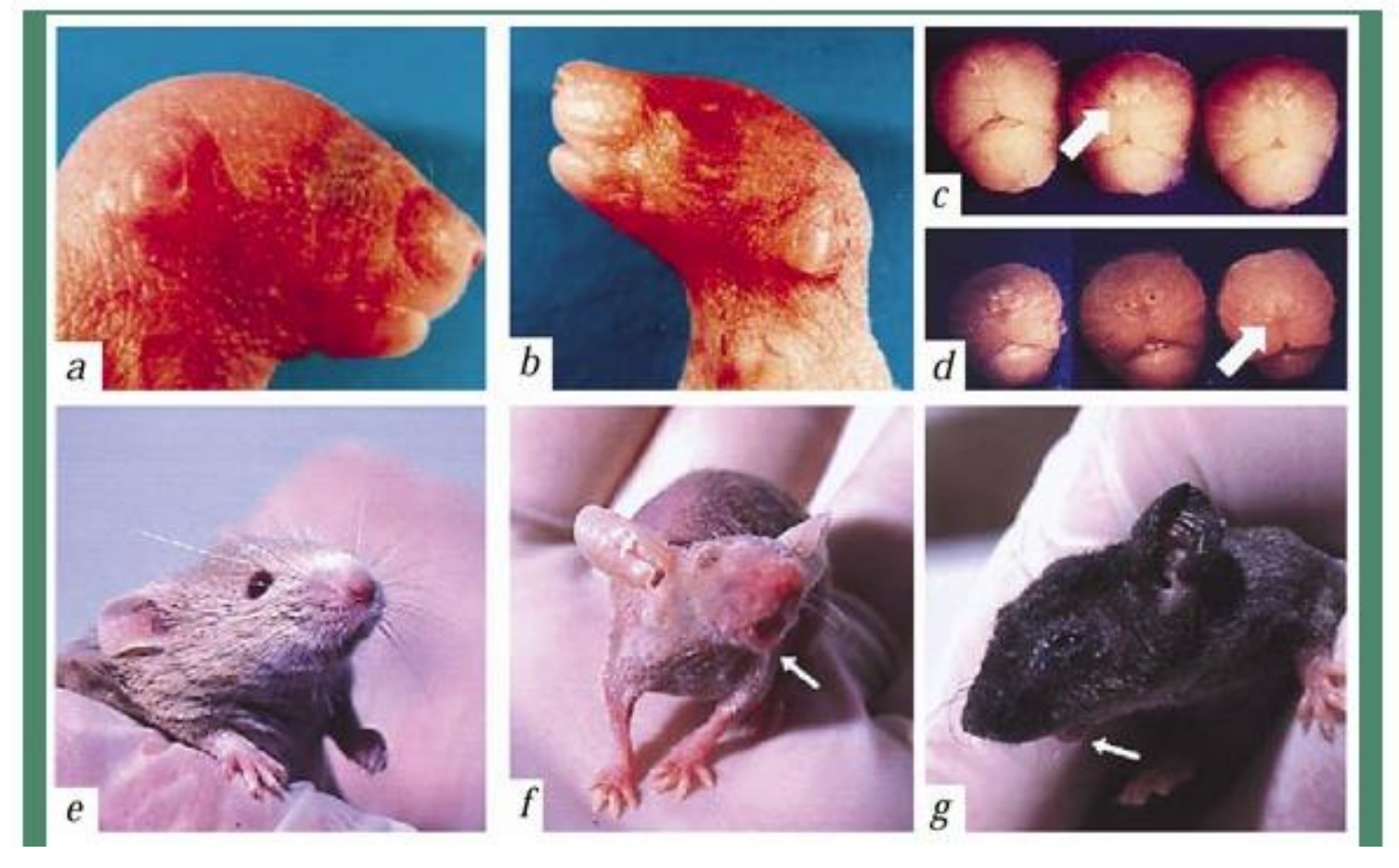

Figure 1.2 The effects of EGFR knockout on craniofacial development in mice. a) A wild-type newborn mouse has a round snout, whereas b) an EGFR (/-) mouse has a narrower snout. c) The nostrils of wild-type mice are open (arrow), d) but are often closed or narrow (arrow) in EGFR (-/-) mice. e) A wildtype mouse at four months of age has long whiskers and a well-shaped snout, whereas $\mathbf{f}, \mathbf{g}$ ) EGFR (-/-) mice have smaller lower jaws (arrows), deformed eyes, and short, curly whiskers. (Used with permission [license \# 4332530233617] from Nature Genetics (1999), 22, 69-73) 
the first cancer associated with mutated EGFRs. Approximately $70 \%$ of GBMs express a constitutively active truncation mutant (EGFRvIII) with deletions in exons 2-7 of the extracellular domain [18]. The loss of the extracellular domain allows spontaneous, ligand-independent receptor dimerization and activation. The EGFRvIII mutation is also overexpressed due to gene amplification. In addition, constitutively active mutations of the receptor are frequently associated with non-small cell lung cancer (NSCLC), one of the most common and lethal forms of lung cancer with a 5 -year survival rate of only $17 \%[19,20]$. Approximately $50 \%$ of NSCLC patients who identify as "never smokers" have EGFR exon 19 deletions, exon 20 insertions, and the amino acid point mutation L858R [21]. All three of these mutations change the kinase domain of the receptor to favor an active state to induce constitutive kinase activity and signaling of EGFR.

In contrast to activating mutations, other cancers seem to be driven by EGFR overexpression (e.g. colorectal, breast, pancreatic, and head and neck). There are multiple mechanisms by which EGFR levels may be enhanced, including increased gene amplification, mRNA production, or protein translation. In breast carcinomas, EGFR gene amplification occurs in $6 \%$ of tumors, and $91 \%$ of these tumors also exhibit EGFR protein overexpression [13]. In approximately $20 \%$ of high grade cervical intraepithelial neoplasia (CIN) and invasive cervical carcinomas, EGFR gene amplification has also been linked to EGFR overexpression and poor prognosis [15]. However, approximately $65 \%$ of pancreatic ductal adenocarcinomas (PDAC) exhibit overexpression of EGFR, but 
without EGFR-specific gene amplification [14]. For PDAC, these changes in protein levels are likely due to overexpression of other ErbB family members such as ErbB2 [14] .

There are currently several FDA-approved anti-EGFR cancer therapies on the market. These drugs are generally split up into two classes-monoclonal antibodies and kinase inhibitors. The monoclonal antibodies (e.g. Cetuximab) target the extracellular portion of the receptor and block the interaction of the receptor with extracellular activating ligands. Cetuximab is approved for the treatment of cancers that express high levels of EGFR, including colorectal and head and neck cancers [22]. Tyrosine kinase inhibitors (TKIs) (e.g. Erlotinib) are small molecules that enter the cell and bind (reversibly or irreversibly) to the kinase domain of the receptor, blocking effector activation and downstream signaling cascades. Erlotinib is approved for use in NSCLC patients whose cancers express EGFR kinase activating mutations, including exon 19 deletion and exon 21 (L858R) substitution mutations [23]. While these drugs tend to be very effective initially for patients whose cancers express over-activated receptors, eventually all of these patients will develop resistance to the drugs [24]. The exact mechanism by which this resistance occurs is unclear, although several studies suggest that the inhibited receptors can form heterodimers with other ErbB family members and even the insulin-like growth factor type-1 receptor (IGF-1R), another RTK with mitogenic effects [25]. In addition to drug resistance, patients also tend to develop adverse side-effects to anti-EGFR therapies. While some rare adverse reactions have occurred, the most common 
side-effects are skin lesions and conjunctivitis [26, 27].

Although significant advances in cell biology research have led to the development of targeted therapeutics such as the anti-EGFR cancer drugs, these therapies provide an overall survival increase of only a few months for these subsets of cancer patients [28]. This lack of improvement, coupled with the resistance that develops from these treatments, reveals that there is an enormous gap in the field's understanding of mitogenic signaling. If more robust cancer treatments are to be developed, it is essential that the mechanisms driving the proliferation and metastasis of these cells are elucidated. Because targeting the EGFR directly has yielded only a minimal benefit to patient outcomes, it would be prudent to find more specific targets within the receptor's signaling pathways.

Unfortunately, there are still many facets to EGFR signaling that have yet to be elucidated. One such question that could play an important role in understanding EGFR downstream signaling is: how does the spatial regulation of the receptor affect its signaling? This is the primary question we seek to answer in this work.

\section{Endocytosis}

The major mechanism through which the EGFR is regulated is the endocytic pathway (Figure 1.3). Once the activated dimer is formed it migrates to a clathrin-rich region of the plasma membrane where it invaginates and pinches off into a clathrin-coated vesicle. The clathrin is then shed, and this intermediate 


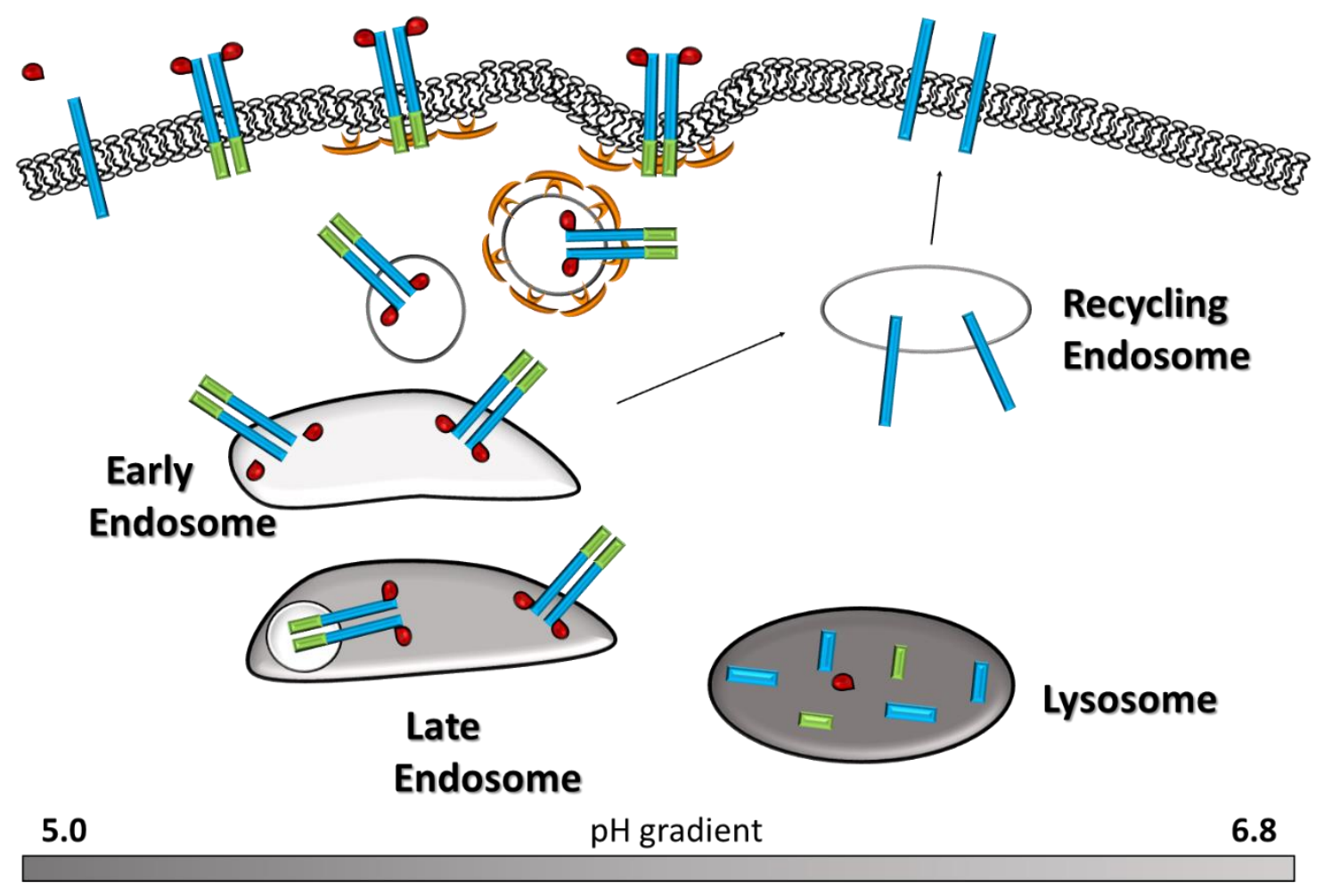

Figure 1.3 Endocytic trafficking of the EGFR. The EGFR undergoes liganddependent, clathrin-mediated endocytosis. Early endosomes either mature into late endosomes where their contents are transported to lysosomes for degradation, or the receptor can be trafficked back to the plasma membrane via a recycling endosome. The increasing acidity of these compartments induces dissociation of the ligand:receptor complex. The EGFR can continue to elicit signaling cascades from the early endosome. Red=ligand, green=active kinase domain, orange=clathrin . 
vesicle fuses with an early endosome [29]. The early endosome, sometimes referred to as the signaling or sorting endosome, is the epicenter of endocytic trafficking. This organelle is responsible for determining the fate of its contents, depending on several factors including what ligand is bound and with which ErbB family member the EGFR is dimerized. The early endosome can send proteins back to the plasma membrane (recycling) [30], or sequester cargo to be sent to and degraded in a lysosome [31]. It has been reported that endocytosis can also transport EGFR to the endoplasmic reticulum and the nucleus [32,33]. Over time early endosomes increase in acidity and "mature" into late endosomes [34]. The late endosomes will fuse with a lysosome, where the receptor is degraded and thus down-regulated. It is important to note that while in the early endosome the kinase domain of the receptor remains exposed to the cytosol, allowing the receptor to continue interacting with other proteins and downstream effectors [35].

Until the 1990s, EGFR spatial regulation by the endocytic pathway was viewed primarily as a mechanism for downregulating receptor expression after activation. Chen et al. discovered in 1989 that an 18 amino acid sequence of the EGFR C-terminus is required for both kinase activation and internalization/ downregulation of the receptor [36]. Shortly thereafter in 1990, Wells et al. discovered that mutated EGFRs that are endocytosis-deficient enhance cell transformation [8]. They concluded from this study that without endocytosis, the receptor cannot be degraded and thus increases ligand-dependent cell transformation. As such, endocytosis was viewed as a negative regulator of 
EGFR expression. However, in 1994 Bergeron's group discovered that certain EGFR scaffolding proteins involved in Ras signaling (i.e. Shc, Grb2, and mSOS) retain their association with active EGFR when it is internalized [30]. Further, in 1996, Vieira et al. created an endocytosis-defective cell line to study the changes in EGFR downstream effector activation after EGF treatment. They found that blocking EGFR endocytosis enhanced PLCY and Shc phosphorylation, but decreased ERK1/2, EGFR, \& PI3K phosphorylation [31]. These works, among others, pushed the field of EGFR trafficking toward a new line of thinking: endocytosis can positively and negatively affect receptor:effector communication. However, there is currently no consensus on how these changes occur, or how they contribute to EGFR signaling and overall cellular physiology.

It has been well established that the endocytic pathway is important in the spatial as well as temporal regulation of the EGFR. The receptor is regulated temporally by the amount of time it takes to traverse the entire endocytic pathway, and how long the receptor is sequestered at each point of the pathway. About $10 \%$ of a cell's inactive EGFRs are constitutively recycled into early endosomes and back to the plasma membrane [37]. It has also been shown that different ligands induce varied endocytic responses. For example, it is known that TGF $\alpha$ triggers rapid recycling of the receptors, while EGF triggers the receptor to be maintained in early endosomes, leading to its eventual degradation and downregulation [38].

One explanation for these distinct differences in ligand:receptor trafficking amongst ligands is their affinity for the receptor. EGF is known to have a 
relatively high affinity for binding EGFR of $0.42 \mathrm{nM}$ [39], and thus does not dissociate from the receptor in the acidic environment of early endosomes $(\mathrm{pH}$ 6). However, TGFa has a slightly lower affinity for the receptor at 11.9nM [39], causing the ligand:receptor complex to dissociate in early endosomes, permitting receptor recycling to the plasma membrane [38]. Though both ligands are considered to have "high" affinities for EGFR [40], they do not have the same effects on receptor trafficking. Conversely, the work of Moriai et al. suggests that EGF and TGFa have similar affinities for EGFR, and that certain mutations in the ligand binding domain of some EGFRs may contribute to the different binding affinities and downstream signaling effects of ligands [41].

The endocytic pathway is a complex and dynamic system made up of various organelles [42]. Endocytosis is a fundamental cellular process in which extracellular nutrients and portions of the plasma membrane are internalized into the cell [42]. A section of plasma membrane will invaginate and pinch off to form an intracellular vesicle [42]. These preliminary vesicles are typically formed with the assistance of several adaptor and scaffolding proteins that are found near or on the plasma membrane [43]. For example, clathrin-mediated endocytosis (CME) requires the cytosolic protein clathrin, which forms a triskelion coat around the portion of plasma membrane that is to be internalized [43]. This process also requires another protein called dynamin that plays a critical role in the scission of the new vesicle from the plasma membrane [43]. CME is also referred to as receptor-mediated endocytosis, as it occurs when a plasma-membrane receptor is bound and activated by an extracellular ligand, triggering its internalization 
(e.g. EGF binding to EGFR) [43]. During CME, after the new vesicle is created the clathrin coat is shed. This intermediate vesicle is then trafficked to and fused with an endosome, of which there are several types [43]. The destination of each vesicle is specific to its cargo and has a direct impact on the fate of that cargo. This process is highly regulated by actin filaments and microtubules, adaptor proteins, and GTPases such as the RAB proteins [43]. The RAB family of proteins are Ras-like GTPases that play an essential role in the endocytic pathway by recruiting effectors that induce the formation and motility of endosomes [44]. There are more than 60 different RAB proteins, and each one is generally specific to a distinct cellular compartment [45]. In 1990, Chavrier and Zerial determined that RAB5 is specific to the plasma membrane and early endosomes, and RAB7 localizes to late endosomes [46]. RAB11 is another member of the RAB family that is specifically localized to recycling endosomes [47]. These three RAB proteins are the major players involved in generating the vesicles involved in the early phases of endocytosis (i.e. early, late, and recycling endosomes).

Clathrin-mediated endocytosis is the primary pathway by which activated EGFR enters early endosomes when stimulated with low, endogenous concentrations of ligand (i.e. $\sim 1 \mathrm{ng} / \mathrm{mL}$ or $0.16 \mathrm{nM}$ EGF) [48]. However, there are other types of endocytosis that utilize adapter proteins similar to clathrin. For example, caveolae are small pits in the plasma membrane made up of lipid rafts and the protein caveolin [49]. Caveolae are also involved in the endocytosis of plasma membrane and extracellular ligands and nutrients. This process is similar 
to $\mathrm{CME}$, as it also requires dynamin for the scission and formation of vesicles [43]. It also differs from CME in that caveolae cargo can either be delivered to early endosomes or to caveosomes [49]. Caveosomes are pH-neutral intracellular vesicles that strictly contain cargo transported from caveolae, and they do not contain early endosome proteins, although their function is similar to early endosomes [49]. There are other routes of endocytosis that do not involve clathrin or caveolae, which are collectively termed clathrin- and caveolaeindependent endocytosis [43]. The major routes of EGFR-endocytosis are CME at low ligand concentrations, and caveolae-mediated endocytosis (CavME) at high ligand concentrations (i.e. $>10 \mathrm{ng} / \mathrm{mL}$ or $>1.6 \mathrm{nM}$ EGF) [48].

Whether via CME or CavME, most endocytic cargo will be transported into early endosomes. Early endosomes are so named because they are found in the cytosol near the plasma membrane, and they are the first major constituent within the endocytic pathway. These organelles are considered to be slightly acidic, with a $\mathrm{pH}$ of $\sim 6.0$ and a density of $1.035-1.042 \mathrm{~g} / \mathrm{mL}[34,50]$. Early endosomes are the first pit-stop in the pathway, and the sequestration of receptors here is critical to their ultimate fate.

There are two distinct populations of early endosomes: dynamic and static. In 2006 Lakadamyali and Rust discovered and characterized these types of endosomes by their mobility and maturation kinetics [51]. To do this, RAB5 and RAB7 were fluorescently tagged and the association of these proteins with various ligands that undergo CME were tracked using live cell imaging. They found that the static population of early endosomes are the most abundant, and 
they mature very slowly. The dynamic early endosomes are strongly associated with microtubules and mature rapidly into late endosomes. Remarkably, ligand:receptor complexes that are normally degraded via the endocytic pathway, such as EGF:EGFR and low density lipoprotein and its cognate receptor (LDL:LDLR), were preferentially trafficked into the dynamic population of early endosomes. On the other hand, complexes that are typically recycled, such as transferrin and its receptor (Tfn:TfnR), were trafficked non-specifically to both populations of early endosomes [51]. This study provides further evidence that the endocytic pathway is highly regulated and the fate of every cargo that enters is tightly monitored.

As evidenced by the fates of the EGFR and TfnR, early endosomal contents can be segregated into various legs of the endocytic pathway. Certain proteins that are marked for recycling back to the plasma membrane can be sent directly to the cell membrane by an intermediate vesicle, or trafficked to a larger specialized vesicle called the recycling endosome [42]. Contents that are not recycled will remain sequestered in early endosomes. The organelles that comprise the endocytic pathway possess proton pumps on their membranes that maintain their luminal $\mathrm{pH}[34,52]$. However, over time these pumps will increase the acidity of early endosomes. This is a crucial step in the "maturation" process of an early endosome into a late endosome [53].

Late endosomes are also termed "multivesicular bodies" or MVBs, and have an acidic $\mathrm{pH}$ of $\sim 5.3$ and a density of $1.048-1.070 \mathrm{~g} / \mathrm{mL}[34,50]$. The name MVBs comes from the presence of intraluminal vesicles that are created within 
the organelle [54]. These are small, membrane-bound vesicles that are internalized from the outer membrane of the late endosome itself, which is also referred to as the "limiting membrane" [54]. Receptors and other cargo found in the late endosome that are to be degraded are marked as such by entering into these intraluminal vesicles [54]. There are specific protein complexes called ESCRTs (endosomal sorting complex required for transport) that are required for the transport of cargo from the limiting membrane into intraluminal vesicles of late endosomes [55]. ESCRT complexes specifically interact with ubiquitinated cargo within the late endosome, as ubiquitination marks proteins for degradation [55]. Once a cargo is sequestered into an intraluminal vesicle, it is destined to be transported to a lysosome where it will be degraded. The late endosome will temporarily fuse with a lysosome and transfer its contents (intraluminal vesicles) to the lysosome [56].

Lysosomes are separate organelles that have a $\mathrm{pH}$ of $\sim 5.0$ and a density of between $1.070-1.110 \mathrm{~g} / \mathrm{mL}[34,50]$. The sole purpose of a lysosome is to degrade proteins, as they are filled with acid hydrolases to break down cargo [56]. This compartment is the final stop in the endocytosis of cargo that is marked for degradation (i.e. ubiquitinated). This degradation process is essential for the down-regulation of a multitude of cellular components, including signaling receptors like EGFR [56].

D. Significance and Statement of Specific Aims

The EGFR is an important endogenous RTK that is overexpressed and/or 
hyperactivated in multiple cancer types (e.g. breast, colon, lung, pancreatic, etc.). While there are currently several FDA-approved therapies that target EGFR in these cancers, in many cases these cancers either do not respond or quickly develop resistance [24]. Further, patients who do benefit from anti-EGFR therapies only gain a few additional months of life. As a result, it is clear that targeting EGFR directly is not the most effective way to mitigate its signaling in cancer. We propose that better alternative approaches for disrupting EGFR signaling will come from examining the molecular mechanisms that regulate EGFR activity, i.e. endocytosis. It has been well understood for decades that endocytic spatial regulation plays a major role in receptor expression and downregulation. However, in recent years it has been discovered that receptor endocytosis also plays a role in downstream effector activity. How this process specifically affects overall EGFR signaling is not completely understood, and it could be a useful target for disrupting hyperactivated signaling.

My research goal was to understand how endocytosis affects EGFR signal transduction, and to use this information to discover new targets for cancer therapies. The objective of this work was to determine the effects of EGFR spatial regulation on its signaling. My central hypothesis was that the spatial regulation of EGFR permits specific effector interactions that directly influence downstream signaling. This hypothesis was based on the most recent data in the field which suggest that endocytic trafficking of EGFR induces changes in downstream effector activation. For example, blocking EGFR endocytosis decreases the activity of certain effectors, such as ERK1/2 and PI3K [31]. More 
recently, the work of Galperin and Sorkin suggests that MEK enters endosomes and acts as a negative regulator of MAPK signaling upon EGF stimulation [57]. While the spatial regulation of EGFR clearly plays a role in effector activity, there is controversy within the field surrounding endosome-specific effectors and their implications on overall signal transduction. The rationale for this work was that a comprehensive understanding of the effects of EGFR:effector interactions within endosomes will be a means for discovering many new drug targets for altering EGFR mitogenic signaling. Considering the current outcomes for EGFR targeting in cancer, this information is critical for the discovery of more effective treatments.

My hypothesis was tested with the following aims:

\section{Aim 1: Identify and characterize key effectors within early endosomes.}

\section{Aim 1a. Develop a non-invasive strategy to purify early endosomes.}

In order to achieve a global, comprehensive picture of the early endosome effector population, we isolated intact early endosomes from cultured cell lines.

\section{Aim 1b. Characterize effector activation in early endosomes.}

We used mass spectrometry to characterize early endosome-specific effectors following treatment with and without EGF. The goal of this sub-aim was to determine which effectors are constitutively present in the early endosome, and which effectors are selectively localized to early endosomes by EGFR membrane trafficking.

Aim 2: Determine the physiologic effects of endocytic spatial regulation on EGFR signaling. 
Based on my hypothesis, we determined how the spatial regulation of EGFR influences cell physiology using cultured cell lines. We used assays to measure cell growth and viability to determine how these processes are affected by the absence of specific downstream effectors of EGFR.

The aim of this work was to provide a systematic and comprehensive approach to understanding how EGFR signaling is regulated, which will lead to discovering new ways to attenuate it more effectively. The work proposed in Aim 1 gave us a more complete picture of early endosome-specific effectors. More specifically, we discovered that the proteins RUFY1, PTPN23, STOML2, and CCDC51 associate with early endosomes in an EGF-dependent manner. The work proposed in Aim 2 helped us identify what roles the proteins discovered in Aim 1 play in the endocytic trafficking of EGFR. This work has been published in the Journal of Biological Chemistry. Additional work has been done to characterize how the loss of RUFY1 and PTPN23 affects cell number and viability. These results are discussed at length in Chapter IV of this dissertation. 


\section{CHAPTER II}

\section{MATERIALS AND METHODS}

A. Cell Lines-HeLa cells were acquired from American Type Culture Collection (ATCC). Cells were cultured at $37^{\circ} \mathrm{C}$ in $5 \% \mathrm{CO}_{2}$ and maintained in Dulbecco's Modified Eagle Medium (DMEM, Gibco) supplemented with 5\% Fetal Bovine Serum (FBS, Invitrogen), 100 units $/ \mathrm{mL}$ streptomycin, 100 units $/ \mathrm{mL}$ penicillin, and $2 \mathrm{mM}$ glutamine [58].

B. Post-Nuclear Supernatant Preparation-Cells were grown to confluence in $15 \mathrm{~cm}$ dishes, serum starved for 2 hours at $37^{\circ} \mathrm{C}$, then incubated with or without 10ng/mL EGF ligand (ProSpec, \#cyt-217-a) for 15 minutes immediately prior to harvest. Cell lysates were prepared by washing twice with room temperature (RT) PBS and equilibrating to $4^{\circ} \mathrm{C}$ on ice, followed by equilibrating in ice-cold lysis buffer (TES-10mM triethanolamine, 1mM EDTA, 0.25M sucrose $\mathrm{pH}$ 7.2). Cells were incubated on ice with TES buffer (supplemented with 2mM PMSF, $1 \mathrm{mM} \mathrm{Na} \mathrm{VO}_{4}, 10 \mu \mathrm{M}$ pepstatin, and $1 \mu \mathrm{M}$ aprotinin) until cells began to swell, but before bursting (approximately 5 minutes), and scraped with a rubber policeman. The collected cells were pipetted up and down 40 times with a P1000 pipetman and centrifuged at $200 \times \mathrm{g}$ for 10 minutes at $4^{\circ} \mathrm{C}$ in a tabletop centrifuge to create a post-nuclear supernatant (PNS) which was subsequently collected. The pellet was resuspended in TES buffer and centrifuged a second time at $200 \mathrm{xg}$ for 10 minutes at $4^{\circ} \mathrm{C}$. Supernatants were pooled to yield a final PNS [50]. 
C. Percoll Gradient Fractionation-Twenty-four hours prior to experimentation, stock Percoll (GE Healthcare) was equilibrated with 2.5M sucrose at a ratio of 9:1. The $90 \%$ Percoll/ $/ 0.25 \mathrm{M}$ sucrose solution was stored at $4^{\circ} \mathrm{C}$ until use. Samples were prepared as indicated (by PNS preparation via either osmotic lysis or mechanical lysis, or by sucrose gradient fractionation), and each sample was mixed with the $90 \%$ Percoll solution (final concentration $17 \%$ Percoll) and TES to a total volume of $11.5 \mathrm{~mL}$. Buffers were supplemented with $2 \mathrm{mM}$ PMSF, $1 \mathrm{mM}$ $\mathrm{Na}_{3} \mathrm{VO}_{4}, 10 \mu \mathrm{M}$ pepstatin, and $1 \mu \mathrm{M}$ aprotinin before use. PNS/Percoll/Buffer mixtures were pipetted into $16 \mathrm{~mm} \times 67 \mathrm{~mm}$ OptiSeal ${ }^{\mathrm{TM}}$ polypropylene tubes (Beckman Coulter) and loaded into a pre-chilled VTi65.1 vertical rotor. Density beads (with known densities in 17\% Percoll/250mM sucrose) (GE Healthcare) were loaded into a separate tube containing $17 \%$ isotonic Percoll in buffer and mixed. Samples were spun in a Beckman Coulter Optima L-100 XP Ultracentrifuge at 50,000 $\mathrm{xg}$ for 25 minutes with max acceleration and brake. Samples were then fractionated from the bottom of the centrifuge tube in 10-drop aliquots $(\sim 330 \mu \mathrm{L})$ into pre-chilled Eppendorf tubes ( 30 fractions per gradient) using a peristaltic pump and a glass pipet at $4^{\circ} \mathrm{C}$ [50]. For experiments where fractions were subjected to affinity purification, the fractions in which EEA1 protein concentration peaked were pooled together ( $\sim 6$ fractions per condition, $\sim 2 \mathrm{~mL}$ total) and mixed by inverting and gently pipetting up and down. For experiments where fractions were not pooled but analyzed directly via immunoblot, each fraction was diluted in 6X SDS sample buffer containing $10 \%$ $\beta$-mercaptoethanol $(\beta M E)$, boiled at $100^{\circ} \mathrm{C}$ for 3 minutes, and centrifuged at 
$21,000 \times \mathrm{g}$ to pellet Percoll. The tube containing density beads was imaged and $\mathrm{R}_{f}$ values were calculated based on bead migration in the gradient.

D. Affinity Purification of Early Endosomes—Approximately $0.44 \mu \mathrm{g}$ of EEA1 monoclonal antibody (Cell Signaling, \#3288) was pre-conjugated to $\sim 2 \mathrm{~mL}$ of pooled EEA1 peak fractions $\left(\mathrm{R}_{f}\right.$ of $\left.\sim 0.25-0.10\right)$ from Percoll gradient samples overnight at $4^{\circ} \mathrm{C}$ with rotation. Protein G Dynabeads (Invitrogen) were washed three times in PBS before use and $\sim 4.0 \times 10^{7}$ Dynabeads were incubated with each antibody-conjugated sample and rotated at $4^{\circ} \mathrm{C}$ for 1 hour. Magnetic beads were isolated and the first supernatant (pass through) was collected. The beads were then washed three times in ice-cold PBS and eluted in 6X SDS buffer containing $10 \% \beta \mathrm{ME}$ and boiled at $100^{\circ} \mathrm{C}$ for 3 minutes. Remaining samples collected were diluted in 6 X SDS buffer with $10 \% \beta M E$ and boiled. Any samples containing Percoll were centrifuged at $21,000 \times \mathrm{g}$ to pellet Percoll.

E. Immunoblotting-Samples were loaded as a percentage of total sample volume, resolved by SDS-PAGE, and transferred to nitrocellulose. Membranes were probed with the following antibodies according to manufacturer's directions: EGFR (Santa Cruz, \#sc-03), TfnR (BD Biosciences, \#612124), LAMP2 (University of lowa Hybridoma Bank, \#H4B4), EEA1 (BD Biosciences, \#610456), $\mathrm{Na} / \mathrm{K}-\mathrm{ATP}$ ase (Sigma, \#A276-only used where indicated), Na/K-ATPase (Cell Signaling, \#3010), Calnexin (Assay Designs, \#SPA-850), pY1068 (Cell Signaling, \#2236), PTPN23 (Proteintech, \#A304-883A), RUFY1 (ThermoFisher Scientific, \#PA5-31400), STOML2 (Abcam, \#ab191884), a-tubulin (Sigma-Aldrich, \#T6199), and PARP (Cell Signaling, \#9542). Following incubation with the appropriate 
horseradish peroxidase conjugated secondary antibody (anti-mouse or antirabbit, Thermo Fisher-Pierce), immunoreactive proteins were subjected to Enhanced Chemiluminescence and visualized using a Fotodyne imaging system. Western blots were quantified using Image $\mathrm{J}$ software.

F. Indirect Immunofluorescence-HeLa cells were grown to confluency on $\mathrm{NaOH}$ treated, sterile $12 \mathrm{~mm}$ round glass coverslips. Serum starved cells were incubated with EGF (ProSpec, \#cyt-217-a) ligand for the indicated amount of time. Cells were stimulated with $10 \mathrm{ng} / \mathrm{mL}$ fluorescent Alexa-647-EGF ligand (Invitrogen) for $10 \mathrm{~min}$ and pulse-chased following previously described methods [59]. After EGF stimulation, cells were subjected to indirect immunofluorescence as described previously [60] using EGFR (Ab-1, EMD Millipore, \#GR01), EEA1 (BD Biosciences, \#610456), PTPN23 (Proteintech, \#A304-883A), RUFY1 (ThermoFisher Scientific, \#PA5-31400), and STOML2 (Abcam, \#ab191884) primary antibodies prepared by manufacturer recommended dilutions. Immunoreactive proteins were visualized using goat anti-rabbit Alexa488- and goat anti-mouse Alexa568-labeled secondary antibodies (Life Technologies), respectively. Coverslips were mounted onto glass slides with Prolong Gold Antifade (Life Technologies) [60]. Slides were cured in the dark overnight before imaging. Images were taken in the middle plane of the cells using a $60 \mathrm{X}$ oil immersion objective lens on a Nikon A1R confocal microscope.

G. Colocalization Analysis-Colocalization of EGF or EGFR with EEA1 was quantified as described by Lopez-Alcala et al. (50) and Vanlandingham et al. [59]. Briefly, analysis was carried out using ImageJ Software and the 
Colocalization plug-in (Pierre Bourdoncle, Institut Jacques Monod, Service Imagerie, Paris) to generate a binary image of colocalized pixels from two separate channels. ImageJ was used to automate channel thresholding, and colocalization was established for pixels whose intensities were higher than threshold and for which the ratio of intensity was greater than $50 \%$. The data were plotted as the ratio of the integrated intensity from the two images. All data represent the average of three independent experiments, with a total of $~ 300$ cells measured per experiment.

H. Coomassie Staining - Immunoprecipitated early endosomes were resolved on a $12 \%$ SDS-PAGE. The gel was rinsed once in $\mathrm{ddH}_{2} \mathrm{O}$ and covered with Coomassie (50\% MeOH, 0.05\% Coomassie Brilliant Blue R [Sigma], 10\% acetic acid, $40 \% \mathrm{ddH}_{2} \mathrm{O}$ ) and microwaved for 5 seconds. The gel was incubated with Coomassie at RT with gentle rocking for 15 minutes. The Coomassie was removed and the gel was rinsed twice in $\mathrm{ddH}_{2} \mathrm{O}$. The gel was then covered in destain solution ( $7 \%$ glacial acetic acid, $\left.5 \% \mathrm{MeOH}, 88 \% \mathrm{ddH}_{2} \mathrm{O}\right)$ and incubated overnight at RT with gentle rocking. The gel was rinsed in $\mathrm{ddH}_{2} \mathrm{O}$, imaged using a Fotodyne imaging system, and stored in $7 \%$ acetic acid/dd $\mathrm{d}_{2} \mathrm{O}$ at $4^{\circ} \mathrm{C}$.

I. In-Gel Protein Digestion-This protocol is modified from Jensen et al. [61]. A Coomassie stained SDS-PAGE gel was cut into $1 \mathrm{~mm}^{3}$ plugs and incubated in $100 \mathrm{mM}$ triethylammonium bicarbonate (TEA-BC, Sigma) at RT for 15 minutes. Acetonitrile ( $\mathrm{ACN}$ ) was added to the TEA-BC solution and the gel plugs were incubated at RT for 15 minutes with gentle vortexing. The solvent was removed and the washing process was repeated until the Coomassie blue stain was no 
longer visible. Solvent was removed and the gel plugs were dried in a SpeedVac for 5 minutes. The dried plugs were incubated in dithiothreitol (DTT) (20mM DTT [BioRad], $100 \mathrm{mM}$ TEA-BC) at $56^{\circ} \mathrm{C}$ for 45 minutes, followed by iodoacetamide (55mM iodoacetamide [Sigma], 100mM TEA-BC) at RT for 30 minutes protected from light. lodoacetamide was removed and gels were washed in 50mM TEA-BC at RT for 15 minutes, followed by the addition of $A C N$ for 15 minutes at RT with gentle vortexing. The gel plugs were again dried for 5 minutes in a SpeedVac, and incubated in digestion buffer (20ng/ $\mu \mathrm{L}$ modified Trypsin [Promega] in 50mM TEA-BC) for approximately 10 minutes until the gel plugs swelled. After swelling, $50 \mathrm{mM}$ TEA-BC was added to the plugs, followed by $37^{\circ} \mathrm{C}$ overnight incubation in a shaker. Digestion supernatants from the upper and lower half of the gel were combined for each sample.

J. Extraction of Peptides-This protocol is modified from Shevchenko, et al. [62]. LC-MS grade water was added to the digested gel plugs to give a final concentration of $25 \mathrm{mM}$ TEA-BC. Two volumes of $1: 25 \% \mathrm{v} / \mathrm{v}$ formic acid:acetonitrile was added and incubated at RT for 15 minutes in a shaker (100rpm in a C25 Incubator Shaker [New Brunswick Scientific]). Liquid surrounding the gel pieces was transferred to a clean microtube and dissolved in Chromatography Buffer A ( $2 \% \mathrm{v} / \mathrm{v}$ acetonitrile/0.1\% v/v formic acid). The dissolved sample was filtered through a $0.45 \mu \mathrm{m}$ regenerated cellulose syringe filter (Thermo \#F2504-7) to remove any remaining gel material. Resolubilized gel band digests were desalted and concentrated using C18 PROTO ${ }^{\mathrm{TM}}, 300 \AA$ Ultra MicroSpin Column (The Nest Group, Inc., Southborough, MA, USA). Samples 
were cooled to $-80^{\circ} \mathrm{C}$, dried using a SpeedVac, and redissolved in Chromatography Buffer A. Sample absorbance was read at 205nm using a NanoDrop 2000 spectrophotometer to determine peptide concentration. Sample volumes were adjusted in Buffer A to normalize peptide concentrations to $0.1 \mu \mathrm{g} / \mu \mathrm{L}$

K. Liquid Chromatography/Tandem Mass Spectrometry (LC-MS/MS)-Gel band digests $(0.5 \mu \mathrm{g})$ were separated on $12 \mathrm{~cm}$ of Aeris Peptide XB-C18, 3.6 $\mu \mathrm{m}$, $100 \AA ̊$ material (Phenomenex, Torrance, CA, USA) packed into a $360 \mu \mathrm{m}$ OD $\mathrm{x}$ $100 \mu \mathrm{m}$ ID fused silica tip that was pulled using a Model P-2000 Micropipette Puller (Sutter Instrument Co., Novato, CA, USA). Peptides were eluted from the column using an EASY n-LC UHPLC system (Thermo Fisher Scientific, Waltham, MA, USA) in an 80 minute linear gradient using Buffer $A$ and Buffer $B(80 \% \mathrm{v} / \mathrm{v}$ acetonitrile/0.1\% v/v formic acid) as mobile phases (from 0\% Buffer B to $50 \%$ Buffer B). The samples were then separated by a 5 minute linear gradient from $50 \%$ Buffer B to $95 \%$ Buffer B, followed by a 5 minute wash in $95 \%$ Buffer B. The sample was introduced into the LTQ-Orbitrap Elite (ThermoElectron) mass spectrometer by nanoelectrospray using a Nanospray Flex source (ThermoElectron). The ion transfer capillary temperature was set to $225^{\circ} \mathrm{C}$ and the spray voltage was set to $1.6 \mathrm{kV}$. An Nth Order Double Play was created in Xcalibur v2.2. Scan event one of the method obtained an FTMS MS1 scan (normal mass range; 240,000 resolution, full scan type, positive polarity, profile data type) for the range $300-2000 \mathrm{~m} / z$. Scan event two obtained ITMS MS2 scans (normal mass range, rapid scan rate, centroid data type) on up to twenty peaks 
that had a minimum signal threshold of 5,000 counts from scan event one. The lock mass option was enabled ( $0 \%$ lock mass abundance) using the $371.101236 \mathrm{~m} / \mathrm{z}$ polysiloxane peak as an internal calibrant. Proteome Discoverer v1.4.1.14 (Thermo Fisher Scientific) was used to analyze the mass spectrometer data. MS2 scan data were extracted from the Xcalibur RAW file, CID MS2 scans were searched in Mascot v2.5.1 (Matrix Science, Inc., Boston, MA, USA) and SequestHT, and results were collected in a single file. The protein database UniprotKB Homo sapiens version 3/9/2016 reference proteome canonical and isoform sequences, with cRAP database (thegpm.org) version 1/1/2012 appended to it, were used in the Mascot and SequestHT searches. The resulting files from Proteome Discoverer were loaded into Scaffold Q+S v4.4.5 (Proteome Software, Inc., Portland, OR, USA). The peptide false discovery rate was calculated with Scaffold Local FDR algorithm, and protein probabilities were calculated using the Protein Prophet algorithm. Results were annotated with human gene ontology information from the Gene Ontology Annotations Database (ftp.ebi.ac.uk).

L. Electron Microscopy—Early endosomes were precipitated on Protein G Dynabeads as described above. Endosome-Dynabead complexes were pelleted and fixed in $2 \%$ paraformaldehyde/2\% glutaraldehyde in $0.1 \mathrm{M}$ phosphate buffer (PB) overnight at $4^{\circ} \mathrm{C}$. Pellets were subsequently washed in PB and fixed in $1 \%$ osmium tetroxide $\left(\mathrm{OsO}_{4}\right)$ in $\mathrm{PB}$ for 90 minutes at $\mathrm{RT}$. Pellets were washed in PB and dehydrated in an ethanol and propylene oxide series and embedded in Durcupan epoxy resin. Ultrathin sections (80nm) were cut using a diamond knife 
and collected on nickel mesh grids. The grids were stained with uranyl acetate and lead citrate. Images were collected using a Hitachi HT7700 transmission electron microscope. Individual vesicles were measured and quantified using ImageJ (National Institutes of Health). The diameters of 651 endosomes were measured, and the corrected mean diameter (D) of all endosomes was calculated using the Fullman equation $\left[\mathrm{D}=(\pi / 2)^{*} \mathrm{~N} /(1 / \mathrm{d} 1+1 / \mathrm{d} 2 \ldots 1 / \mathrm{dN})\right]$, where $\mathrm{N}$ represents the total number of compartments, and $d$ represents the diameter of each individual compartment. This equation corrects for the differences in the positioning of the vesicles within the ultrathin sections that were cut.

M. siRNA Knock Down of RUFY1 and PTPN23-RUFY1 siRNA (siGENOME SMARTpool Human RUFY1 Cat \#M-016355-01, Lot \#170711) and PTPN23 siRNA (siGENOME SMARTpool Human PTPN23 Cat \#M-009417-01, Lot \# 170711) were obtained from Dharmacon (Lafayette, CO). Each $5 \mathrm{nmol}$ stock siRNA was reconstituted into $20 \mu \mathrm{M}$ aliquots. Scramble control siRNA (siCON) was acquired from Integrated DNA Technologies (Coralville, IA). HeLa cells were seeded at 500,000 cells/60mm dish and transfected with final concentrations of 50nM siRNA (or 50nM siCON) with INTERFERin (Polyplus Transfection, Strasbourg, France) according to manufacturer's instructions. The following day (24 h post-transfection) cells were split and plated into 24-well dishes with $\mathrm{NaOH}$ washed coverslips. Seventy-two hours post-transfection, cells were serum starved for $2 \mathrm{~h}$ and then stimulated for the indicated time-points with fluorescent 10ng/mL Alexa-647-EGF (Invitrogen) ligand, followed by indirect immunofluorescence. 
A 6-well dish was plated for each siRNA knock-down experiment. These cells were harvested in RIPA buffer as previously described [63] 72-hours posttransfection and immunoblotted for RUFY1 and PTPN23 to ensure at least $90 \%$ knock-down efficiency.

N. Cell Counting-Twenty-four hours after siRNA knockdown, cells were plated in $35 \mathrm{~mm}$ dishes at a density of 100,000 cells/dish. Cells were incubated for the indicated periods of time, and harvested using two distinct procedures. Immediately prior to harvest, cells were imaged at 100x magnification on a Nikon Eclipse Ti widefield epifluorescence microscope. To collect only viable cells, dishes were first washed in RT PBS. The dishes were then incubated in 250uL trypsin for 5 min until adherent cells were displaced. The cells were then collected in a final volume of $1 \mathrm{~mL}$ in DMEM and counted using a hemocytometer [64]. The cells were then pelleted and harvested in RIPA buffer. To collect both viable and inviable cells, cells were scraped and counted using a hemocytometer, followed by pelleting and harvesting in RIPA buffer. Harvested cells were then prepared for immunoblotting.

O. 125I-EGF Radioligand Degradation-HeLa cells transfected with the indicated siRNA were replated at a density of 200,000 cells/35mm dish. Seventytwo hours after transfection, cells were incubated for 7.5 minutes in $\sim 0.05 \mu \mathrm{g} / \mathrm{mL}$ 125/-EGF (0.5mL per dish, $5000 \mathrm{cpm} / 10 \mu \mathrm{L})$ (catalog number NEX160, PerkinElmer Life Sciences) at $37^{\circ} \mathrm{C}$ in binding buffer (DMEM, 10mM HEPES, $0.1 \%$ bovine serum albumin, $\mathrm{pH} 7.3$ ). Cells were washed four times in binding buffer to remove unbound ${ }^{125}$-EGF. Prewarmed medium was added to the cells, 
and they were returned to $37^{\circ} \mathrm{C}$ for the indicated periods of time. At each time point, the medium was collected (secreted ${ }^{125}$ I-EGF). Remaining cells were then solubilized in 1\% NP-40, 20mM Tris, pH 7.4. Intact ${ }^{125}$ /-EGF was precipitated in $10 \%$ trichloroacetic acid and $1 \%$ bovine serum albumin for at least 60 minutes at $4^{\circ} \mathrm{C}$. Intact ${ }^{125}$ I-EGF was separated from degraded ${ }^{125}$ I-EGF by centrifugation for 15 min at $14,000 \mathrm{rpm}$ at $4^{\circ} \mathrm{C}$. Radioactivity for each fraction was counted using a PerkinElmer Wizard² Gamma Counter [59].

P. alamarBlue Viability Assay-HeLa cells were transfected with the indicated siRNA and were replated 24 hours after transfection into 96-well dishes at a density of either 5,000 or 10,000 cells/well. When the cells reached $\sim 50 \%$ confluency, they were serum starved for two hours, followed by 24-hour incubation with either 0,10 , or $100 \mathrm{ng} / \mathrm{mL} E G F$ to induce cell growth, or with either $1 \mu \mathrm{M}$ AG1478 to inhibit EGFR activity or $1 \mathrm{mM}$ AG1478 to induce cell death. After incubation, alamarBlue reagent (ThermoScientific, Waltham, MA) was added at $10 \%$ of the total volume of media (i.e. $10 \mu \mathrm{L}$ ) and incubated at $37^{\circ} \mathrm{C}$ and $5 \% \mathrm{CO}_{2}$ for 2 hours. Fluorescence was then measured in an $\mathrm{HT}$ plate reader using Gen5 BioTek software at 530nm excitation and 590nm emission [63]. Q. Inhibition of EGFR Phosphorylation via AG1478-HeLa cells transfected with the indicated siRNA were replated into either 96 -well dishes or $35 \mathrm{~mm}$ dishes 24 hours after transfection. Cells were treated with the indicated concentration (either $1 \mu \mathrm{M}$ or $1 \mathrm{mM}$ ) of AG1478 inhibitor (Cayman) for 24 hours prior to the indicated time point [65]. Cells plated in 96-well dishes were serum starved for two hours prior to treatment. Viability of cells in 96-well dishes was assessed 
using the alamarBlue assay. Cells in 35mm dishes were harvested to collect both viable and inviable cells. Cells were scraped and counted using a hemocytometer.

R. Statistical Analyses_Unpaired student's t-tests were used to determine significance. A p value of less than 0.05 is considered significant, and is denoted with a single asterisk $\left({ }^{*}\right)$. A p value of less than 0.001 is denoted with two asterisks $\left({ }^{* *}\right)$. A p value of less than 0.0005 is denoted with three asterisks $\left({ }^{* * *}\right)$. A p value of less than 0.0001 is denoted with four asterisks $\left({ }^{* * * *}\right)$. 


\section{CHAPTER III}

\section{ISOLATION OF EGFR-CONTAINING EARLY ENDOSOMES}

A. Introduction

A multitude of labs have studied the biochemical properties of various endosomes, and have done so by isolating and separating endosomes from cells. The process of breaking open cells to separate out and study specific intracellular compartments is termed subcellular fractionation. Subcellular fractionation can be applied and modified in many ways to study the contents and functions of the various endocytic organelles. In this chapter, these methods will be outlined to determine the strengths and weaknesses of each method.

The process of subcellular fractionation is generally made up of three parts: lysing cells, separating cytosolic organelles, and isolating the target organelle [66]. There are several ways to perform these steps, each of which must also be optimized for the type of cells being used. Subcellular fractionation can be utilized to study virtually any organelle or compartment inside cells.

However, the focus of this review will be on the application of these methods for isolating endocytic organelles.

The first step of subcellular fractionation involves breaking open cells to access internal compartments. The two major methods used to achieve this are hypotonic and mechanical lysis. Hypotonic lysis of cells involves incubating cells with a buffer containing lower than physiologic concentrations of either salt or 
sucrose until enough water moves into the cells via osmosis that the cells swell and eventually burst. This is a very effective method for lysing cells, however, if the organelles are continuously exposed to a hypotonic buffer, it is possible that the organelles themselves risk being lysed as well. Some organelles, like lysosomes, are sensitive to hypotonic lysis, while others like early endosomes are not [67].

The second option for lysing cells is to use mechanical disruption. This can be achieved by passaging cells through a syringe and a small needle (typically 20-25 gauge), a ball-bearing homogenizer, or exposing cells to sonication. All of these methods work to lyse cells by applying physical force to the membrane of the cell. This method is less invasive than a hypotonic buffer and is generally considered to have little effect on the integrity of the intracellular compartments. However, it has been documented that these mechanical techniques can cause the formation of new, non-physiologically relevant vesicles as a result of hybrid fusion of distinct organelles [68]. The pros and cons of both of these lysis methods should be considered when selecting a lysis method for subcellular fractionation.

The second step of subcellular fractionation is separating intracellular components. Typically after lysis, the cell lysates will be gently centrifuged to pellet and remove large debris and nuclei. The nuclei can be discarded or used for further analysis of nuclear proteins or DNA. The resulting supernatant contains all cytosolic organelles, proteins, cytoskeleton, and the broken plasma membrane. This is referred to as the post-nuclear supernatant (PNS). The 
contents of the PNS must then be separated out to make the target organelle more accessible for the final isolation step of subcellular fractionation. The most common methods of organelle separation utilize centrifugation. There are two widely used types of centrifugation—rate zonal or differential, and isopycnic. Rate zonal/differential centrifugation separates samples by size, and isopycnic/density centrifugation separates samples by density. Creating a PNS from cell lysates utilizes differential centrifugation. This type of separation can also be used to separate any other subcellular compartments based on size. Generally, increasingly higher speeds are required to pellet increasingly smaller organelles. Large nuclei require low speeds to pellet $(\sim 600 \times \mathrm{g})$, while much smaller mitochondria and endosomes require much higher speeds to pellet $(\sim 10,000-20,000 \times \mathrm{g})$, and still smaller ribosomes and endoplasmic reticulum fragments require extremely high speeds to pellet $(\sim 100,000 \times \mathrm{g})$ [66].

Differential centrifugation is typically applied in sequence, beginning with low speeds to pellet large organelles and collecting the supernatant to spin at higher speeds to pellet smaller organelles. This process allows rapid and distinct separation of target compartments. However, because several organelles can sediment together due to size similarities, further separation methods may be necessary for isolation of a pure population of the target organelle. Differential centrifugation has been used for early/late endosome isolation [67, 69], but recently isopycnic centrifugation has been more commonly used.

Isopycnic centrifugation requires the use of media to create a density gradient. One type of density gradient is a continuous gradient. A continuous 
gradient is typically created with the use of a commercially available heterogeneous media. During centrifugation, the media creates a spontaneous, self-forming gradient throughout the sample tube-the least dense materials will migrate to the top of the tube, and the densest materials will migrate to the bottom. Percoll is an example of a commonly used density gradient media for isopycnic centrifugation. Percoll is a mixture of colloidal silica coated with polyvinylpyrrolidone. When cell lysates are mixed with and centrifuged in a continuous gradient, organelles migrate to their isopycnic point within the gradient. The gradients can then be collected in multiple "fractions" to separate the contents with varying densities. An advantage of using a continuous gradient is the ability to resolve compartments with minute differences in density. However, a distinct disadvantage is that samples are diluted within the media, decreasing their concentration. This becomes more of an issue when the target organelle exhibits a range of densities and migrates within several fractions of the gradient, further decreasing their concentration. For example, early and late endosomes exhibit two separate ranges of densities (i.e. $1.035-1.042 \mathrm{~g} / \mathrm{mL}$ and $1.048-1.070 \mathrm{~g} / \mathrm{mL}$, respectively) [50]. Although this increases the range of fractions within the gradient that will contain these vesicles, their densities are distinct enough to still separate both, with minimal overlap. Percoll gradients have been utilized for decades to separate and isolate endosomes [70-72].

The second type of density gradient is a discontinuous gradient. Discontinuous gradients are pre-formed and made of layers of media with increasing densities. Sucrose is the most common media used to create a 
discontinuous gradient—also referred to as a "step" gradient. The final products of a discontinuous gradient are distinct "fractions" that can be collected from the "interface" between each layer of media. The number of interfaces/fractions in the gradient is dependent upon the number of layers in the gradient, and the quantity and density of the layers can be optimized based on the target subcellular compartment being collected. This is a distinct advantage of using a step gradient over a continuous gradient. The fractions from a discontinuous gradient can also be collected in much smaller volumes, providing more concentrated samples. While samples still migrate to their isopycnic point in a step gradient, there are a finite number of isopycnic points as they correlate to each distinct interface. As such, compartments collected at each fraction can exhibit a wide range of densities. This feature can serve as either an advantage or a disadvantage to this technique, depending on the target compartment. A disadvantage is the increased potential for samples to be contaminated with other subcellular organelles. Sucrose step gradients are also commonly used to isolate endosomes $[72,73]$.

The third and final step of subcellular fractionation is purification of the target organelle. Technically, this step is not a requirement for subcellular fractionation. In fact, depending on the scientific question being asked, this step is frequently omitted altogether. In many cases, the separation and enrichment of target organelles with density gradients is sufficient for further study with biochemical techniques $[59,65]$. However, obtaining a pure organelle sample is essential for analyzing the proteome of a compartment. Multiple platforms can be 
used for this step, and it is arguably the most important component of organelle isolation. Typically, in order to isolate a particular cellular compartment, a protein specific to the compartment of interest will be targeted. For example, antibodies against RAB11a, a protein specifically associated with recycling endosomes, were conjugated to magnetic beads, incubated with subcellular fractions, and placed on a magnet to purify recycling endosomes in the work of Silvis et al. [73]. The affinity of the antibody for its antigen, as well as the substrate to which the antibody is conjugated, are two critical components of this method [66]. Magnetic (Dynabeads), sepharose, and agarose beads are commercially available binding substrates with either Protein A or Protein G (or a mixture of both) coupled to the beads. Protein A \& G are immunoglobulin-binding proteins that should be selected based on the source of the monoclonal antibody they will bind. The material make-up of the beads (Dynabeads, agarose, or sepharose) can also be selected based on their properties. Agarose and sepharose beads must be centrifuged or loaded on a column to isolate the beads and their bound organelles. Dynabeads, however, can be placed on a magnet and the supernatant removed with a pipette. Magnetic beads generally provide a gentler platform for isolating the target organelle, however they tend to be more expensive. The target organelles can be eluted off of the beads using either $\mathrm{pH}$ washes or a protein solubilizing buffer.

Various modifications of these methods of subcellular fractionation detailed in this chapter were tested in order to develop a protocol optimized for the isolation of early endosomes from HeLa cells to study EGFR signaling from 
these compartments.

B. Results ${ }^{1}$

\section{EGF colocalizes with EEA1-positive vesicles}

To determine the time-point at which the EGFR was maximally localized to the early endosome, we used indirect immunofluorescence probing for the early endosome marker, Early Endosome Autoantigen 1 (EEA1) [74] following Alexa647-EGF treatment (Figure 3.1). The addition of EGF induces a timedependent redistribution of EGFR into the cytosol and colocalization with EEA1. Fifteen minutes after the addition of EGF, there is a peak accumulation of EGF co-staining with EEA1. These kinetics of endocytic trafficking are consistent with previous reports $[59,75]$. After 30 minutes of EGF treatment, there is a decrease in EGF and EEA1 co-staining, which is consistent with reports that the EGF:EGFR complex is trafficked out of the early endosome 30-60 minutes after EGF stimulation $[76,77]$. Subsequent experiments use 15 minutes of EGF treatment to maximize the receptor association with the early endosome.

EGFR colocalizes with early endosomal proteins in isotonic Percoll gradient fractions

To biochemically enrich the early endosome population, PNS was prepared from HeLa cells treated without and with EGF, and separated on a $17 \%$ isotonic Percoll gradient [78]. Fractions of Percoll gradients were subjected to immunoblot for EEA1, EGFR, phosphorylated EGFR (pY1068), transferrin 


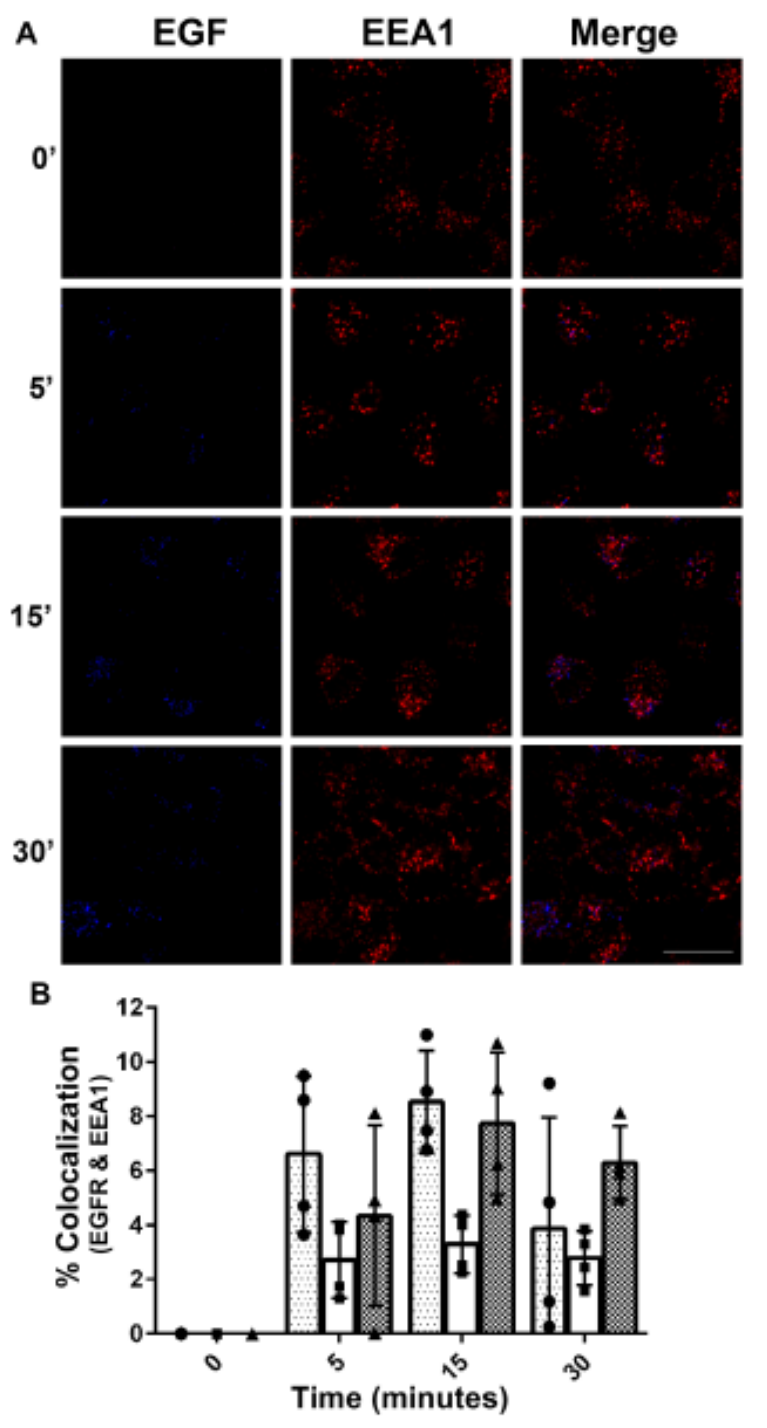

Figure 3.1 EGF colocalization with EEA1-positive vesicles. Serum-starved HeLa cells were pulse-chased with Alexa-647-EGF $(10 \mathrm{ng} / \mathrm{mL})$ for $0,5,15$, and $30 \mathrm{~min}$. Cells were fixed and processed for indirect immunofluorescence using an EEA1 antibody and fluorescently-labeled secondary antibody (goat anti-rabbit Alexa488). Scale bar=20 $\mu \mathrm{m}$. A. Images are representative of three independent experiments. B. The extent of colocalization between EGF or EGFR and EEA1 was measured as described in Chapter II. Data are plotted as the percent colocalization for each time point (four images were taken per time point, i.e. each data point measured one image). Three independent experiments are represented with three distinct bars. Approximately 300 cells total were analyzed per time point per condition, per experiment. Scale bars $=20 \mu \mathrm{m}$. Images were quantified using ImageJ software. A Pearson's correlation was calculated for each of the three experiments comparing EGF fluorescence to total EEA1 fluorescence: $r=0.8790, r=0.9608$, and $r=0.9659$. 
receptor (TfnR) (early/recycling endosome marker), and late endosome/ lysosome associated membrane protein-2 (LAMP2) (late endosome/lysosome marker) (Figure 3.2A). EGFR peaked in the same fractions as EEA1 and TfnR $\left(R_{f} \sim 0.25-0.10\right)$ independent of EGF treatment. The gradient distribution of LAMP2 indicated that there is a distinct, but not complete separation of early and late endosomes/lysosomes within the Percoll gradient, although a lesser amount of LAMP2 is present in the early endosome peak fractions. This less intense peak of LAMP2 increases upon EGF ligand stimulation. Phosphorylated EGFR (at tyrosine residue 1068, i.e. pY1068) was detected to differentiate between active and inactive receptors. There was a low basal level of phosphorylation in the unstimulated fractions, likely reflecting the population of constitutively recycling EGFR. These levels increased upon EGF stimulation and corresponded with EEA1 peak fractions.

We also monitored the distribution of Na/K-ATPase (plasma membrane marker) and Calnexin (endoplasmic reticulum marker) in Percoll gradient fractions and found that both markers peaked in the same fractions as EEA1 and EGFR. These immunoblots were quantified and the relative distribution of each protein in the Percoll gradient was plotted (Figure 3.2B). We noticed that $\mathrm{Na} / \mathrm{K}$ ATPase has peak concentrations in the same fractions as EEA1. This is because the density of plasma membrane is very close to the density of early endosomes (i.e. $1.045 \mathrm{~g} / \mathrm{mL}$ ) [79]. $\mathrm{Na} / \mathrm{K}$-ATPase has also been shown to undergo endocytosis under certain conditions, and its presence in these fractions may also indicate and early endosomal localization [80-82]. These data highlighted that despite 

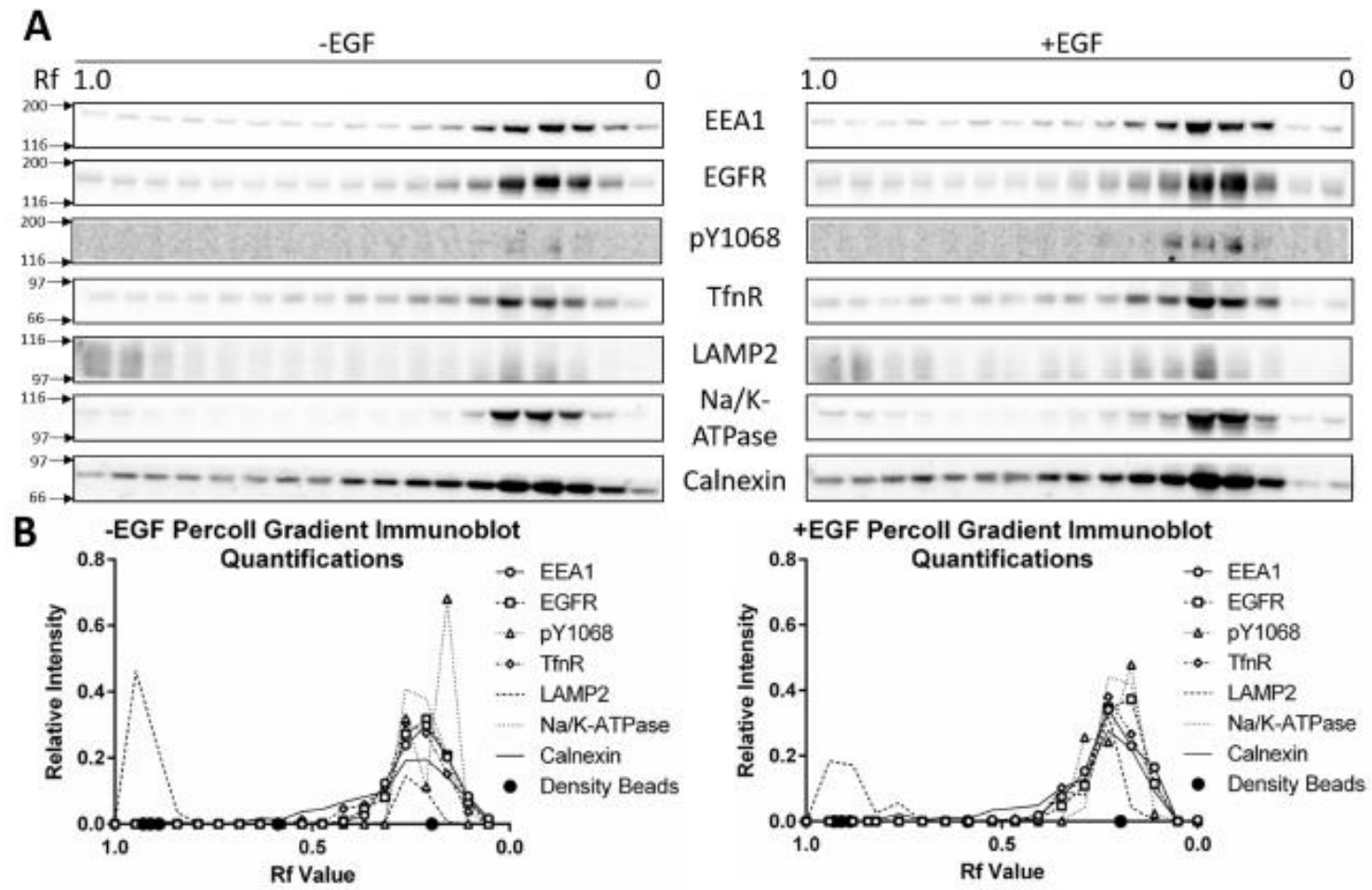

Figure 3.2 Total and phosphorylated EGFR colocalize with early endosomal markers following isotonic Percoll gradient fractionation. A. PNS was prepared from HeLa cells treated with and without EGF $(10 \mathrm{ng} / \mathrm{mL})$ for $15 \mathrm{~min}$. PNS was resolved on a $17 \%$ isotonic Percoll gradient, fractionated, and resolved by $7.5 \%$ SDS-PAGE. Proteins were transferred to a nitrocellulose membrane and immunoblotted for phosphorylated (pY1068) and total EGFR as well as the following marker proteins: EEA1 (early endosomes), TfnR (early and recycling endosomes), LAMP2 (late endosomes and lysosomes), Na/K-ATPase (plasma membrane), and Calnexin (endoplasmic reticulum). Immunoblots are representative of three independent experiments. B. Relative intensity of the immunoblots in A. Circles on the x-axis represent density bead migration $\left(\mathrm{R}_{f}\right.$ $\sim 0.93=1.109 \mathrm{~g} / \mathrm{mL}, \sim 0.91=1.070 \mathrm{~g} / \mathrm{mL}, \sim 0.89=1.057 \mathrm{~g} / \mathrm{mL}, \sim 0.59=1.049 \mathrm{~g} / \mathrm{mL}$, $\sim 0.20=1.042 \mathrm{~g} / \mathrm{mL}$ ). 
significant enrichment of the early endosome, there is a need for additional endosome purification.

\section{EEA1 targeting antibodies purify early endosomes}

Due to the presence of other contaminating organelles in the EEA1 fractions, an affinity purification strategy was used to further isolate the enriched early endosomes. Percoll gradient fractions with an $\mathrm{R}_{f}$ of $\sim 0.25-0.10(\sim 1.04 \mathrm{~g} / \mathrm{mL}$ $1.03 \mathrm{~g} / \mathrm{mL}$ density) were immunoisolated using an EEA1 monoclonal antibody (Cell Signaling) and Protein G conjugated to magnetic Dynabeads (Invitrogen). Magnetic beads were selected for the purification strategy to provide a rapid and gentle platform, as the substrate can be quickly and easily precipitated on a magnet. The steps of this newly developed purification strategy are outlined in Figure 3.3. Samples from each step of the process were collected and immunoblotted for multiple organelle marker proteins (Figure 3.4A). This strategy yielded $100 \%$ pull-down of EEA1, and approximately $7 \%$ pull-down of the constitutively recycled TfnR in both EGF stimulated and unstimulated samples. Although we expected greater pull-down of $T f n R$, it is not surprising as the constitutively recycled receptor is also localized to the plasma membrane and recycling endosomes. Alternatively, this low yield of TfnR could indicate that the early endosomes are not remaining intact throughout the isolation procedure. Immunoisolated fractions contained early endosome markers (e.g. EEA1 and TfnR) and were largely devoid of markers of other organelles (LAMP2, Na/KATPase, and Calnexin) (Figure 3.4B). EGF treatment increased total and 


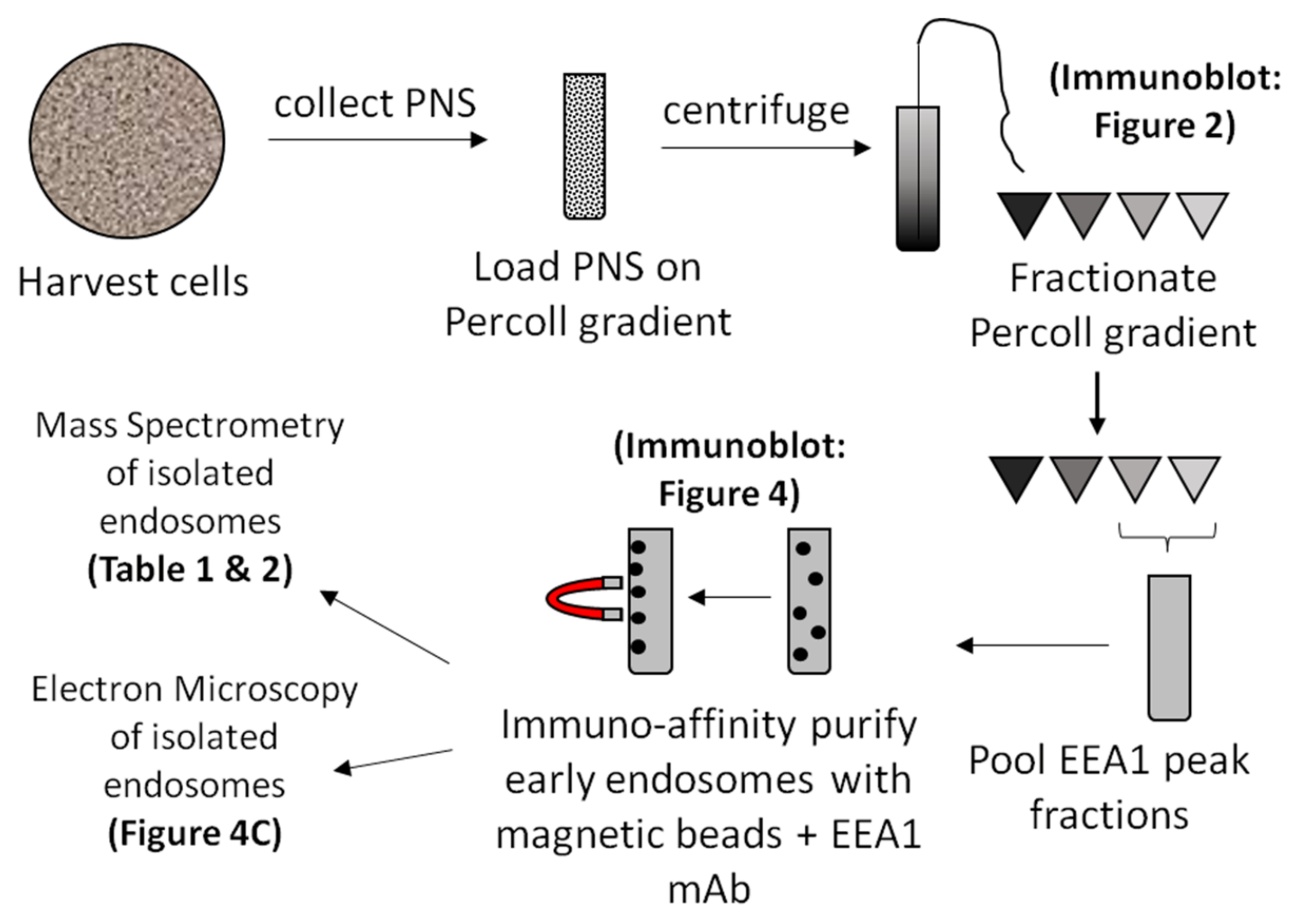

Figure 3.3 Schematic of the Percoll Gradient purification protocol. 
phosphorylated EGFR. Together, these data indicate we are successfully enriching EGFR-containing early endosomes. In both samples, the majority of phosphorylated EGFR was detected in the pass-through and not in the elution. This result, along with the low levels of TfnR in the elution, could also suggest that the early endosomes do not remain intact during isolation. However, EGF stimulation increases the amount of total EGFR precipitated with EEA1 more than 3-fold. Further, the consistent precipitation of virtually $100 \%$ of EEA1 from enriched gradient fractions indicates that these membrane preparations are highly specific for early endosomes.

The absence of other organelle marker proteins was used as a negative control for early endosome precipitation. The vast majority of LAMP2, Na/KATPase, and Calnexin were present in the pass-through of both samples. However, low but detectable amounts were present in the elutions. It is possible that their presence indicates contamination in the preparations. It is not likely that Calnexin would be found in early endosomes under normal conditions, however we cannot completely rule out this possibility. LAMP2 on the other hand was detected in the Percoll gradient early endosome fractions at low levels (see Figure 3.2), and because it is involved in trafficking, it is likely that its presence in the sample is representative of hybrid endosomes that are undergoing maturation [83]. Very low levels of Na/K-ATPase in the elutions indicates that there is minimal but detectable plasma membrane contamination.

EEA1-purified compartments exhibit early endosome morphology 


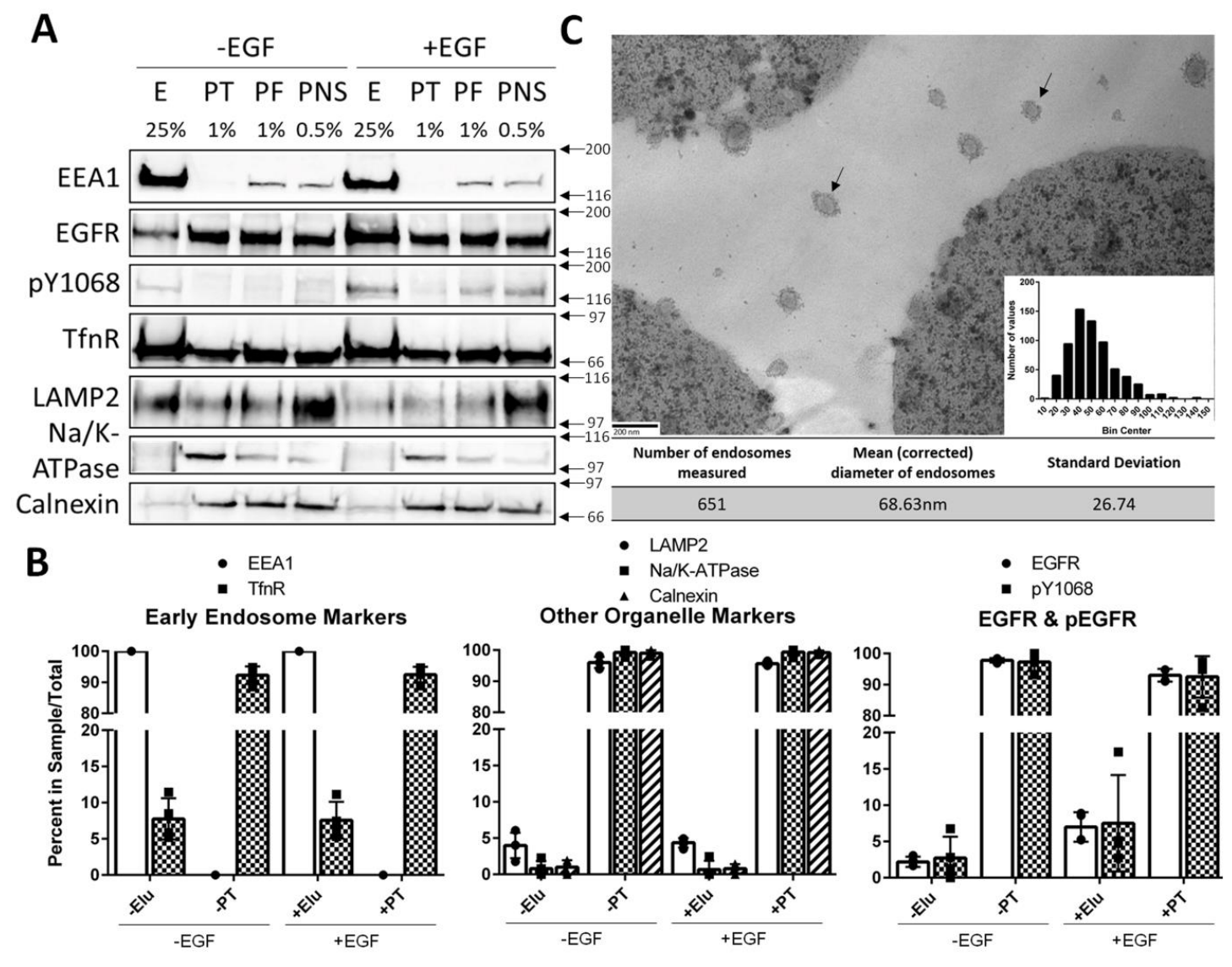

Figure 3.4 Affinity purification of early endosomes from Percoll gradient fractions. A. PNS from HeLa cells treated with or without EGF $(10 \mathrm{ng} / \mathrm{mL})$ were separated on a $17 \%$ isotonic Percoll gradient. Fractions containing early endosome markers were immunoisolated using an EEA1 antibody as outlined in Chapter II. Samples were loaded by percent of total sample volume and proteins were resolved on a $7.5 \%$ SDS-PAGE. $E=$ =elution, $\mathrm{PT}=$ pass through, $\mathrm{PF}=$ pooled fractions (Percoll gradient fractions with $\mathrm{R}_{f}$ values of $\sim 0.25-0.10$ ), PNS=postnuclear supernatant. Percent of sample total is noted above each lane. Membranes were immunoblotted for EEA1, total EGFR, phosphoEGFR (pY1068), TfnR, LAMP2, Na/K-ATPase, and Calnexin. Data are representative of three independent experiments. B. Quantifications are shown as percentages of the total IP sample (i.e., elution + pass-through $=100 \%$ ). Data are plotted \pm S.D. C. Electron micrograph of immunoisolated early endosomes. A representative micrograph of Dynabeads and early endosomes $(30,000 x)$. Scale bar $=200 \mathrm{~nm}$. The diameters of 651 individual endosomes were measured using ImageJ software. Correcting with the Fullman equation, the mean diameter of the endosomes was calculated to be $68.63 \mathrm{~nm}$. A histogram of endosome size is inset in panel C. Arrows indicate endosomes. 
While the biochemical data confirmed that early endosome proteins were being purified and other organelles excluded, we wanted to determine whether intact vesicles or membrane fragments were being pulled down. Early endosomes were enriched in Percoll gradients and affinity purified using an EEA1 antibody and magnetic beads. The magnetic beads-endosome complexes were fixed and stained for transmission electron microscopy (TEM) as outlined in Chapter II. The mean ( \pm standard deviation) diameter (corrected using the Fullman equation) of the vesicles was $68.63 \pm 26.74 \mathrm{~nm}$ (Figure 3.4C).

TEM has been used by many investigators to visualize endosomes. Early endosomes appear as round structures with low density staining, while late endosomes stain darker and contain intraluminal vesicles. This makes the two endosome types easy to distinguish using TEM. The endosomes we isolated exhibit staining, morphology and size distribution that is indistinguishable from reports of early endosomes in the literature [84].

Mass spectrometry reveals early endosome proteins and novel EGF-dependent associations

Affinity purified endosomes were collected and subjected to liquid chromatography/tandem mass spectrometry as outlined in Chapter II. The resulting data were uploaded into a repository (ftp://massive.ucsd.edu/MSV000081692). Amongst all three replicates, a total of more than 900 distinct proteins were detected. Here, we report an abridged list of proteins in Figure 3.5. Multiple proteins with known associations and functions with early endosomes and endocytosis were present with and without EGF 


\begin{tabular}{|c|c|c|c|}
\hline $\begin{array}{l}\text { Protein } \\
\text { Abbreviation }\end{array}$ & Protein Name & $\mathrm{MW}(\mathrm{kD})$ & Molecular Function \\
\hline DNAJC13 & DnaJ homolog subfamily $\mathrm{C}$ member 13 & 254 & Early endosomal trafficking \\
\hline EEA1 & Early Endosome Antigen 1 & 162 & Early endosomal trafficking \\
\hline SNX6 & Sorting nexin- 6 & 47 & Intracellular trafficking \\
\hline SNX2 & Sorting nexin-2 & 58 & Intracellular trafficking \\
\hline STX7 & Syntaxin-7 (Isoform 2) & 27 & Endocytic trafficking \\
\hline MYOF & Myoferlin (Isoform 6) & 233 & Endocytic recycling \\
\hline SCAMP1 & Secretory carrier-associated membrane protein 1 & 38 & Intracellular recycling \\
\hline SCAMP2 & Secretory carrier-associated membrane protein 2 & 37 & Intracellular recycling \\
\hline SCAMP3 & Secretory carrier-associated membrane protein 3 & 38 & Intracellular recycling \\
\hline SNX27 & Sorting nexin-27 (Isoform 2) & 60 & Intracellular recycling \\
\hline TBC1D5 & TBC1 domain family member 5 (Isoform 2) & 91 & Retrograde transport of cargo from endosomes \\
\hline VP26A & Vacuolar protein sorting-associated protein $26 \mathrm{~A}$ & 38 & $\begin{array}{l}\text { Component of the retromer cargo-selective } \\
\text { complex }\end{array}$ \\
\hline VPS35 & Vacuolar protein sorting-associated protein 35 & 92 & $\begin{array}{l}\text { Component of the retromer cargo-selective } \\
\text { complex }\end{array}$ \\
\hline CHMP4B & Charged multivesicular body protein $4 \mathrm{~b}$ & 25 & Component of ESCRT-III complex \\
\hline CTSZ & Cathepsin Z & 34 & Lysosomal cysteine proteinase \\
\hline STAM2 & Cluster of Signal transducing adapter molecule 2 & 58 & Down-regulates RTKs via ESCRT-0 \\
\hline
\end{tabular}

Figure 3.5 Early endosome and membrane trafficking proteins. Proteins were detected in all EGF-treated and untreated samples from three independent LC-MS/MS analyses of EEA1-affinity purified early endosomes. Early endosomes from HeLa cells treated with $\pm 10 \mathrm{ng} / \mathrm{mL}$ EGF for 15 min were enriched in a Percoll gradient and affinity purified using an EEA1 monoclonal antibody. Purified endosomes were eluted in sample buffer, resolved on a $12 \%$ SDS-PAGE, stained with Coomassie and subjected to LC-MS/MS as outlined in Chapter II. Data are compiled from 3 independent experiments and quantified using intensity based absolute quantification (iBAQ). A complete list of proteins can be found at ftp://massive.ucsd.edu/MSV000081692. 
treatment, including sorting nexins, secretory carrier-associated membrane proteins, EEA1, and TfnR. These data, along with the TEM images, validate the early endosome purification technique.

We also compared the protein composition of the endosomes collected from cells treated with and without EGF ligand. As expected, both EGF treated and untreated samples contain EEA1, as well as transport receptors localized to the early endosome (e.g. TfnR, LDLR, and IGF2R) (Figure 3.6). This methodology was indirectly validated by the presence of proteins involved in endocytosis, intracellular trafficking, membrane recycling, etc. Among the proteins identified, there were five that were specifically present in EGF-treated samples: EGFR, CCDC51, PTPN23, RUFY1, and STOML2 (Figure 3.6). Of these proteins, PTPN23 and RUFY1 play known roles in early endosome trafficking and cargo sorting $[85,86]$. STOML2 is a mitochondrial protein with well documented roles in mitochondrial and cardiolipin biogenesis [87, 88]. CCDC51 is a recently discovered coiled coil domain containing protein that has only been described based on its structure. We have used PTPN23, RUFY1, and STOML2 to validate EGF-dependent protein associations with the early endosome.

\section{Discussion}

In this study, we developed a novel method for enriching early endosomes. Immunoblotting of Percoll gradient fractions validated the separation of early and late endosomes using EEA1 and LAMP2 as respective marker proteins. In Figure 3.2, there is a discreet amount of LAMP2 staining in the EEA1 


\begin{tabular}{llll} 
Protein Abbr. & Protein Name Identified & MW (kD) & Molecular Function \\
\hline EEA1 & Early Endosome Antigen 1 & 162 & Early endosomal trafficking \\
TFRC & Transferrin Receptor Protein 1 & 85 & Transport of transferrin \& iron \\
IGF2R & Cation-independent mannose-6-phosphate receptor & 274 & Transport to lysosome \\
LDLR & Low-density lipoprotein receptor & 105 & Binds \& transports LDL \\
EGFR & Cluster of Epidermal Growth Factor Receptor & 134 & Receptor tyrosine-kinase \\
STOML2, SLP2 & Cluster of Isoform 2 of Stomatin-Like Protein 2 & 33 & Mitochondrial biogenesis \\
CCDC51 & Isoform 2 of Coiled-Coil Domain-Containing Protein 51 & 34 & Unknown \\
PTPN23, HD-PTP & Tyrosine-Protein Phosphatase Non-Receptor Type 23 & 179 & MVB cargo sorting \\
RUFY1, Rabip4' & RUN and FYVE domain-containing protein 1 & 80 & Early endosomal trafficking
\end{tabular}

Figure 3.6 Receptors detected in early endosomes and proteins that associate with the early endosome in an EGF-dependent manner. Early endosomes from HeLa cells treated with $\pm 10 \mathrm{ng} / \mathrm{mL}$ EGF for 15 min were enriched in a Percoll gradient and affinity purified using an EEA1 monoclonal antibody. Purified endosomes were eluted in sample buffer, resolved on a $12 \%$ SDS-PAGE, stained with Coomassie and subjected to LC-MS/MS as outlined in Chapter II. Data are compiled from 3 independent experiments and quantified using intensity based absolute quantification (iBAQ). Receptors listed (i.e. TFRC, IGF2R, LDLR) and EEA1 were detected in EGF treated and untreated samples in all three replicates. EGFR \& the four novel proteins were detected in only the EGF treated samples, and in at least two of the three replicates. 
peak fractions. While these results could be interpreted as incomplete separation of early and late endosomes, we propose that this lower density peak of LAMP2 represents a population of early endosomes that are maturing into late endosomes. The literature supports this notion, particularly regarding EGFR internalization driving endosomal maturation [51]. This is supported by the increased intensity of the lower density LAMP2 peak after EGF stimulation. Further, the peak of EGFR aligns with the EEA1 peak, independent of EGF treatment. The presence of EGFR in these fractions without ligand stimulation suggests that these receptors could be present in early endosomes, plasma membrane, or endoplasmic reticulum membranes. For this reason, the affinity purification strategy was applied to the gradient enriched early endosomes.

Biochemical and cell biological assays (TEM, immunoblotting, and mass spectrometry) validated the purification strategy developed in this study. These assays confirmed that the isolated endosomes were of the proper size and morphology, contained many expected resident proteins, and excluded markers of other organelles. TEM images also confirmed that the isolated compartments exhibit morphology characteristic of early endosomes.

Despite the isolation protocol being designed to be rapid and gentle, there is always the possibility that the endosomes did not remain intact during isolation, and some associated proteins were lost. TEM was employed to test for this possibility (Figure $3.4 \mathrm{C}$ ), and the data from those images suggest that the compartments collected were mostly intact.

This method for endosome isolation can be adapted to isolate many other 
organelles, by selecting an antibody that targets an antigen with high specificity for the organelle of interest. LC-MS/MS provides the sensitivity and unbiased detection in this screen. While other labs have monitored the subcellular location of other trafficking and signaling proteins, they have relied primarily upon biochemical techniques that require a previous knowledge or predication as to what proteins to monitor. The process developed in this study supersedes this prerequisite. Using this technique, we report an EGF-dependent association of novel proteins with the early endosome. This protocol can be extrapolated to study the spatial regulation of other endocytosed receptors, including the other ErbB family members (i.e. Her2, ErbB3, and ErbB4), and other RTKs such as PDGFR, IGF1-R, and VEGFR. 


\section{CHAPTER IV}

\section{THE RELATIONSHIP OF RUFY1 AND PTPN23 WITH EARLY ENDOSOMES}

A. Introduction

Thus far, the scope of this study has taken a very focused viewpoint on the protein composition of early endosomes. For the sake of simplicity and relevance, we have stayed within the realm of proteins that have been reported in the literature to play a role in EGFR trafficking and signaling. In this chapter, we will expand that focus to include the novel and not-so-novel proteins that we found to associate with EGFR in endosomes. We detected four proteins that associated with isolated early endosomes in an EGF-dependent manner: RUFY1, PTPN23, STOML2, and CCDC51. Both RUFY1 and PTPN23 have been previously reported to be involved in endosomal trafficking, while STOML2 and CCDC51 have not. This introduction will focus on what is currently known in the literature about the roles of these proteins in endosomal trafficking and signaling. Due to the lack of information on STOML2 and CCDC51 in these roles, this review focuses heavily on RUFY1 and PTPN23.

\section{i. RUFY1}

RUFY1 is a RAB4 effector protein and is commonly referred to by its isoforms rapib4 and rabip4'. The name RUFY1 derives from its structure, as the protein contains both a RUN domain and a FYVE domain. The RUFY1 family of 
proteins contain an $\mathrm{N}$-terminal RUN domain that binds proteins, followed by two coiled-coil domains, and a C-terminal FYVE finger which binds phosphatidylinositol 3-phosphate (Figure 4.1A) [89].

The first work and initial discovery of the RUFY1 protein was published in 2001 [86]. Cormont and colleagues were searching for a protein that specifically binds to active, GTP-bound RAB4, and thus cloned and first identified RUFY1, initially named rabip4 (RAB4-interacting protein) [86]. Using confocal and electron microscopy, they characterized rabip4 as associating with EEA1containing early endosomes, but not with RAB11-containing recycling endosomes. Their initial cloning techniques uncovered the coiled-coil domains and the FYVE domain of the protein, but not the RUN domain. The RUN domain of rabip4 was discovered and published later that same year by the same group [89]. They characterized the RUN domain as being responsible for tethering the protein to endosomal microdomains. This work also proposed that rabip4 may lead to sorting and recycling endosome fusion.

In 2002, Yang and colleagues discovered what they believed to be a "novel" protein identical to rabip4, and coined the name RUFY1 [90]. This protein was discovered by screening for new effectors of the protein Etk, a tyrosine kinase (commonly referred to as BMX). They discovered that phosphorylation of RUFY1 by Etk was necessary for RUFY1 to localize to endosome membranes. In this study, they co-transfected B82L cells with EGFR, Etk, and various mutations of the FYVE domain of RUFY1 and monitored their subcellular localization via immunofluorescence. These researchers discovered that Etk plays an important 
A RUFY1

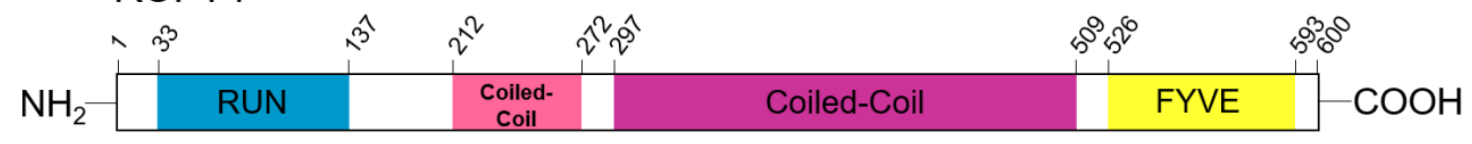

B PTPN23

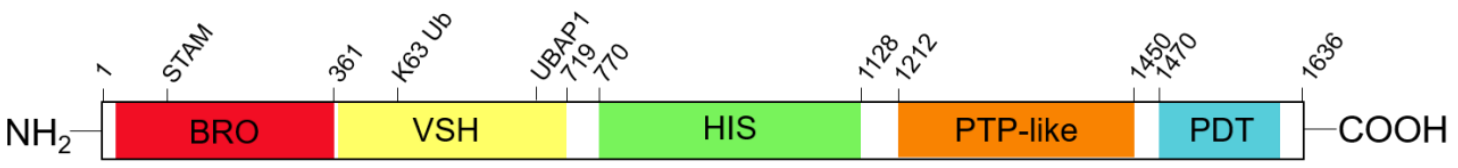

Figure 4.1 Secondary protein structure of RUFY1 and PTPN23. A. A

schematic of the secondary protein structure of RUFY1. The protein consists of an N-terminal RUN domain, two coiled-coil domains, and a C-terminal FYVE domain. B. A schematic of the secondary structure of PTPN23. The protein consists of an N-terminal BRO-homology domain, a V-shaped homology domain, a histidine-rich domain, a PTP-like domain, and a proteolytic degradation targeting motif. Regions where STAM, K63 ubiquitin, and UBAP1 binding occur are also labeled. Structures were modeled after work done by Mari et al. and Gingras et al. [89, 91] 
role in EGFR localization. When Etk was co-transfected with EGFR, there was a significant increase in the localization of EGFR to the plasma membrane of cells. Conversely, co-transfecting the FYVE domain of RUFY1 into these cells caused a reversal of the Etk-induced localization of EGFR to the cell periphery. To support this claim even further, they found that a mutant RUFY1 FYVE domain that lacked the Etk-binding site did not induce this effect. These interactions between RUFY1 and Etk, and between Etk and EGFR, are likely key factors that influence this work's findings in RUFY1 KD cells.

More recent studies have further elucidated the role of RUFY1 in endocytic trafficking. It was initially accepted that the activity of RUFY1 in endosomes was restricted to early and recycling endosomes. Several studies have shown that RUFY1 activity in the early phases of endocytic trafficking plays a role in periodontal disease, early onset Alzheimer's disease, and type 2 diabetes mellitus [92-94]. While the role of RUFY1 and its interactions with early endocytic RAB proteins (including RAB4, RAB5, and RAB14) have been well studied, it has also been shown to mediate lysosome distribution in conjunction with the protein AP-3 [95-97]. It is clear that all of the functions and interactions between RUFY1 and other proteins have not yet been uncovered, and the field of RUFY1 research is still in its youth.

ii. PTPN23

In 1998, a novel protein was discovered in rat cardiomyocytes called PTPTD14 [98]. The abbreviation PTP stands for protein tyrosine phosphatase. Soon 
after, the human homolog was discovered, and was coined histidine domain phosphotyrosine phosphatase (HD-PTP) [99]. The protein was referred to as HDPTP in the literature until 2009, when Gingras and colleagues discovered that the protein was distinct from other PTP proteins, and coined the name tyrosineprotein phosphatase non-receptor type 23 (PTPN23) [100]. Currently, there is not a consensus on the name of this protein, and it is frequently referred to as both HD-PTP and PTPN23. For the sake of simplicity, we refer to the protein as PTPN23 from this point forward.

PTPN23 has been well studied and characterized in its role as an endosomal protein. The major function of this protein is to sort ubiquitinated endocytic cargo into multivesicular bodies (MVBs) via ubiquitin binding and the ESCRT-I complex (Figure 4.1B). PTPN23 was first discovered about 20 years ago, by Cao and Zhou in 1998 [98]. They sought to discover new protein tyrosine phosphatases in their search to understand their role in myocardial signaling in rat neonatal cardiomyocytes. Cloning and expressing this protein into NIH-3T3 cells revealed that the protein localized to "vesicle-like structures," and inhibited Ha-ras-mediated transformation of these cells [98]. Two years later, researchers discovered that the gene for this protein was located at a specific loci on chromosome 3 that was frequently deleted in cancer [99]. These studies showed that this novel protein seems to play some sort of tumor suppressor role.

Multiple studies in the early 2000 s would corroborate the role of PTPN23 as a tumor suppressor. It was implicated in angiogenesis and cell migration in several studies by Mariotti and Maier [101-104]. It was hypothesized by this 
group and others that the mechanism of PTPN23 activity in these processes was by its catalytic activity as a phosphatase. However, in 2009, Gingras and colleagues performed an enzymatic analysis on the protein and discovered that PTPN23 has neither tyrosine phosphatase nor lipid phosphatase activity [100], changing the way the field approached the function of PTPN23.

The Woodman group began studying PTPN23 in relation to the protein Alix. The Alix protein was known to be structurally similar to the yeast protein Bro1p, but did exhibit the same MVB sorting activity as Bro1p [85]. In their search for determining the role of Alix in MVB sorting, they found that PTPN23 is a Bro1 domain containing protein with critical implications in MVB sorting. Knocking down PTPN23 resulted in a 94\% reduction in MVB sorting of HRP-conjugated EGF ligand [85]. Further studies confirmed this finding and extrapolated upon its mechanism. PTPN23 plays a critical role in MVB cargo sorting via interactions with UBPY, CHMP4B, UBAP1, SARA, and other ESCRT-0 complex proteins [105-107]. The mechanisms of PTPN23 cargo sorting of EGFR and other receptors has been and continues to be well understood.

\section{iii. CCDC51}

The protein CCDC51 was also found to associate with early endosomes in an EGF-dependent manner. At the current time, there have been zero studies on the function of CCDC51. The only known information about this protein is that it was named for its structure (coiled-coil domain containing protein 51 ). 
iv. STOML2

STOML2 has been well characterized, however, the literature seems to give no guidance as to the nature of the possible role of this protein in EGFR signaling or trafficking. The function of STOML2 has only been studied in mitochondria, and it is known to play important roles in mitochondrial regulation and biogenesis. There also seems to be some confusion in the literature as to the name for STOML2, as it is sometimes referred to as SLP-2. It is important to note that SLP-2 is sometimes used to describe a separate protein, synaptotagmin-like protein 2.

In light of the discovery of an association of STOML2 with early endosomes, the author would like to point out that there are a few minor indications in the literature that could be useful guides for future research into this function of STOML2. First, it seems that a family member of STOML2, STOML1 (sometimes called SLP-1), has been shown to associate with late endosomes [108]. Second, and even more intriguing is the well-documented but unknown role of STOML2 in cancers. STOML2 has been found to be overexpressed in multiple types of cancer, including esophageal squamous cell carcinoma (ESCC), glioma, and breast cancer [109-111]. STOML2 overexpression has also been linked to poor patient outcomes [111-113]. This presents a potential avenue for future studies: if STOML2 associates with early endosomes in HeLa cells, perhaps the mislocalization of STOML2 away from mitochondria and into endosomes plays a role in driving cancer cell proliferation. 


\section{B. Results ${ }^{1}$}

Analysis of the candidate proteins and other downstream effectors in early endosomes

To determine whether these proteins associate with the early endosome in an EGF-dependent manner, HeLa cells were treated with and without EGF, prepared as a PNS, and separated over an isotonic Percoll gradient. The gradient fractions were immunoblotted for the candidate proteins PTPN23, RUFY1, and STOML2. It was expected that, as primarily early endosomeassociated proteins, RUFY1 and PTPN23 would be found in the same fractions in which EEA1 peaks, or those with an $\mathrm{R}_{f}$ value of $\sim 0.25-0.10$. There was a peak concentration of both proteins in the EEA1 peak fractions (Figure 4.2). STOML2, being a predominately mitochondria-associated protein, was expected to be found in the densest fractions, as mitochondria have a density of $\sim 1.1 \mathrm{~g} / \mathrm{ml}$. Interestingly, STOML2 staining was somewhat diffuse throughout the gradient and decreased in the EEA1 peak fractions. This suggests the possibility that STOML2 is not found strictly within mitochondria, and may be associated with other organelles of various densities. The concentration of RUFY1 appeared to increase in the EEA1 peak fractions upon EGF stimulation (Figure 4.2B). Although RUFY1 (and STOML2) appear in these fractions without EGF stimulation as well, this likely indicates the association of these proteins with other organelles in these fractions, such as plasma membrane. RUFY1 is known to associate with early endosomes regardless of EGFR activation, and it has also been suggested that RUFY1 may shuttle between the plasma membrane and 
A
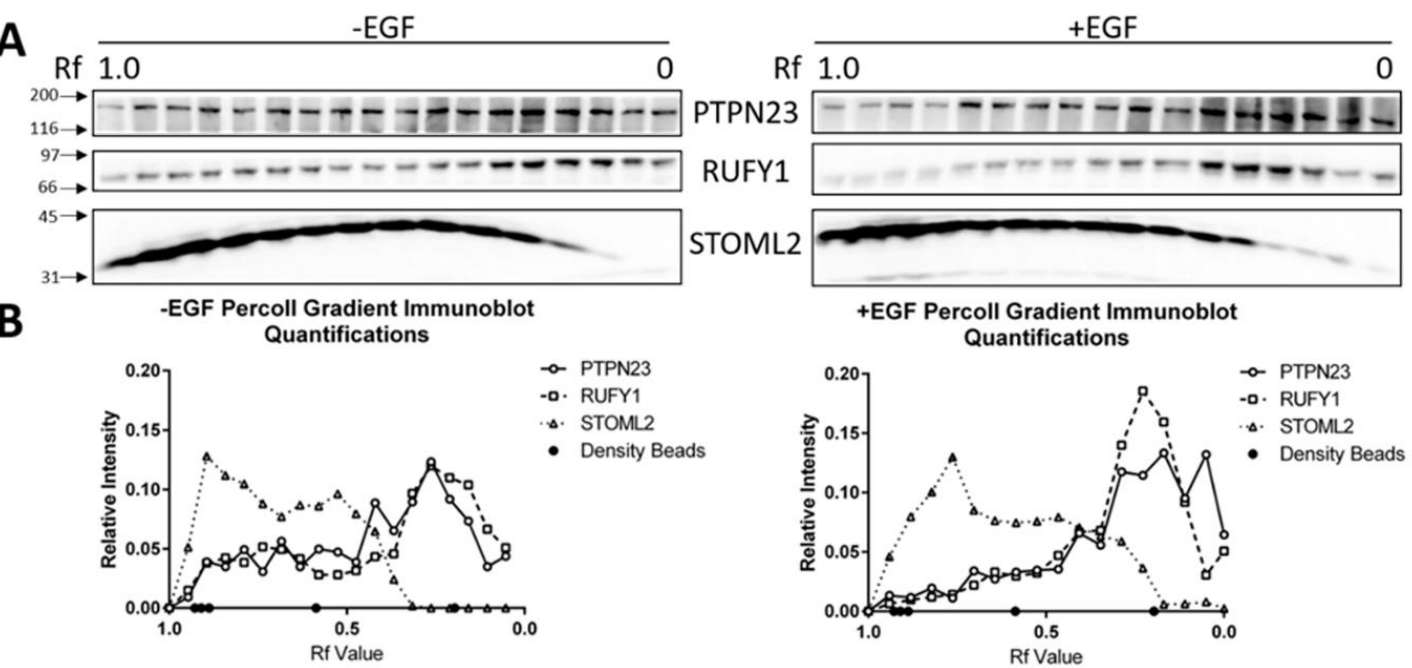

-a PTPN23

-o. RUFY1

๑. STOML2

- Density Beads

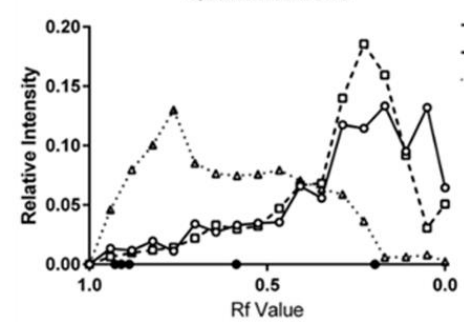

- PTPN23

o. RUFY1

- Density Beads

Figure 4.2 Immunoblot validation of candidate proteins from

immunoisolated early endosomes. HeLa cells treated with $\pm 10 \mathrm{ng} / \mathrm{mL} E G F$ were subjected to Percoll gradient fractionation and EEA1-targeted immunoisolation as described in Chapter II. A. Percoll gradient fractions were resolved on a 10\% SDS-PAGE and immunoblotted for EEA1, PTPN23, RUFY1, or STOML2. B. Quantification of the immunoblots in A. 
endosomes [90] and can likely be found localized to both membrane populations.

RUFY1, STOML2, and PTPN23 colocalize with EGF and EEA1

We used indirect immunofluorescence to monitor the kinetics of association of the candidate proteins with the early endosome. HeLa cells were pulse-labeled with fluorescently-labeled EGF (Alexa-647-EGF) for 0-30 minutes. Cells were fixed and immunostained for EEA1 and each of the candidate proteins. For all three proteins, there was a time-dependent association with the labeled EGF. This is consistent with the model of the liganded receptor internalizing and trafficking to the early endosome. RUFY1 and PTPN23 colocalized with EEA1 independent of EGF treatment (Figure 4.3A and 4.3C), whereas STOML2 had low levels of colocalization with EEA1 that increased with EGF treatment (Figure 4.3B).

Loss of PTPN23 or RUFY1 changes the kinetics of EGFR endocytic trafficking We used RNA interference to knock down PTPN23 and RUFY1 in HeLa cells to determine the functional relevance of these proteins in EGFR trafficking. HeLa cells were transfected with 50nM siRNA or siCON (scramble control) for 72 hours, serum starved, and treated with $10 \mathrm{ng} / \mathrm{mL}$ Alexa-647-EGF ligand for 0-120minutes as described in Chapter II. Each experiment was repeated in triplicate, and a knockdown efficiency of more than $90 \%$ was achieved for each experiment (Figure 4.4D).

Loss of RUFY1 resulted in sustained activation of EGFR, as evidenced by 
A
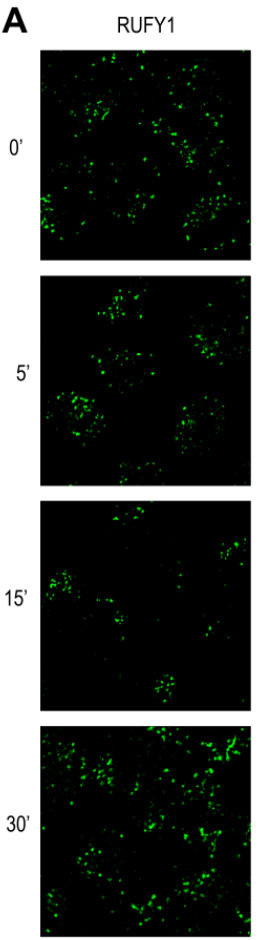

B
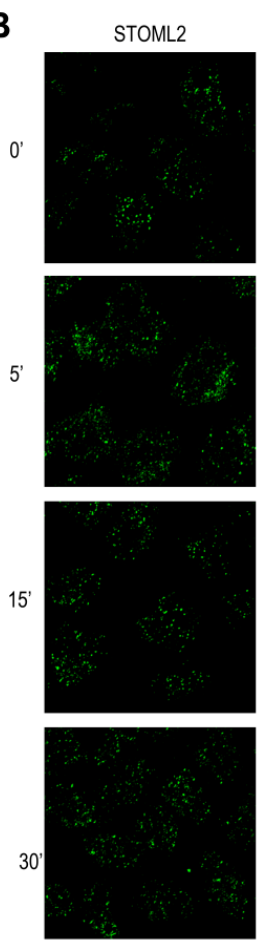

EGF
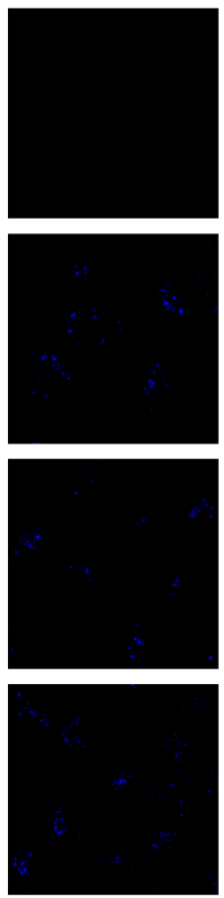

EGF
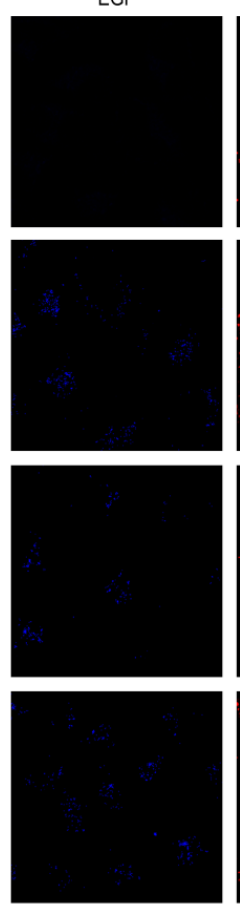

EEA1
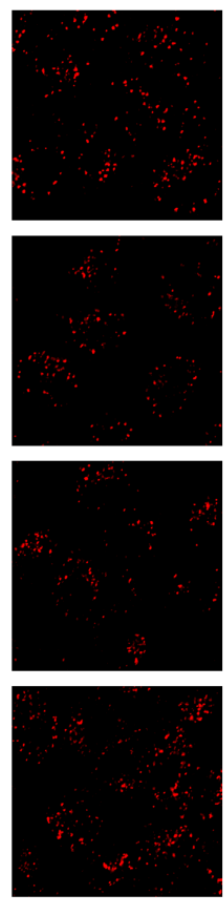

EEA1
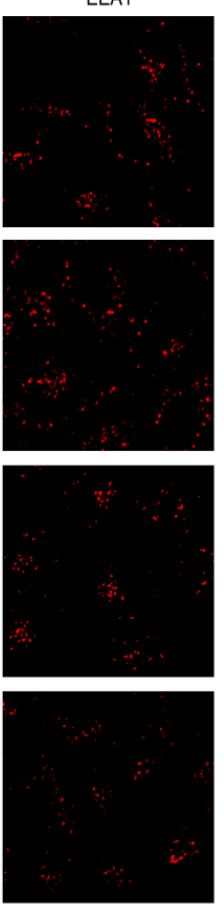

MERGE
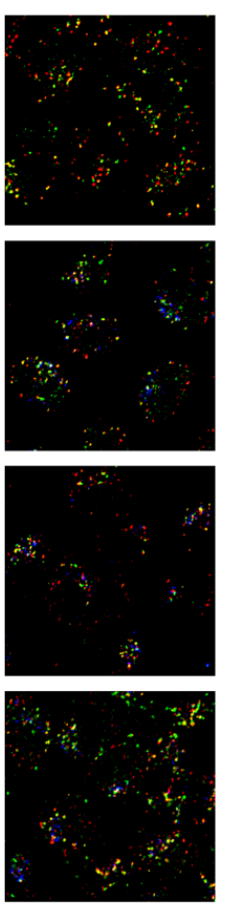

MERGE
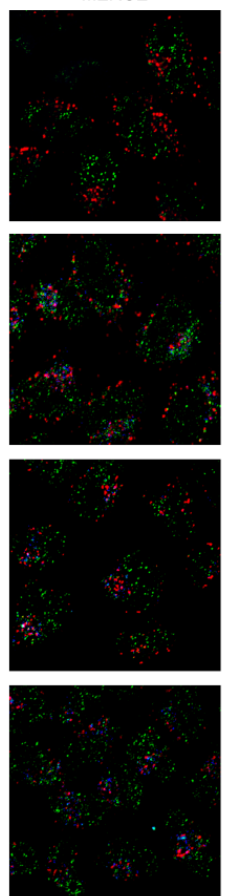

RUFY1 \& EGF

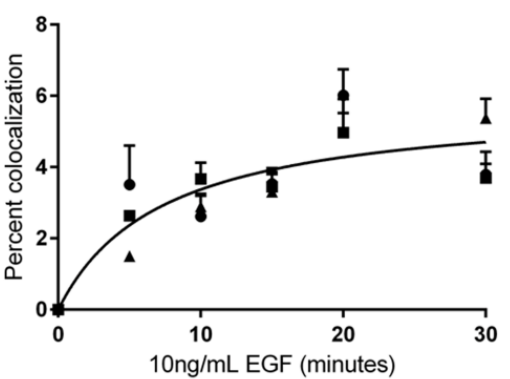

RUFY1 \& EEA1

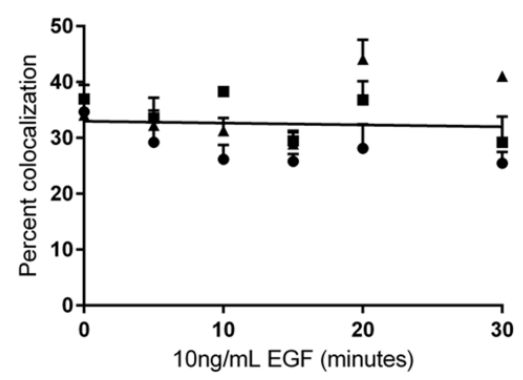

STOML2 \& EGF

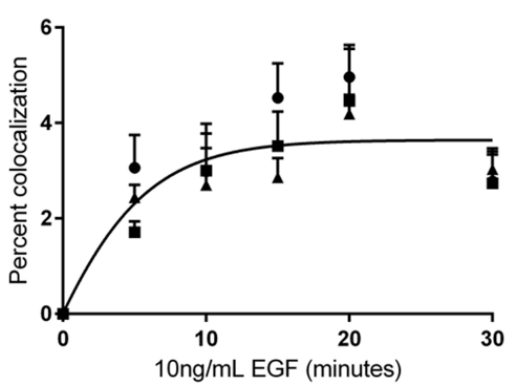

STOML2 \& EEA1

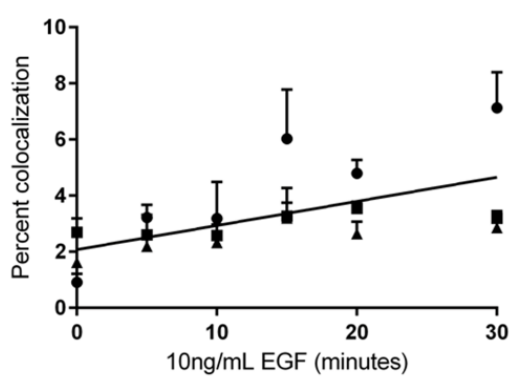



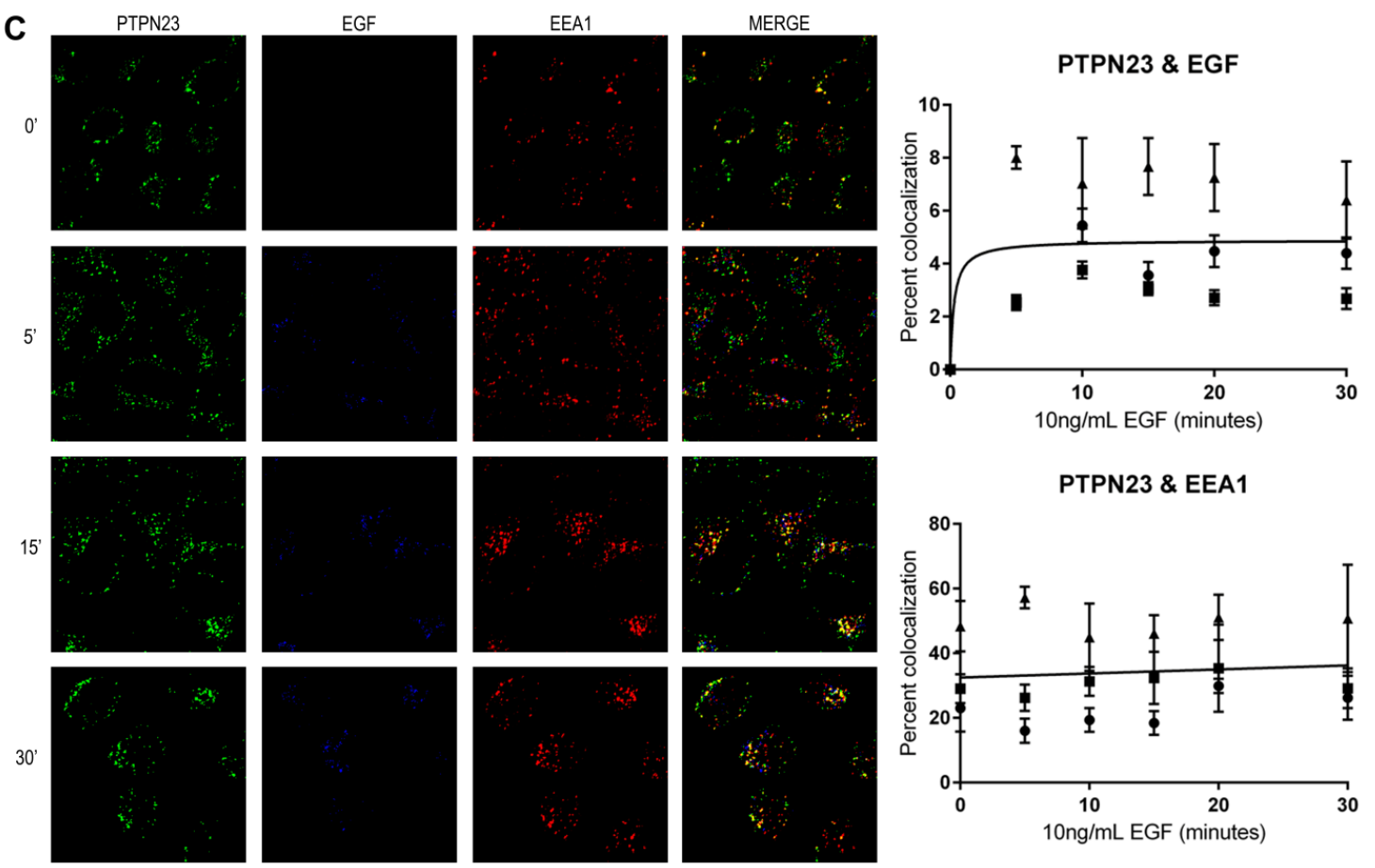

Figure 4.3 RUFY1, STOML2, and PTPN23 colocalize with early endosomes and internalized EGF. A-C. HeLa cells were pulse-labeled with $10 \mathrm{ng} / \mathrm{mL}$ AlexaFluor-647-EGF ligand (Invitrogen) for 0, 5, 10, 15, 20 and 30 minutes, followed by fixation in $4 \%$ paraformaldehyde. The cells were permeabilized and immunostained for EEA1 and either RUFY1, STOML2, or PTPN23 and visualized using either a goat anti-rabbit Alexa568 or goat anti-mouse Alexa-488, respectively. Images are representative of $0,5,15$, and 30 -minute time-points from three independent experiments. The extent of colocalization between EGF and each candidate protein or EEA1 and each candidate protein was measured as described in Chapter II. Data are plotted as the percent colocalization for each time point. Approximately 300 cells were analyzed per time point per condition, per experiment. Scale bar=20 $\mu \mathrm{m}$. Images were quantified using ImageJ software. 


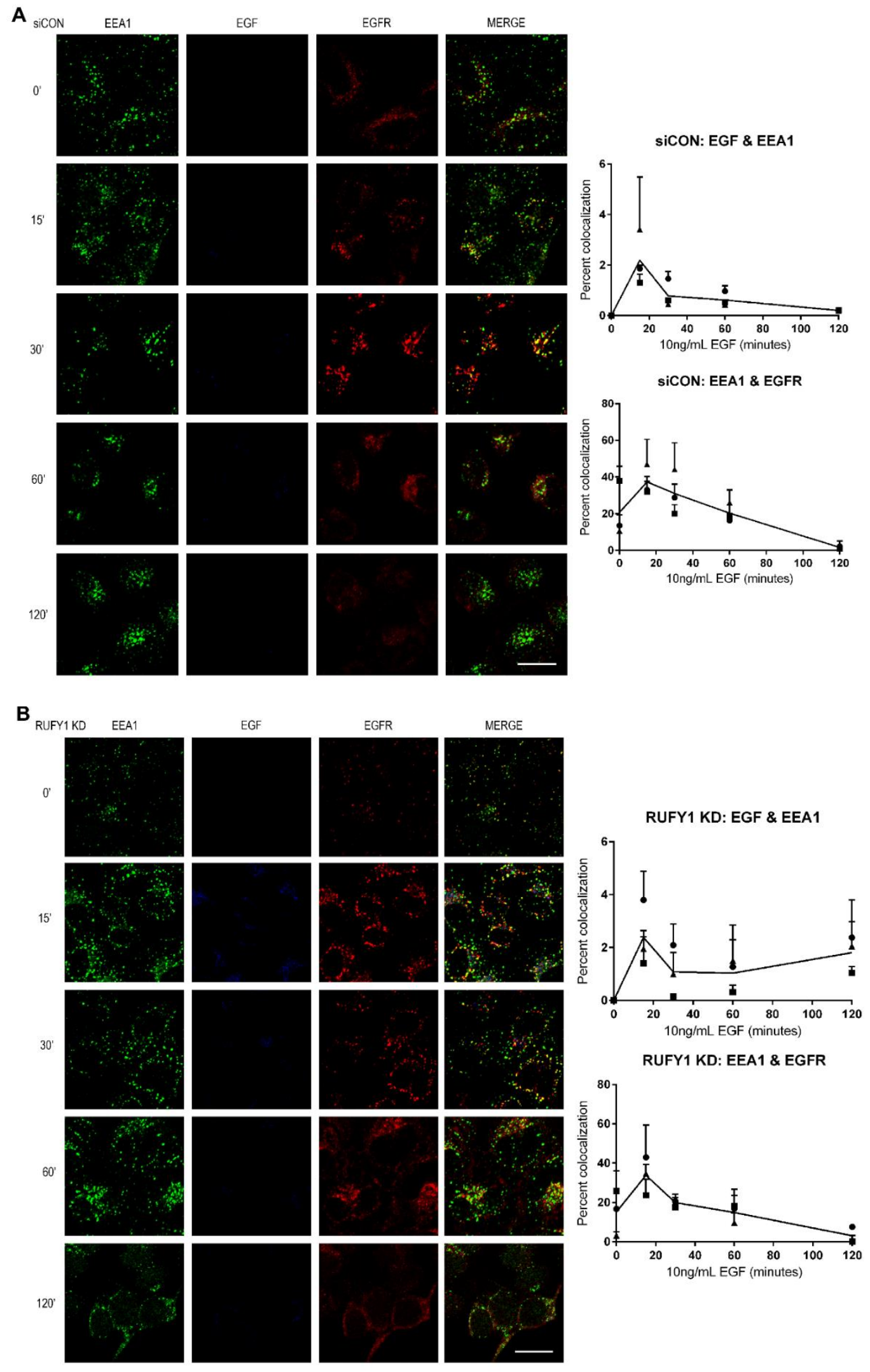




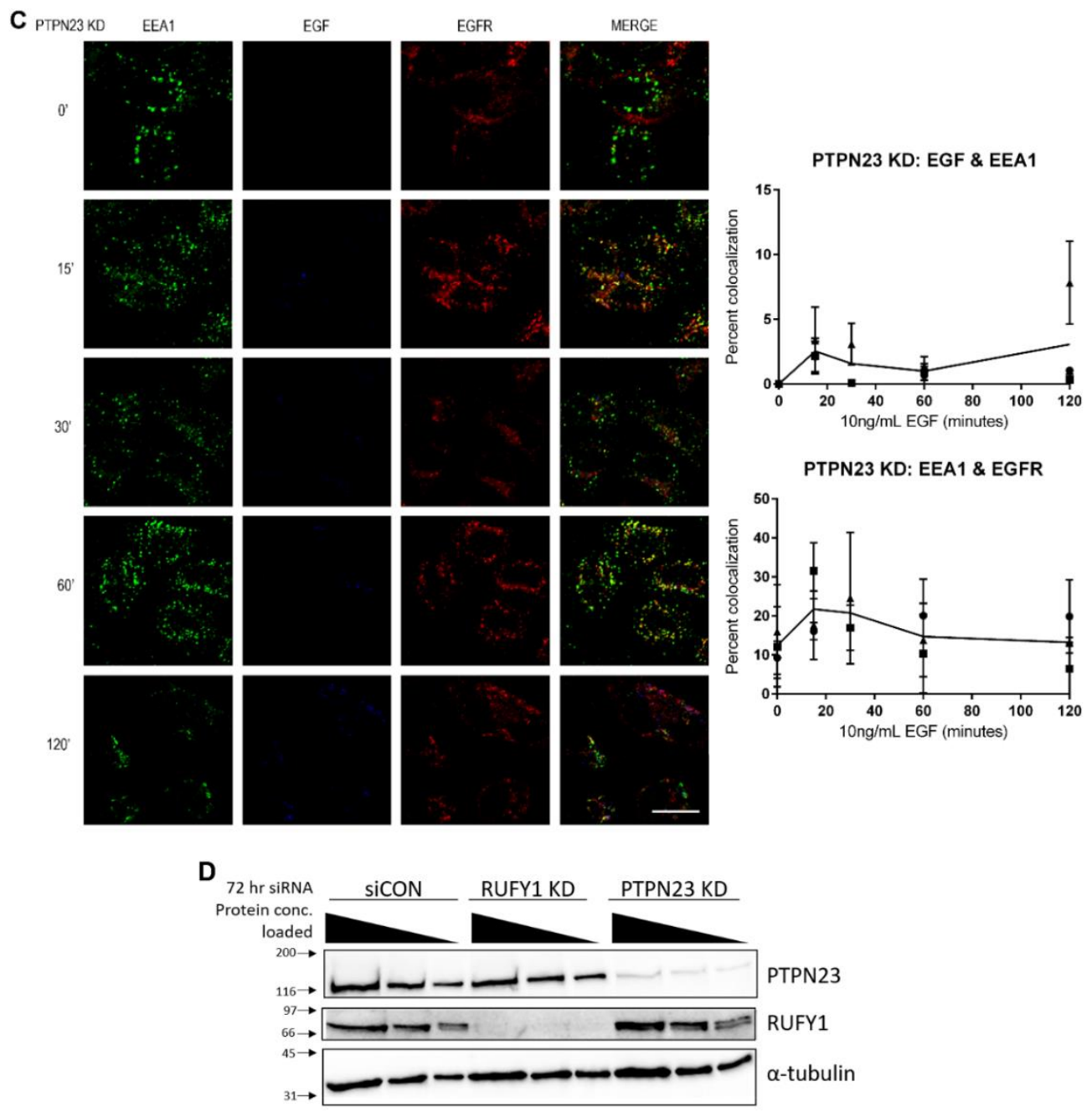

Figure 4.4 EGF and EGFR colocalization with EEA1 in siCON, RUFY1 KD, and PTPN23 KD cells. A-C. HeLa cells were incubated with scramble control (siCON), RUFY1, or PTPN23 siRNA for 72 hours prior to serum starving. The serum starved cells were pulse-labeled with $10 \mathrm{ng} / \mathrm{mL}$ AlexaFluor-647-EGF ligand (Invitrogen) for $0,15,30,60$, and 120 minutes, followed by fixation in $4 \%$ paraformaldehyde. The cells were permeabilized and immunostained for EEA1 and EGFR and visualized using either a goat anti-rabbit Alexa488 or goat antimouse Alexa-568, respectively. Images are representative of time-points from three independent experiments. The extent of colocalization between EGF or EGFR and EEA1 was measured as described in Chapter II. Data are plotted as the percent colocalization for each time point. Approximately 300 cells were analyzed per time point per condition, per experiment. Scale bars $=20 \mu \mathrm{m}$. Images were quantified using ImageJ software. D. A representative immunoblot from each knock-down experiment, probing for PTPN23, RUFY1, and $\alpha$-tubulin. For each knock-down experiment, samples were loaded in multiple protein concentrations $(20 \mu \mathrm{g}, 10 \mu \mathrm{g}$, and $5 \mu \mathrm{g})$ and the percent knockdown was calculated. Only experiments with a knock-down efficiency of $>90 \%$ were used. 
the prolonged colocalization of EGF ligand with EEA1 at 60- and 120- minutes when compared to siCON (Figure 4.4A and 4.4B). A similar prolonged association of EGF ligand with EEA1 is also seen in the PTPN23 KD samples (Figure 4.4C). In addition, the loss of PTPN23 in HeLa cells also yields an increase in the colocalization of total EGFR with EEA1. This suggests that EGFR is sequestered in early endosomes after activation, and that PTPN23 plays a role in the endocytic progression (e.g. MVB cargo sorting or endosomal maturation) of the receptor. This is consistent with the results of PTPN23 KD in other labs $[85,107,114]$.

PTPN23 loss results in slowed degradation and secretion of 125I-EGF

In order to further understand the roles of PTPN23 and RUFY1 in EGFR trafficking, we used a radiolabeled EGFR ligand ( ${ }^{125}$-EGF) and monitored its degradation and secretion in knock-down cell lines. RNAi was used to knockdown PTPN23 and RUFY1 in HeLa cells, and these cells were then stimulated with ${ }^{125}$ I-EGF for 7.5 minutes. Unbound radioligand was washed off of the cells, and the dishes of cells were incubated for the various periods of time. At each time-point, the media was collected from each dish, which contained any radioligand that was secreted from the cells during the incubation process. The cells were then solubilized, and intact proteins were precipitated out via centrifugation. The supernatant contained degraded proteins that did not precipitate. The radioactivity in the media (secreted), pellet (intact), and supernatant (degraded) were counted on a gamma counter (Figure 4.5). 

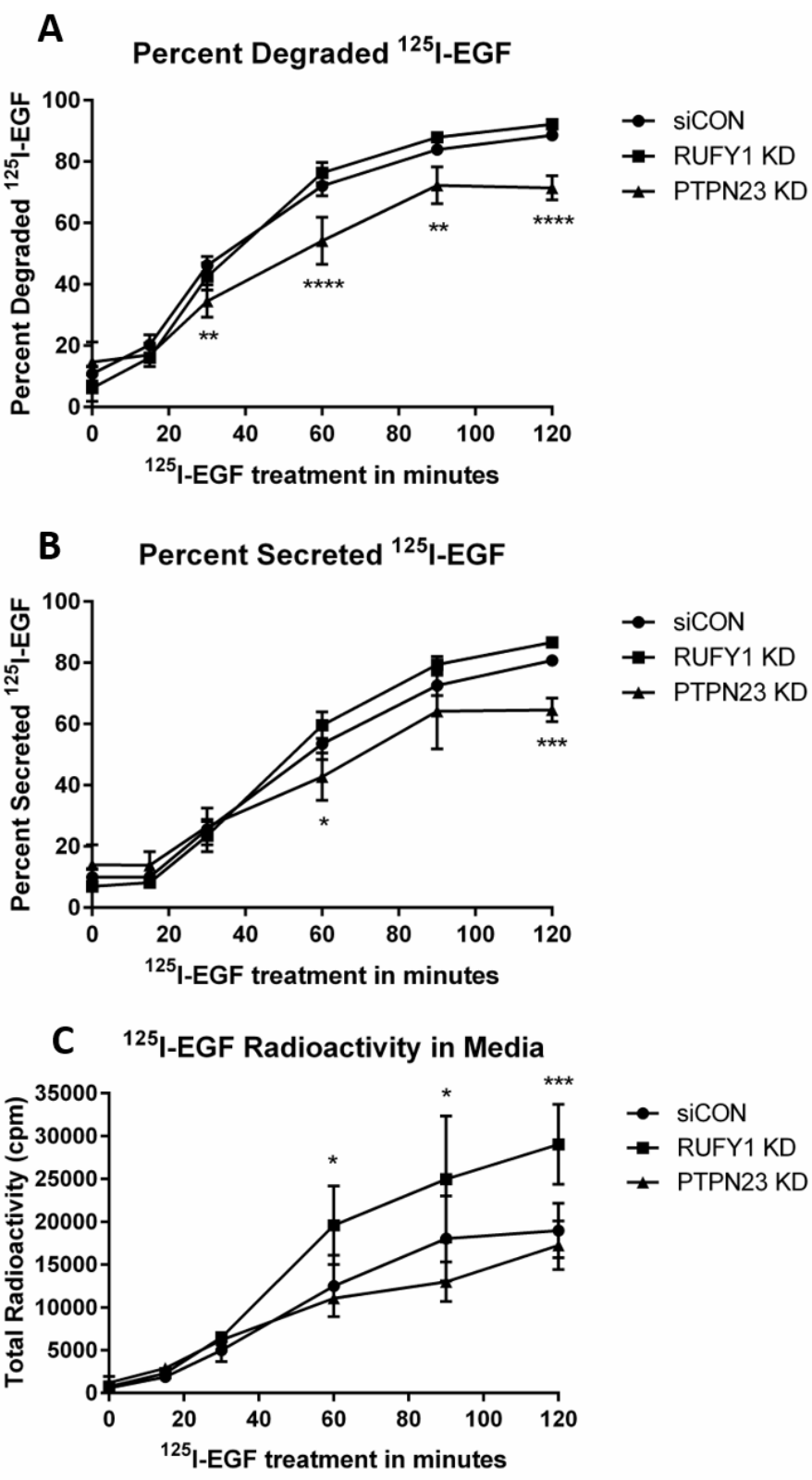

Figure 4.5 ${ }^{125}$ I-EGF radioligand trafficking in RUFY1 KD and PTPN23 KD cells. HeLa cells were transfected with the indicated siRNA for 72 hours prior to treatment. Cells were then treated with $0.05 \mu \mathrm{g} / \mathrm{mL}{ }^{125} \mathrm{I}$-EGF as described in Chapter II and incubated at $37^{\circ} \mathrm{C}$ for the indicated period of time. At each timepoint, the media was collected and the cells were solubilized. A. Intracellular degraded and B. extracellular (secreted) ${ }^{125}$ I-EGF radioactivity was counted in a PerkinElmer Wizard ${ }^{2}$ Gamma Counter and divided by the total radioactivity of each sample to calculate the percent degraded or secreted. C. Total radioactivity (cpm) of the collected media measured in each sample. All data are plotted as the mean \pm standard deviation $(n=3)$. 
There was a significant decrease in ${ }^{125}$-EGF ligand degradation in PTPN23 KD cells (Figure 4.5A). This result was expected, and is consistent with other PTPN23 KD studies in the literature. There was also a significant decrease in the secretion of ${ }^{125}$ I-EGF in these cells (Figure 4.5B). This supports the notion that there is less degradation of the ligand:receptor complex, and therefore less degraded ligand secreted from the cells. These data support the claim that PTPN23 is crucial for proper sorting of cargo into MVBs prior to lysosomal degradation.

While reviewing the raw data, we noticed that there was an increase in the total radioactivity in the media of the RUFY1 KD cells (Figure 4.5C). Even though there was not an increase in the percent of ligand secretion in the samples, there was still more radioactivity in all of the samples taken from these cells. We hypothesized that the increase in total radioactivity may be an artifact of an increase in total cell number of the RUFY1 KD cells. This was another observation we made during the propagation and experimentation using these cells. The RUFY1 KD cells seemed to grow more rapidly in comparison to siCON control HeLa cells. Next, we decided to quantify this change, and determine if it was EGFR-mediated.

RUFY1 loss leads to a significant increase in cell number

In order to quantify differences in cell number due to RUFY1 and PTPN23 loss, HeLa cells were transfected with 50nM siRNA for 24-hours prior to replating at 100,000 cells in $35 \mathrm{~mm}$ dishes. The dishes were then incubated 

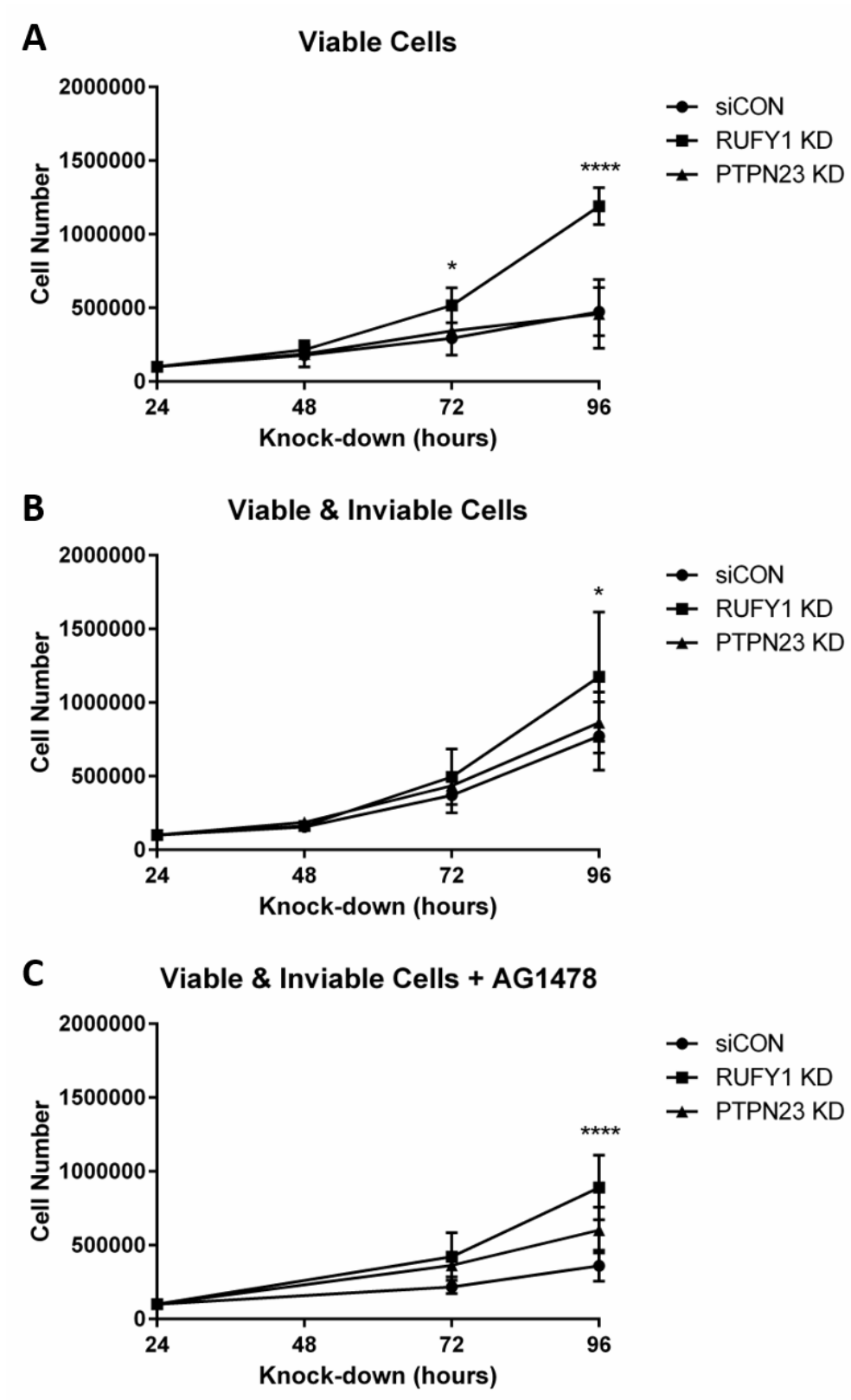

Figure 4.6 Cell number of siCON, RUFY1 KD, and PTPN23 KD HeLa cells under various conditions. A-C. HeLa cells were transfected with the indicated siRNA for the indicated time-points. Twenty-four hours after transfection, cells were split and plated at 100,000 cells in $35 \mathrm{~mm}$ dishes for each time-point. They were then allowed to proliferate and dishes were harvested every twenty-four hours. Cells were harvested as indicated and as outlined in detail in Chapter II. Cells were counted using a hemocytometer after harvest. Cells treated with AG1478 were incubated with $1 \mu \mathrm{M}$ AG1478 for 24-hours prior to harvest. All data are plotted as the mean \pm the standard deviation $(n=3)$. 
under growth conditions and cells were harvested and counted every 24hours. To collect viable cells, dishes were washed in PBS, trypsinized, and counted with a hemocytometer. There was a statistically significant increase in the number of viable RUFY1 KD cells as compared to siCON (Figure 4.6A). In addition to counting viable cells, we also counted viable and inviable cells under the same experimental conditions. While monitoring the cells under a microscope over time, there appeared to be more dead cells floating in the media of dishes with PTPN23 KD and siCON cells compared to RUFY1 KD cells. For this reason we repeated the cell counting experiments, but adjusted the protocol to collect both viable and inviable cells from the dishes.

In order to harvest the entire population of cells on the dish, we used a cell scraper to harvest all of the cells in the media. The cells were counted on a hemocytometer, and then pelleted and resuspended in lysis buffer (see Chapter II). Counting the cells in this manner, we found there was still a statistically significant increase in the amount of RUFY1 KD cells 96 hours after transfection (Figure 4.6B). However, the difference between the average number of siCON and PTPN23 KD cells at this time-point was diminished when compared to only counting viable cells. This suggests that the RUFY1 KD cells grow faster than PTPN23 KD and siCON cells, and that there are fewer dead cells in the RUFY1 KD dishes.

Next, we wanted to determine if the increased relative number of the RUFY1 KD cells was driven by EGFR activity. To test this, we treated cells with an EGFR small molecule inhibitor, AG1478. We repeated the counting and 
harvesting of viable and inviable cells, and in addition, treated the 72- and 96hour time-points with $1 \mu \mathrm{M}$ AG1478 for 24 hours prior to harvest. This concentration has been previously reported to be effective for attenuating EGFR activation [65]. Although these cells were not stimulated with any EGFR ligands, it was a possibility that the loss of RUFY1 KD had an effect on EGFR signaling. We found that AG1478 did not change the relative cell number in the RUFY1 KD cells 96-hours after transfection (Figure 4.6C).

PTPN23 loss and treatment with AG1478 leads to membrane blebbing

During the cell counting experiments, we monitored the morphology of the cells at each time-point prior to harvest. Because there were less dead cells in the RUFY1 KD dishes as compared to siCON control, we wanted to visualize any potential morphological changes that might have been occurring in these cells. We noticed that there were not any obvious changes in the morphology of the RUFY1 KD cells (Figure 4.7B).

We also took images of the cells treated for 24-hours with the EGFR inhibitor AG1478. Although this drug did not block the enhanced growth effect in the RUFY1 KD cells, we did notice that, at the 96-hour time-point, there appeared to be membrane blebbing in the PTPN23 KD cells treated with AG1478 (Figure 4.7C, inset). Though not quantified, this effect was seen in a multitude of cells on the dish, and in all three replicates of the experiment.

Loss of RUFY1 reduces apoptosis, and loss of PTPN23 enhances apoptosis in 
A

siCON

siCON +AG1478

B

RUFY1 KD

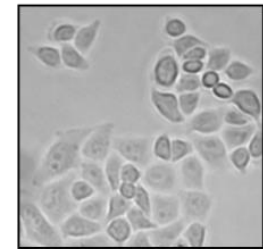

RUFY1 KD +AG1478

C

PTPN23 KD

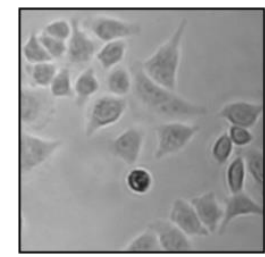

PTPN23 KD +AG1478

$48 \mathrm{hrs}$

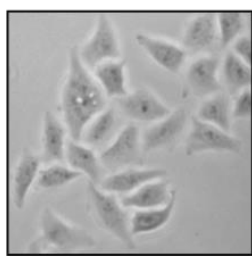

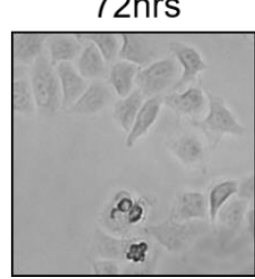
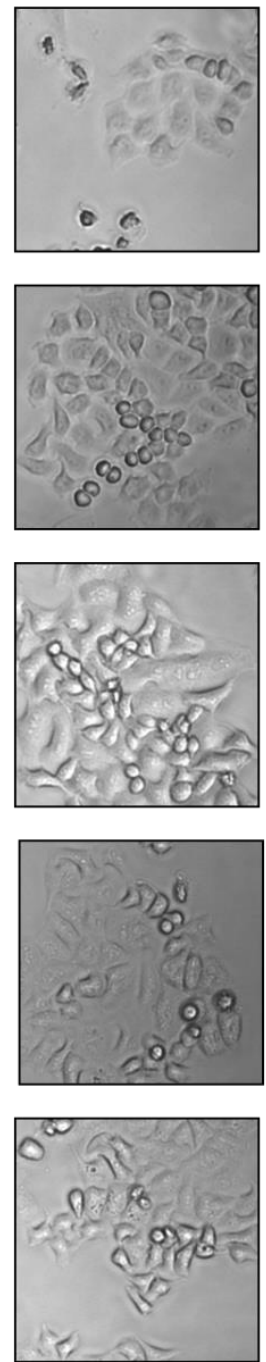

$96 \mathrm{hrs}$
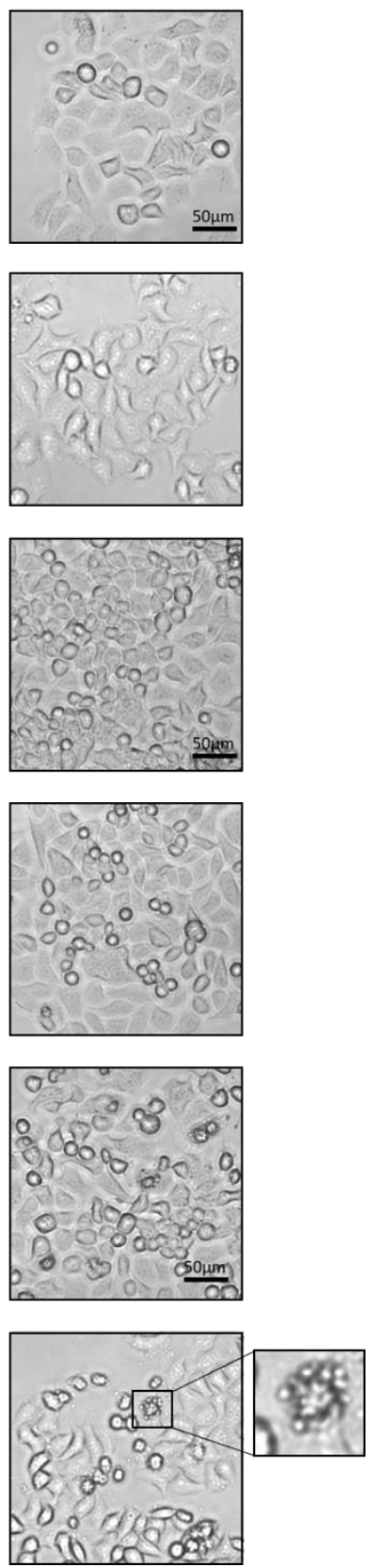

Figure 4.7 Cell morphology of HeLa cells transfected with siCON, RUFY1, and PTPN23 siRNA, and treated with AG1478. HeLa cells were transfected with the indicated siRNA for 24-hours and replated at a density of 100,000 cells $/ 35 \mathrm{~mm}$ dish. Cells were then grown for the indicated period of time and imaged at 100x magnification on a Nikon Eclipse Ti widefield epifluorescence microscope. Cells treated with an EGFR-inhibitor were incubated with $1 \mu \mathrm{M}$ AG1478 for 24-hours prior to imaging. Scale bar=50 $\mathrm{mm}$. Images are representative of three independent experiments. 


\section{HeLa cells}

Due to the decreased number of dead cells in the RUFY1 KD cells and the membrane blebbing seen in the PTPN23 KD cells, we wanted to determine if there were any changes in cell death pathways occurring in these cell lines. We chose to monitor PARP cleavage via immunoblotting. PARP cleavage is a commonly used marker for apoptosis induction. After siRNA transfection, cells were harvested and lysates were resolved on a 7.5\% SDS-PAGE and immunoblotted for PARP and $\alpha$-tubulin. Quantification of the immunoblots by Image $\mathrm{J}$ software showed a statistically significant decrease in PARP cleavage in the RUFY1 KD cells as compared to siCON control (Figure 4.8). Conversely, there was a significant increase in PARP cleavage in the PTPN23 KD cells 96hours after transfection (Figure 4.8). These results suggest that there is decreased apoptosis induction in RUFY1 KD cells, and increased apoptosis induction in PTPN23 KD cells.

\section{Cell viability in RUFY1 KD and PTPN23 KD cells under various conditions}

Finally, we set out to corroborate these findings with another assay, this time monitoring cell viability using the alamarBlue assay. Due to distinct differences in PARP cleavage and cell number seen at the 72- and 96-hour timepoints previously, we monitored the viability of knock-down cells at both timepoints. In addition, we treated the cells with varying concentrations of EGF ligand or AG1478 EGFR inhibitor for 24 hours to determine if these had any effect on cell viability. The $1 \mathrm{mM}$ AG1478 concentration was used as a positive 

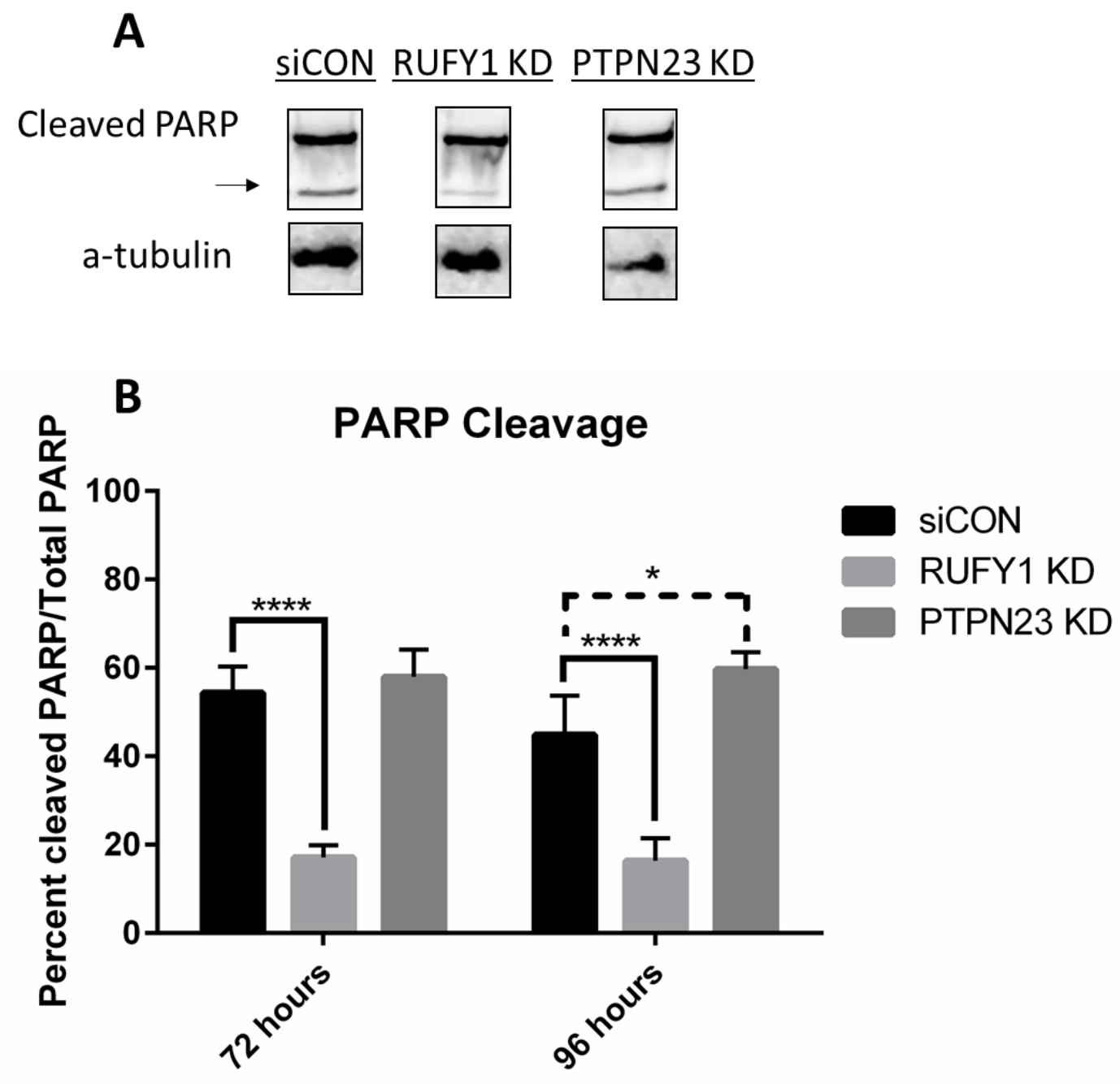

Figure 4.8 PARP-cleavage induction in RUFY1 KD and PTPN23 KD cells. HeLa cells were transfected with 50nM siRNA for 72- and 96-hours and harvested to collect viable and inviable cells (see Chapter II). A. Lysates were resolved on a 7.5\% SDS-PAGE and immunoblotted for PARP and $\alpha$-tubulin. Immunoblots shown are representative of the 96-hour time-point from three independent experiments. B. Immunoblots were quantified using Image $\mathrm{J}$ software. The mean \pm the standard deviation are plotted from three independent experiments. PARP cleavage was calculated by dividing the quantification from the bottom band in the immunoblot, and dividing it by the sum of the top and bottom bands (cleaved PARP/total PARP). 


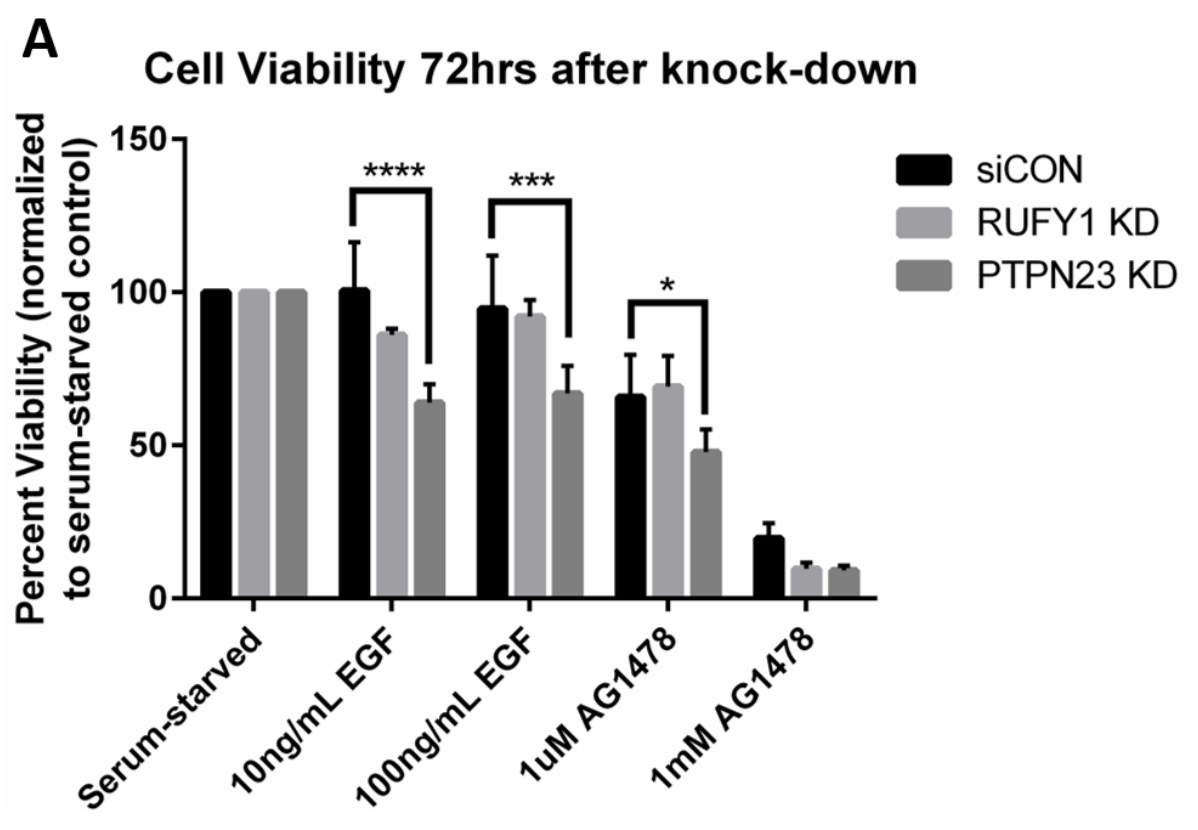

B Cell Viability $96 \mathrm{hrs}$ after knock-down

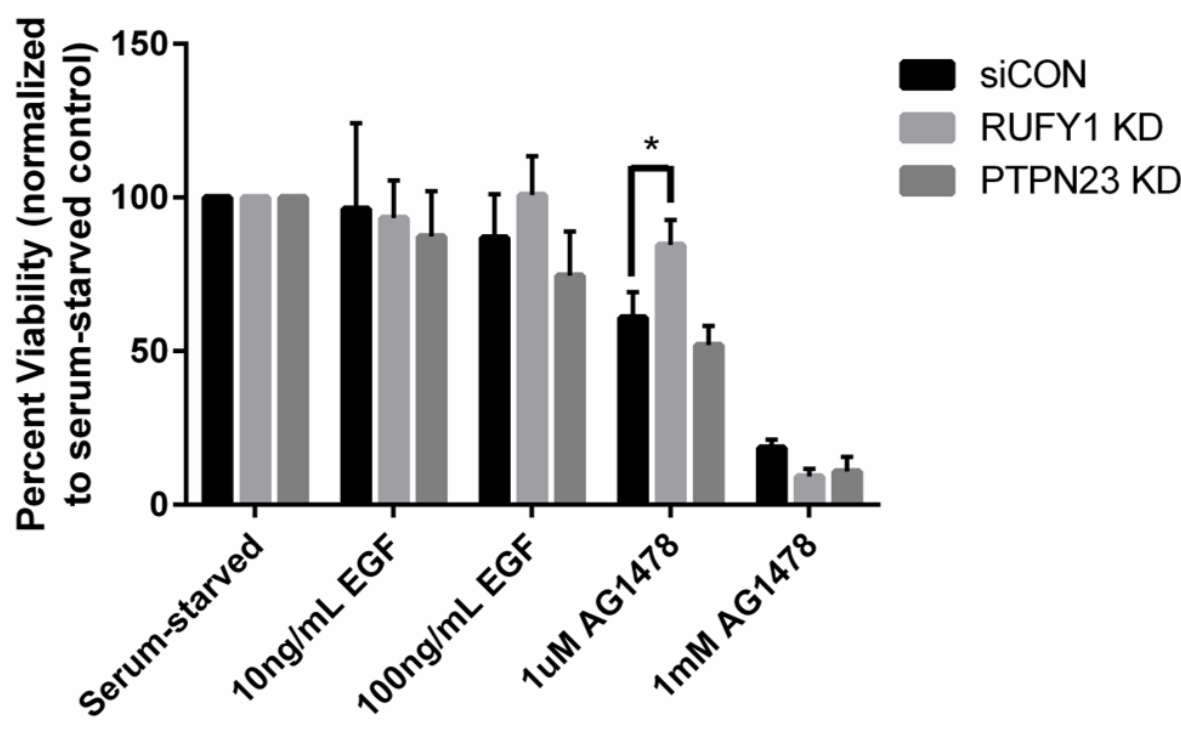

Figure 4.9 Cell viability in siCON, RUFY1 KD, and PTPN23 KD cells under various conditions. HeLa cells were transfected with the indicated siRNA for 24 hours and then plated into 96 -well dishes. After 24 hours of growth, the cells were serum-starved for two hours, followed by 24 hours of incubation with either $10 \mathrm{ng} / \mathrm{mL}$ EGF, $100 \mathrm{ng} / \mathrm{mL}$ EGF, $1 \mu \mathrm{M}$ AG1478, or $1 \mathrm{mM}$ AG1478. The cells were then incubated with alamarBlue reagent for two hours and the fluorescence was read on a plate reader. The average of six replicates was taken and normalized to the serum-starved control. The data plotted as the mean \pm the standard deviation $(n=3)$. A. Cell viability 72 -hours after knock-down. B. Cell viability 96hours after knock-down. 
control for cell death.

We found that EGF ligand stimulation did not increase cell viability, but significantly decreased viability in PTPN23 KD cells at 72-hours (Figure 4.9A). $1 \mu \mathrm{M}$ concentration of AG1478 also decreased cell viability in PTPN23 KD cells at this time-point. However, the effect was not seen at the 96-hour time-point. RUFY1 KD cells showed a significant increase in cell viability after treatment with $1 \mu \mathrm{M}$ AG1478 at the 96-hour time-point (Figure 4.9B). This supports the claim that RUFY1 KD cells appear to have a reduced susceptibility to cell death processes, as this treatment reduced cell viability in siCON and PTPN23 KD cells.

C. Discussion

The LC-MS/MS analysis of the isolated endosomes revealed that EGFR, PTPN23, and three previously uncharacterized proteins (i.e. STOML2, RUFY1, and CCDC51) associate with early endosomes in an EGF-dependent manner. Unfortunately, there are no antibodies commercially available for the uncharacterized coiled-coiled domain containing protein CCDC51, so we restricted further studies to RUFY1, PTPN23 and STOML2. The temporal and spatial association with the EGFR-containing endosomes could reflect an important role for these proteins in regulating EGFR signaling.

We were struck by the absence of effector proteins among those associated with the early endosome (ftp://massive.ucsd.edu/MSV000081692) -more specifically, those that had been previously reported to be associated with 
EGFR containing endosomes (e.g. Shc, Grb2, MEK2, etc.) [30, 57, 69]. As such, we wondered why these proteins were not detected in the mass spectrometry analyses. Despite LC-MS/MS being a more sensitive detection method, it does have limitations. As mentioned above, low-affinity associations with the endosomes may have dissociated during the isolation procedure. Previous work showing an association of these scaffold and effector proteins with early endosomes used immunofluorescence and immunoblotting. An alternative explanation is that the antibodies in those immune-detection methods generate an amplification of a signal, whereas LC-MS/MS quantifies only the total number of peptides present in a sample. As such, it is possible that the quantities of these and other effector proteins in the early endosomes were too low to be detected by LC-MS/MS; but, sufficient for detection via immunoblot and immunofluorescence due to signal amplification.

RUFY1 has been previously reported to have a role in receptor tyrosine kinase signaling; loss of RUFY1 has been shown to inhibit PDGF-induced migration of fibroblasts [115]. These data support what other investigators have found—-that RUFY1 colocalizes with EEA1 [90, 96, 115] (Figure 4.3A). PTPN23 is the only of the four identified proteins to have been well studied in the context of EGFR signaling and trafficking. PTPN23 acts as a coordinator of the ESCRT complex pathway to transport internalized EGFR into multivesicular bodies [107, 114]. These data support the involvement of PTPN23 in EGFR endocytic trafficking (Figure 4.3C). The third protein, STOML2, has been studied exclusively in mitochondria. The literature contains numerous clinical reports of 
STOML2 being a driver of proliferation in multiple cancer types and is associated with poor patient prognosis $[109-111,116]$. Yet, the mechanism of STOML2 in cancer cell proliferation remains unknown and the association of STOML2 with EGFR in early endosomes introduces some possibilities. Together, these findings initiate some important questions: What are the roles of these proteins in the early endosome? Are these proteins required for EGFR functions? Do they impact membrane trafficking? Do they affect EGFR signaling?

Of the three proteins, only STOML2 increases its colocalization with EEA1 with EGF treatment using immunofluorescence assays (Figure 4.3B). Although this association is modest, it is consistent with a model in which the liganded EGFR recruits STOML2 to the early endosome. This change in subcellular location could permit novel interactions that drive new, previously unknown functions of this protein. This is the first published result testing STOML2 fluorescence using the specified STOML2 antibody and it is worth noting that the localization of the protein does not mirror what has been published using other STOML2 antibodies [87]. This could be due to several possibilities: 1) STOML2 may have an abnormal distribution in HeLa cells, 2) STOML2 may be overexpressed in HeLa cells and a large subgroup of the proteins are mislocalized away from mitochondria and into endosomes, or 3) STOML2 has an additional association with endosomes. Another protein in the STOML2 family, SLP-1/STOML1, has been shown to localize to late endosomes [108], which is consistent with STOML2 having a role in endocytic trafficking.

Biochemical and immunofluorescence analyses indicate that RUFY1 and 
PTPN23 colocalize with EEA1 independent of EGF treatment (Figure 4.3). This observation contradicts the LC-MS/MS data that suggested an EGF-dependent association of these proteins with early endosomes. One possible explanation for this discrepancy is that the presence of active EGFR in early endosomes increased the affinity of the candidate proteins with the compartment. As such, the proteins may have dissociated from the endosomes during the biochemical isolation protocol without EGF stimulation; trafficking of the receptor to the endosomes stabilizes these proteins to the vesicles.

In an attempt to further elucidate their functional role in EGFR endocytic trafficking, we used siRNA to knock down these proteins in HeLa cells. We selected RUFY1 and PTPN23 for RNA silencing, because both RUFY1 and PTPN23, but not STOML2, have previously reported endosomal functions. As such, it is more plausible that their recruitment to the early endosome would affect endocytic trafficking of EGFR.

Loss of either RUFY1 or PTPN23 slowed trafficking of the EGF:EGFR complex and increased its colocalization with EEA1 (Figure 4.4). RUFY1 KD yielded sustained EGF and EEA1 colocalization. This suggests that RUFY1 loss slows the endocytic trafficking of the EGFR indicating RUFY1 enhances EGFR trafficking. RUFY1 has been reported to play a role in early endosome transport and recycling $[86,96]$ and these data support this role. PTPN23 KD yielded sustained colocalization of EGFR with EEA1. This suggests that PTPN23 loss resulted in the sequestration of the receptor in early endosomes upon EGF stimulation. This is consistent with PTPN23 regulating EGFR trafficking toward 
the late endosomes/lysosomal degradation. This aligns with the work of Woodman and colleagues, who found that PTPN23 plays a critical role in MVB morphogenesis and EGFR cargo sorting [85, 107].

We wanted to use an additional assay to monitor changes in EGFR trafficking upon RUFY1 and PTPN23 KD. We chose to monitor radioligand degradation, as these assays are extremely sensitive and highly repeatable. While immunofluorescence allowed us to monitor the subcellular localization of EGFR in the KD cells, using radio-labeled ligand allowed us to quantify changes in ligand:receptor complex degradation. There was a significant decrease in both radioligand degradation inside the cells, and secretion of ligand into the media in PTPN23 KD cells (Figure 4.5). This supports previous findings that PTPN23 loss slows EGF:EGFR trafficking to lysosomes and thus, degradation. Though the immunofluorescence data showed an increase in EGF colocalization with EEA1 in RUFY1 KD cells, the radioligand assay did not show any changes in EGF degradation or secretion as compared to siCON control. Taken together, these data suggest that RUFY1 loss does not contribute to changes in EGFR trafficking.

While propagating the RUFY1 KD HeLa cells, we noticed an increase in their growth rate. We used cell counting methods to quantify this change, and found a statistically significant increase in the number of RUFY1 KD cells (Figure 4.6). Other researchers have also used RNAi to knock down RUFY1 in various cell lines, and have seen various effects. Vukmirica et al. knocked down RUFY1 in NIH 3T3 fibroblasts, and monitored cell migration. They reported that these 
cells exhibited decreased migration in response to PDGF-stimulation, as well as a decrease in basal migration rates without ligand stimulation [115]. While migration and cell growth are unique processes, it is still surprising that RUFY1 KD enhances cell growth or survival in one cell line, but stunts migration in another. In a separate study, Ivan et al. knocked down RUFY1 in HEK293T cells, and detected a $40 \%$ increase in plasma membrane protrusions as compared to controls [97]. We monitored the morphology of RUFY1 KD HeLa cells, but did not notice any changes in plasma membrane protrusions (Figure 4.7B). One explanation for these discrepancies is the use of different cell lines. Regardless, the loss of RUFY1 in HeLa cells lead to a dramatic increase in cell growth, and we wanted to uncover the mechanism of this effect.

Naturally, we hypothesized that the increase in cell growth after RUFY1 loss could have been a result of changes in EGFR activity. Although the trafficking of EGFR in these cells did not appear to be altered, it was possible that the activity of EGFR was changed in some way. Because EGFR activity is a known driver of cell proliferation, and we found an association of RUFY1 with EGFR-containing early endosomes, this seemed to be a reasonable hypothesis. We initially used biochemical techniques to monitor EGFR phosphorylation in the knock-down cell lines, but the results were inconclusive (data not shown). As such, we decided to use a chemical inhibitor of EGFR activity, AG1478. If EGFR activity was driving cell survival or growth in HeLa cells that lacked RUFY1, AG1478 would block this effect. However, we found that AG1478 did not decrease the relative cell number of these cells (Figure 4.6C). In addition, we 
monitored viability of the RUFY1 KD cells after being treated with AG1478 for 24 hours, and these cells had increased viability when compared to siCON control treated cells (Figure 4.9B). These data strongly suggested that the increased cell numbers seen after RUFY1 loss in HeLa cells was not driven by EGFR activity.

PTPN23 loss did not lead to the same increased relative cell number effect as RUFY1 loss in HeLa cells. However, we did notice that AG1478 treatment at later time-points induced noticeable membrane blebbing in PTPN23 KD cells, but not in other cell lines (Figure 4.7C). Membrane blebbing is generally attributed to the induction of apoptosis, or programmed cell death [117]. To quantify apoptosis induction in the KD cell lines, we monitored Poly ADPribose polymerase (PARP) cleavage in each knock-down cell line. PARP is a family of proteins that are involved in DNA-repair. When a cell has begun the process of initiating apoptosis, various caspases are activated which cleave proteins to inhibit cell processes [117]. Caspase-3 cleaves PARP proteins, and the cleavage of PARP proteins can be quantified via immunoblotting. We found that, over time, PTPN23 KD cells had increased PARP cleavage (Figure 4.8). This effect was not monitored after AG1478 treatment, but was seen in untreated PTPN23 KD cells. In addition, we monitored the viability of these cells after treatment with EGF ligand or AG1478 and found that all treatments significantly reduced cell viability of PTPN23 KD cells at the 72-hour time-point (Figure 4.9A). These results suggest that PTPN23 KD cells have an increased sensitivity to cell 
death induction. The mechanism of this effect is unknown, and future studies are required to elucidate the cause of this sensitivity. 


\section{CHAPTER V}

\section{SUMMARY AND FUTURE DIRECTIONS}

\section{A. Restatement of Research Goals}

The goal of this dissertation work was to better understand the implications of EGFR spatial regulation on its interactions with downstream signaling proteins. While EGFR trafficking is well understood, there is currently no consensus in the field as to how endocytic trafficking spatially regulates EGFR signaling. Identifying proteins that are recruited to early endosomes in an EGFdependent manner not only provides a platform for further study on mechanisms and outcomes, it also provides a means for finding new potential targets for mediating EGFR signaling cascades.

\section{B. Summary of Findings}

We have developed a rapid and reproducible technique to isolate early endosomes from cultured cells. Biochemical techniques were used to validate the isolation of a pure population of early endosomes with virtually no contamination from other organelles. Morphological studies revealed that the isolated vesicles had similar characteristics to early endosomes.

In addition to developing this isolation technique, we used it to analyze the proteome of early endosomes. We have identified four proteins associating with early endosomes in an EGF-dependent manner: RUFY1, PTPN23, CCDC51, 
and STOML2 [118]. Other studies have reported an association of RUFY1 and PTPN23 with early endosomes $[85,86]$. However, this is the first report of either CCDC51 or STOML2 associating with early endosomes. We validated the association of RUFY1, PTPN23, and STOML2 with early endosomes using indirect immunofluorescence and immunoblotting.

Knock-down studies were utilized to determine the roles that RUFY1 and PTPN23 played in EGFR trafficking. Immunofluorescence revealed that the loss of PTPN23 lead to a prolonged association of EGFR with EEA1, a marker for early endosomes. Radioligand binding studies confirmed this phenomenon. This finding is consistent with the literature and supports the claim that PTPN23 is an important component of cargo sorting from late endosomes to lysosomes for degradation.

Though these knock-down studies did not reveal any changes in EGFR trafficking due to RUFY1 KD, we did notice that these cells had a dramatically increase number of cells. To quantify this, we counted cells and found a significant increase in the number of RUFY1 KD cells when compared to siCON cells plated at the same density. While other reports have knocked down RUFY1 in various cell lines, we are the first to report this characteristic.

We wanted to determine if the increased number of RUFY1 KD cells was driven by EGFR activity. A chemical inhibitor of the EGFR kinase, AG1478, was used to block EGFR activity while monitoring cell number. These studies did not reveal any change in RUFY1 KD cell number-however, monitoring the morphology of the cells under a microscope revealed that AG1478 treatment 
caused membrane blebbing in the PTPN23 KD cells. This suggests that loss of PTPN23 may increase susceptibility to cell death processes.

To quantify the induction of apoptosis in each cell line, PARP cleavage was calculated using immunoblotting. These studies revealed that RUFY1 KD cells had a significant reduction in PARP cleavage as compared to siCON cells, suggesting loss of RUFY1 caused increased cellular stress tolerance. In addition, we found that PTPN23 KD induced an increase in PARP cleavage. This result corroborated the morphological images showing membrane blebbing in PTPN23 KD cells after AG1478 treatment. While the loss of RUFY1 seems to enhance cell survival, the loss of PTPN23 seems to have the opposite effect.

Finally, we used the alamarBlue assay to quantify cell viability in each knock-down cell line. These studies supported the hypothesis that RUFY1 KD cells had increased viability under stressful conditions, and PTPN23 KD cells had decreased viability overall. Future studies will be critical in determining the underlying mechanisms for these findings.

\section{Significance of Findings}

The endosome isolation technique developed here could be utilized by many areas of research. This technique can be applied to the study of numerous proteins, receptors, kinases, and signaling effectors. For researchers interested in other organelles, this technique can be modified by changing what Percoll fractions are collected and what antigen is targeted during the affinity purification step. The implications of application and adaptation of this isolation procedure for 
further research are vast.

Aside from the development of the isolation technique, the discovery of an association of CCDC51 and STOML2 with early endosomes is completely novel. Neither of these proteins has been previously reported to associate with either EGFR or early endosomes. This provides a platform for numerous future studies to elucidate the mechanisms of these interactions. In addition, virtually nothing is known about the function of the protein CCDC51. The finding that CCDC51 associates with EGFR and early endosomes could provide some insights into the roles of this protein.

We have also found that RUFY1 loss leads to enhanced survival. To the author's knowledge, this is the first report of its kind. Until now, RUFY1 has been studied exclusively for its roles in endocytic trafficking. The mechanism for the enhanced survival activity of RUFY1 is currently unknown.

The findings reported within this dissertation are significant for several reasons. First, the early endosome technique developed herein can be used to study myriad endocytic proteins, including other receptors that are endocytosed. The isolation technique can also be modified to isolate other intracellular organelles. Second, we have discovered novel associations of both CCDC51 and STOML2 with both EGFR and early endosomes. Finally, we have discovered a potential role for RUFY1 as driver of cell survival or cell growth. These discoveries will drive multiple fields forward toward better understanding of organelles, receptor trafficking, and CCDC51, STOML2, and RUFY1 functions. D. Strengths and Weaknesses 


\section{i. Strengths}

A major strength of this work is in its use of HeLa cells. This cell line expresses EGFR at levels similar to what has been measured in normal human epithelial tissues ( 50,000 EGFRs per cell), allowing us to correlate findings in these cells with the physiologic activity of EGFR. To this same end, physiologic/ low levels of EGF ligand were used to stimulate EGFR activation $(10 \mathrm{ng} / \mathrm{mL})$. Low concentrations of EGF ligand limit endocytosis of EGFR to the clathrin-mediated type, which is the type of endocytosis that occurs in normal physiology. Further, HeLa cells grow rapidly, permitting the generation of large populations of cells, which was required for subsequent endosome enrichment.

We were able to isolate early endosomes without introducing exogenous factors into the cells. While it is generally acceptable to use cell lines that have been genetically altered to enhance detection and capture of the target protein of interest, we were able to enrich early endosomes without the use of epitope tagged proteins or transfection reagents. As a result of this, the isolated early endosomes are physiologically relevant. The proteomics data obtained from these compartments can thus be taken at face value, without concerns about non-physiologic changes in their structure or function.

The proteomics method used in these studies is also a strength of this work, because LC-MS/MS is a highly sensitive and robust technique. In addition, it provides researchers with an unbiased platform for analyzing the protein composition of a sample. Other techniques require a prerequisite knowledge regarding what proteins to study. Here, we were able to target a highly organelle- 
specific protein, EEA1, and assess the entire proteome of the compartments isolated with this antigen. This approach uncovered a large amount of data from in vitro samples that were reproducible.

\section{ii. Weaknesses}

One of the few limitations of this work is that it was performed using cultured cells. A major drawback to using tissue culture rather than animals is that the results cannot be correlated to the organism level. Cultured monolayers of cells lack the complex interplay of signaling that occurs within organisms and even tissues. Tissue culture models are ideal for preliminary studies, however, isolating early endosomes from an animal would provide a more physiologically relevant analysis of EGFR signaling from these compartments.

Another weakness of this work is that all experiments were conducted using HeLa cells. Although this cell line is useful and extremely common, it is important to remember that these cells are a human cervical adenocarcinoma line. Cancer cells tend to behave and function in different ways from nontransformed cells, and there may be changes in signaling pathways in this cell line for which we have not accounted. For this reason, it is crucial that this work be repeated in other cell lines to validate that the findings reported herein are not specific to HeLa cells.

\section{E. Future Directions}

The findings reported in this dissertation provide numerous avenues for 
future research. We have uncovered novel associations of STOML2 and CCDC51 with early endosomes and EGFR. Because this is the first report of these associations for either protein, future work is needed to understand the roles these proteins play in endocytic trafficking and potentially EGFR signaling. Although there are currently no commercially available antibodies for CCDC51, the production of these would be critical to study the subcellular localization and functions of this protein. STOML2 KD studies would also be a useful start to determining the role of STOML2 in EGFR trafficking and signaling.

While we began studying RUFY1 in the context of EGFR trafficking and signaling, more work is needed to determine the exact role of RUFY1 in this regard, as well as to uncover the newly discovered survival role of RUFY1. One protein that may serve as an intermediate to these processes is Etk, also known as BMX. As discussed briefly in Chapter IV, one group found that Etk is required for proper early endosome localization of RUFY1 by phosphorylating the RUFY1 coiled-coil domains [90]. Their data suggested that Etk plays a role in the plasma membrane localization of EGFR, which was reversed upon introduction of the RUFY1 FYVE domain into cells. They concluded there is an interplay between Etk, RUFY1, and EGFR.

The interplay of Etk, RUFY1, and EGFR provides a novel perspective for the research presented in this dissertation, particularly in regard to the increased cell number effect that is induced upon loss of RUFY1. For example, if Etk enhances plasma membrane localization of EGFR, and RUFY1 inhibits this effect, then the loss of RUFY1 in cells would likely permit Etk to increase basal 
EGFR plasma membrane localization. The Yang group also found that the enhanced localization of EGFR at the plasma membrane by Etk caused an increase in MAPK activity after EGF stimulation [90]. They hypothesized that the tyrosine kinase Etk is downstream of the signaling protein PI3K. If this is true, then RUFY1 acts as a negative regulator of PI3K activity by inhibiting some of the activities of Etk, which supports the finding in this dissertation that RUFY1 enhances cell survival. The inverse of this would be that loss of RUFY1 permits uninhibited Etk activity. This would explain why blocking EGFR activity did not reverse the increased cell number effect seen in RUFY1 KD cells. Although PI3K is technically downstream of EGFR, if Etk is downstream of PI3K, then removing an Etk inhibitor would permit Etk activity without EGFR activation. However, this would require the activity of some other Etk-activating protein, be it PI3K or another protein (Figure 5.1). Elucidating the relationships between Etk, EGFR, and RUFY1 will likely be critical in uncovering how RUFY1 acts as a driver of cell growth or survival.

There are numerous publications demonstrating that Etk has oncogenic activity. Several clinical groups have shown that Etk overexpression drives cancer cell proliferation and chemoresistance, and that loss of Etk diminishes these effects [119-122]. These claims support the hypothesis that if RUFY1 does in fact inhibit Etk activity, then RUFY1 has enhanced cell survival or growth effects. Yang and colleagues reported that there are two potential binding sites for RUFY1 and Etk to interact with one another [90]. This supports the notion of RUFY1 inhibition of Etk. Only one study has demonstrated this effect, and future 


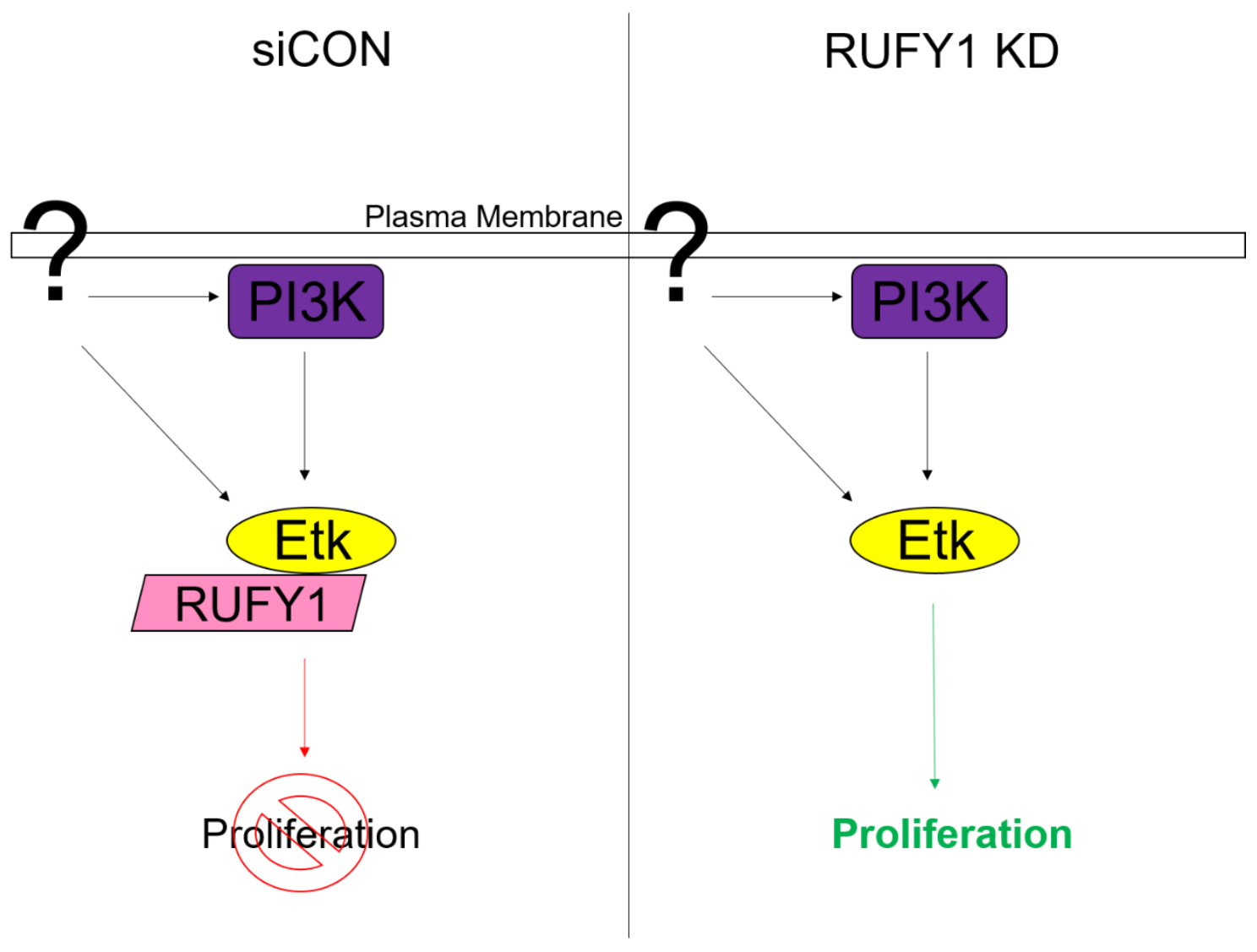

Figure 5.1 A schematic representation of a signaling pathway permitting Etk to drive cell survival rates in RUFY1 KD cells. 
studies will be crucial in validating this finding and determining any other effects induced by RUFY1 and Etk interactions.

One study that will be critical for testing the enhanced cell survival activities of RUFY1 is to measure Etk activity in RUFY1 KD cells. If Etk activity is enhanced after RUFY1 loss, then this should be easily measured using biochemical techniques. It is possible that Etk phosphorylation is not increased, but instead the loss of RUFY1 may permit additional interactions of Etk with other proteins. It will be important to determine not only where RUFY1 and Etk are binding but how this interaction changes the activity of Etk, be it structurally or catalytically. One means to measure this would be to isolate the two proteins and visualize their interaction using X-ray crystallography. Mutating various sites on both proteins and creating dominant negative mutants will also be a useful means for determining what domains of the proteins are interacting and how each domain affects the function of each protein. However, the enhanced survival activity of RUFY1 may be independent of Etk activity. Testing this would require a simple experiment where both RUFY1 and Etk are knocked down in HeLa cells. If loss of Etk inhibits the enhanced growth of RUFY1 KD cells, then Etk is very likely to be the driver of cell growth upon RUFY1 loss. If Etk loss does not inhibit this effect, then there is some other process mediating the increased survival of RUFY1 KD cells that would need to be further explored. It is also possible that Etk KD introduces additional effects to the cells. Etk KD alone in HeLa cells should also be tested to determine how Etk loss affects HeLa cell growth. Then, one could also determine if the loss of both Etk and RUFY1 has a 
synergistic effect on enhancing cell growth or survival. These studies will be important for understanding the relationship between Etk and RUFY1.

Another caveat of RUFY1 and Etk interactions is that Etk phosphorylation of RUFY1 is required for early endosomal localization of RUFY1 [90]. This role could also be due to Etk being downstream of PI3K and could explain why we detected an EGF-dependent localization of RUFY1 with early endosomes in Chapter III. In other words, EGFR activation induces activation of the PI3K pathway, including Etk, which phosphorylates RUFY1 and induces its localization to early endosomes. However, as addressed in Chapter IV, other reports have shown that RUFY1 is predominantly localized to early endosomes [95]. One means for determining the role of Etk in RUFY1 localization is to knock down Etk and monitor the localization of RUFY1 using immunofluorescence. This would determine if Etk is necessary for RUFY1 localization to early endosomes. This is another important aspect of the relationship between Etk and RUFY1 that needs to be elucidated to better understand their functions in endocytic trafficking.

Though not exhaustive, we have presented multiple avenues for future work that will be critical for expanding upon the findings of this dissertation. The functional role of CCDC51 has yet to be determined, in regard to early endosomal trafficking and otherwise. The mitochondrial protein STOML2 has unknown roles in EGFR trafficking and signaling as well as cancer cell proliferation that have yet to be elucidated. Finally, the survival effect of RUFY1 reported herein is the first of its kind. The mechanism behind this effect could be due to the activity of the protein Etk. A number of experiments have been 
proposed that will be critical in determining the role of Etk in this phenomenon, as well as the role of Etk on EGFR trafficking.

The original goal of this research was focused on elucidating the effects of spatial regulation on EGFR signaling. In the process of pursuing this question, we have uncovered several new proteins as effectors of EGFR in early endosomes. While several new avenues of research have been presented that could drive entirely novel fields of work, these proteins may also be important drivers in EGFR trafficking and signaling. Future work that is focused on uncovering the roles of these proteins in this manner will be crucial factors in driving the field's understanding of EGFR spatial regulation, endocytic trafficking, and mitogenic signaling. 


\section{REFERENCES}

1. Levi-Montalcini, R. and S. Cohen, Effects of the extract of the mouse submaxillary salivary glands on the sympathetic system of mammals. Ann N Y Acad Sci, 1960. 85: p. 324-41.

2. Cohen, S., Isolation of a mouse submaxillary gland protein accelerating incisor eruption and eyelid opening in the new-born animal. J Biol Chem, 1962. 237: p. 1555-62.

3. Cohen, S., R.A. Fava, and S.T. Sawyer, Purification and characterization of epidermal growth factor receptor/protein kinase from normal mouse liver. Proc Natl Acad Sci U S A, 1982. 79(20): p. 6237-41.

4. Weltman, J.K., The 1986 Nobel Prize for Physiology or Medicine awarded for discovery of growth factors: Rita Levi-Montalcini, M.D., and Stanley Cohen, Ph.D. N Engl Reg Allergy Proc, 1987. 8(1): p. 47-8.

5. Cohen, S., Purification of a nerve-growth promoting protein from the mouse salivary gland and its neuro-cytotoxic antiserum. Proc Natl Acad Sci U S A, 1960. 46(3): p. 302-11.

6. Cohen, S., et al., A native 170,000 epidermal growth factor receptorkinase complex from shed plasma membrane vesicles. Journal of Biological Chemistry, 1982. 257(3): p. 1523-1531.

7. Garrett, T.P., et al., Crystal structure of a truncated epidermal growth factor receptor extracellular domain bound to transforming growth factor alpha. Cell, 2002. 110(6): p. 763-73.

8. Wells, A., et al., Ligand-induced transformation by a noninternalizing epidermal growth factor receptor. Science, 1990. 247(4945): p. 962-4.

9. Hashimoto, A., et al., Shc regulates epidermal growth factor-induced activation of the JNK signaling pathway. J Biol Chem, 1999. 274(29): $\mathrm{p}$. 20139-43.

10. Miettinen, P.J., et al., Epithelial immaturity and multiorgan failure in mice lacking epidermal growth factor receptor. Nature, 1995. 376(6538): p. 33741.

11. Miettinen, P.J., et al., Epidermal growth factor receptor function is necessary for normal craniofacial development and palate closure. Nat Genet, 1999. 22(1): p. 69-73.

12. Veale, D., et al., Epidermal growth factor receptors in non-small cell lung cancer. Br J Cancer, 1987. 55(5): p. 513-6.

13. Bhargava, R., et al., EGFR gene amplification in breast cancer: correlation with epidermal growth factor receptor $m R N A$ and protein expression and HER-2 status and absence of EGFR-activating mutations. Mod Pathol, 2005. 18(8): p. 1027-33. 
14. Dancer, J., et al., Coexpression of EGFR and HER-2 in pancreatic ductal adenocarcinoma: a comparative study using immunohistochemistry correlated with gene amplification by fluorescencent in situ hybridization. Oncol Rep, 2007. 18(1): p. 151-5.

15. $\mathrm{Li}, \mathrm{Q}$., et al., EGFR protein expression and gene amplification in squamous intraepithelial lesions and squamous cell carcinomas of the cervix. Int J Clin Exp Pathol, 2014. 7(2): p. 733-41.

16. Kearsley, J.H., et al., An immunohistochemical assessment of cellular proliferation markers in head and neck squamous cell cancers. $\mathrm{Br} \mathrm{J}$ Cancer, 1990. 61(6): p. 821-7.

17. Spano, J.P., et al., Impact of EGFR expression on colorectal cancer patient prognosis and survival. Ann Oncol, 2005. 16(1): p. 102-8.

18. Kuan, C.T., C.J. Wikstrand, and D.D. Bigner, EGF mutant receptor vIll as a molecular target in cancer therapy. Endocr Relat Cancer, 2001. 8(2): $\mathrm{p}$. 83-96.

19. Molina, J.R., et al., Non-small cell lung cancer: epidemiology, risk factors, treatment, and survivorship. Mayo Clin Proc, 2008. 83(5): p. 584-94.

20. Motohiro, A., et al., Prognosis of non-surgically treated, clinical stage I lung cancer patients in Japan. Lung Cancer, 2002. 36(1): p. 65-9.

21. Shigematsu, H., et al., Clinical and biological features associated with epidermal growth factor receptor gene mutations in lung cancers. J Natl Cancer Inst, 2005. 97(5): p. 339-46.

22. Bertotti, A. and F. Sassi, Molecular Pathways: Sensitivity and Resistance to Anti-EGFR Antibodies. Clin Cancer Res, 2015. 21(15): p. 3377-83.

23. Jorge, S.E., S.S. Kobayashi, and D.B. Costa, Epidermal growth factor receptor (EGFR) mutations in lung cancer: preclinical and clinical data. Braz J Med Biol Res, 2014. 47(11): p. 929-39.

24. Chong, C.R. and P.A. Janne, The quest to overcome resistance to EGFRtargeted therapies in cancer. Nat Med, 2013. 19(11): p. 1389-400.

25. Morgillo, F., et al., Heterodimerization of insulin-like growth factor receptor/epidermal growth factor receptor and induction of survivin expression counteract the antitumor action of erlotinib. Cancer Res, 2006. 66(20): p. 10100-11.

26. Petrelli, F., et al., Different Toxicity of Cetuximab and Panitumumab in Metastatic Colorectal Cancer Treatment: A Systematic Review and MetaAnalysis. Oncology, 2018. 94(4): p. 191-199.

27. Sun, P., et al., Rapid onset of conjunctivitis associated with overdosing of erlotinib. J Clin Pharm Ther, 2018. 43(2): p. 296-298.

28. Kogure, Y., et al., Post-Progression Survival after EGFR-TKI for Advanced Non-Small Cell Lung Cancer Harboring EGFR Mutations. PLoS One, 2015. 10(8): p. e0135393.

29. Ceresa, B.P. and S.L. Schmid, Regulation of signal transduction by endocytosis. Curr Opin Cell Biol, 2000. 12(2): p. 204-10.

30. Di Guglielmo, G.M., et al., Compartmentalization of SHC, GRB2 and mSOS, and hyperphosphorylation of Raf-1 by EGF but not insulin in liver parenchyma. Embo j, 1994. 13(18): p. 4269-77. 
31. Vieira, A.V., C. Lamaze, and S.L. Schmid, Control of EGF receptor signaling by clathrin-mediated endocytosis. Science, 1996. 274(5295): p. 2086-9.

32. Stamos, J., M.X. Sliwkowski, and C. Eigenbrot, Structure of the epidermal growth factor receptor kinase domain alone and in complex with a 4anilinoquinazoline inhibitor. J Biol Chem, 2002. 277(48): p. 46265-72.

33. Felder, S., et al., Kinetics of binding, endocytosis, and recycling of EGF receptor mutants. J Cell Biol, 1992. 117(1): p. 203-12.

34. Grabe, M. and G. Oster, Regulation of organelle acidity. J Gen Physiol, 2001. 117(4): p. 329-44.

35. Carpenter, G. and S. Cohen, 125I-labeled human epidermal growth factor. Binding, internalization, and degradation in human fibroblasts. J Cell Biol, 1976. 71(1): p. 159-71.

36. Chen, W.S., et al., Functional independence of the epidermal growth factor receptor from a domain required for ligand-induced internalization and calcium regulation. Cell, 1989. 59(1): p. 33-43.

37. Wiley, H.S., et al., The role of tyrosine kinase activity in endocytosis, compartmentation, and down-regulation of the epidermal growth factor receptor. J Biol Chem, 1991. 266(17): p. 11083-94.

38. Ouyang, X., et al., Transforming growth factor-alpha short-circuits downregulation of the epidermal growth factor receptor. J Cell Physiol, 1999. 179(1): p. 52-7.

39. Thoresen, G.H., et al., Response to transforming growth factor alpha (TGFalpha) and epidermal growth factor (EGF) in hepatocytes: lower EGF receptor affinity of TGFalpha is associated with more sustained activation of p42/p44 mitogen-activated protein kinase and greater efficacy in stimulation of DNA synthesis. J Cell Physiol, 1998. 175(1): p. 10-8.

40. Jones, J.T., R.W. Akita, and M.X. Sliwkowski, Binding specificities and affinities of egf domains for ErbB receptors. FEBS Lett, 1999. 447(2-3): p. 227-31.

41. Moriai, T., et al., A variant epidermal growth factor receptor exhibits altered type alpha transforming growth factor binding and transmembrane signaling. Proc Natl Acad Sci U S A, 1994. 91(21): p. 10217-21.

42. Perret, E., et al., Evolving endosomes: how many varieties and why? Curr Opin Cell Biol, 2005. 17(4): p. 423-34.

43. Mosesson, Y., G.B. Mills, and Y. Yarden, Derailed endocytosis: an emerging feature of cancer. Nat Rev Cancer, 2008. 8(11): p. 835-50.

44. Pfeffer, S.R., Rab GTPase regulation of membrane identity. Curr Opin Cell Biol, 2013. 25(4): p. 414-9.

45. Pfeffer, S. and D. Aivazian, Targeting Rab GTPases to distinct membrane compartments. Nat Rev Mol Cell Biol, 2004. 5(11): p. 886-96.

46. Chavrier, P., et al., Localization of low molecular weight GTP binding proteins to exocytic and endocytic compartments. Cell, 1990. 62(2): p. 317-29. 
47. Sonnichsen, B., et al., Distinct membrane domains on endosomes in the recycling pathway visualized by multicolor imaging of Rab4, Rab5, and Rab11. J Cell Biol, 2000. 149(4): p. 901-14.

48. Sigismund, S., et al., Clathrin-independent endocytosis of ubiquitinated cargos. Proc Natl Acad Sci U S A, 2005. 102(8): p. 2760-5.

49. Parton, R.G. and K. Simons, The multiple faces of caveolae. Nat Rev Mol Cell Biol, 2007. 8(3): p. 185-94.

50. Kornilova, E., et al., Lysosomal targeting of epidermal growth factor receptors via a kinase-dependent pathway is mediated by the receptor carboxyl-terminal residues 1022-1123. J Biol Chem, 1996. 271(48): p. 30340-6.

51. Lakadamyali, M., M.J. Rust, and X. Zhuang, Ligands for clathrin-mediated endocytosis are differentially sorted into distinct populations of early endosomes. Cell, 2006. 124(5): p. 997-1009.

52. Lafourcade, C., et al., Regulation of the V-ATPase along the endocytic pathway occurs through reversible subunit association and membrane localization. PLoS One, 2008. 3(7): p. e2758.

53. Cain, C.C., D.M. Sipe, and R.F. Murphy, Regulation of endocytic $\mathrm{pH}$ by the $\mathrm{Na}+, \mathrm{K}_{+}-$ATPase in living cells. Proc Natl Acad Sci U S A, 1989. 86(2): p. 544-8.

54. Felder, S., et al., Kinase activity controls the sorting of the epidermal growth factor receptor within the multivesicular body. Cell, 1990. 61(4): $\mathrm{p}$. 623-34.

55. Eden, E.R., et al., The role of EGF receptor ubiquitination in regulating its intracellular traffic. Traffic, 2012. 13(2): p. 329-37.

56. Bright, N.A., M.J. Gratian, and J.P. Luzio, Endocytic delivery to lysosomes mediated by concurrent fusion and kissing events in living cells. Curr Biol, 2005. 15(4): p. 360-5.

57. Galperin, E. and A. Sorkin, Endosomal targeting of MEK2 requires RAF, MEK kinase activity and clathrin-dependent endocytosis. Traffic, 2008. 9(10): p. 1776-90.

58. Damke, $\mathrm{H}$., et al., Tightly regulated and inducible expression of dominant interfering dynamin mutant in stably transformed HeLa cells. Methods Enzymol, 1995. 257: p. 209-20.

59. Vanlandingham, P.A. and B.P. Ceresa, Rab7 regulates late endocytic trafficking downstream of multivesicular body biogenesis and cargo sequestration. J Biol Chem, 2009. 284(18): p. 12110-24.

60. Dinneen, J.L. and B.P. Ceresa, Continual expression of Rab5(Q79L) causes a ligand-independent EGFR internalization and diminishes EGFR activity. Traffic, 2004. 5(8): p. 606-15.

61. Jensen, O.N., et al., Sample preparation methods for mass spectrometric peptide mapping directly from 2-DE gels. Methods Mol Biol, 1999. 112: $\mathrm{p}$. 513-30.

62. Shevchenko, A., et al., In-gel digestion for mass spectrometric characterization of proteins and proteomes. Nat Protoc, 2006. 1(6): $p$. 2856-60. 
63. Jackson, N.M. and B.P. Ceresa, Protein Kinase G facilitates EGFRmediated cell death in MDA-MB-468 cells. Exp Cell Res, 2016. 346(2): $\mathrm{p}$. 224-32.

64. Hyatt, D.C. and B.P. Ceresa, Cellular localization of the activated EGFR determines its effect on cell growth in MDA-MB-468 cells. Exp Cell Res, 2008. 314(18): p. 3415-25.

65. Rush, J.S. and B.P. Ceresa, RAB7 and TSG101 are required for the constitutive recycling of unliganded EGFRs via distinct mechanisms. Mol Cell Endocrinol, 2013. 381(1-2): p. 188-97.

66. Michelsen, U. and J. von Hagen, Isolation of subcellular organelles and structures. Methods Enzymol, 2009. 463: p. 305-28.

67. Schroter, C.J., et al., A rapid method to separate endosomes from lysosomal contents using differential centrifugation and hypotonic lysis of lysosomes. J Immunol Methods, 1999. 227(1-2): p. 161-8.

68. Salomon, I., H. Janssen, and J. Neefjes, Mechanical forces used for cell fractionation can create hybrid membrane vesicles. Int J Biol Sci, 2010. 6(7): p. 649-54.

69. Bergeron, J.J., et al., Differential and analytical subfractionation of rat liver components internalizing insulin and prolactin. Biochemistry, 1986. 25(7): p. $1756-64$.

70. Marsh, M., et al., Rapid analytical and preparative isolation of functional endosomes by free flow electrophoresis. J Cell Biol, 1987. 104(4): p. 87586.

71. de Araujo, M.E., G. Lamberti, and L.A. Huber, Isolation of Early and Late Endosomes by Density Gradient Centrifugation. Cold Spring Harb Protoc, 2015. 2015(11): p. pdb prot083444.

72. van der Goot, F.G., Separation of early steps in endocytic membrane transport. Electrophoresis, 1997. 18(14): p. 2689-93.

73. Silvis, M.R., et al., Rab11b regulates the apical recycling of the cystic fibrosis transmembrane conductance regulator in polarized intestinal epithelial cells. Mol Biol Cell, 2009. 20(8): p. 2337-50.

74. Zlobina, M.V., et al., [Analysis of vesicle subpopulations carrying early endosomal autoantigen EEA1]. Tsitologiia, 2014. 56(10): p. 741-8.

75. Roepstorff, K., et al., Differential effects of EGFR ligands on endocytic sorting of the receptor. Traffic, 2009. 10(8): p. 1115-27.

76. Oksvold, M.P., et al., Re-localization of activated EGF receptor and its signal transducers to multivesicular compartments downstream of early endosomes in response to EGF. Eur J Cell Biol, 2001. 80(4): p. 285-94.

77. Herbst, J.J., et al., Regulation of postendocytic trafficking of the epidermal growth factor receptor through endosomal retention. J Biol Chem, 1994. 269(17): p. 12865-73.

78. Gosney, J.A. and B.P. Ceresa, Using Percoll Gradient Fractionation to Study the Endocytic Trafficking of the EGFR. Methods Mol Biol, 2017. 1652: p. 145-158. 
79. Wallach, D.F., V.B. Kamat, and M.H. Gail, Physicochemical differences between fragments of plasma membrane and endoplasmic reticulum. $\mathrm{J}$ Cell Biol, 1966. 30(3): p. 601-21.

80. Chibalin, A.V., et al., Receptor-mediated inhibition of renal $\mathrm{Na}(+)-K(+)-$ ATPase is associated with endocytosis of its alpha- and beta-subunits. Am J Physiol, 1997. 273(5 Pt 1): p. C1458-65.

81. Khundmiri, S.J., et al., Clathrin-mediated endocytosis of $\mathrm{Na}+, \mathrm{K}+-$-ATPase in response to parathyroid hormone requires ERK-dependent phosphorylation of Ser-11 within the alpha1-subunit. J Biol Chem, 2004. 279(17): p. 17418-27.

82. Feldmann, T., et al., Role of endosomal $\mathrm{Na+}-K_{+-}$-ATPase and cardiac steroids in the regulation of endocytosis. Am J Physiol Cell Physiol, 2007. 293(3): p. C885-96.

83. Beas, A.O., et al., Galphas promotes EEA1 endosome maturation and shuts down proliferative signaling through interaction with GIV (Girdin). Mol Biol Cell, 2012. 23(23): p. 4623-34.

84. Hammond, J.C., et al., Evidence for abnormal forward trafficking of AMPA receptors in frontal cortex of elderly patients with schizophrenia.

Neuropsychopharmacology, 2010. 35(10): p. 2110-9.

85. Doyotte, A., et al., The Bro1-related protein HD-PTP/PTPN23 is required for endosomal cargo sorting and multivesicular body morphogenesis. Proc Natl Acad Sci U S A, 2008. 105(17): p. 6308-13.

86. Cormont, M., et al., A FYVE-finger-containing protein, Rabip4, is a Rab4 effector involved in early endosomal traffic. Proc Natl Acad Sci U S A, 2001. 98(4): p. 1637-42.

87. Hajek, P., A. Chomyn, and G. Attardi, Identification of a novel mitochondrial complex containing mitofusin 2 and stomatin-like protein $2 . \mathrm{J}$ Biol Chem, 2007. 282(8): p. 5670-81.

88. Da Cruz, S., et al., SLP-2 interacts with prohibitins in the mitochondrial inner membrane and contributes to their stability. Biochim Biophys Acta, 2008. 1783(5): p. 904-11.

89. Mari, M., et al., Role of the FYVE finger and the RUN domain for the subcellular localization of Rabip4. J Biol Chem, 2001. 276(45): p. 42501-8.

90. Yang, J., et al., Interaction between tyrosine kinase Etk and a RUN domain- and FYVE domain-containing protein RUFY1. A possible role of ETK in regulation of vesicle trafficking. J Biol Chem, 2002. 277(33): p. 30219-26.

91. Gingras, M.C., J.M. Kazan, and A. Pause, Role of ESCRT component HDPTP/PTPN23 in cancer. Biochem Soc Trans, 2017. 45(3): p. 845-854.

92. Takeuchi, H., et al., Intracellular periodontal pathogen exploits recycling pathway to exit from infected cells. Cell Microbiol, 2016. 18(7): p. 928-48.

93. Kunkle, B.W., et al., Early-Onset Alzheimer Disease and Candidate Risk Genes Involved in Endolysosomal Transport. JAMA Neurol, 2017. 74(9): p. 1113-1122. 
94. Yamada, Y., et al., Identification of five genetic variants as novel determinants of type 2 diabetes mellitus in Japanese by exome-wide association studies. Oncotarget, 2017. 8(46): p. 80492-80505.

95. Yamamoto, H., et al., Functional cross-talk between Rab14 and Rab4 through a dual effector, RUFY1/Rabip4. Mol Biol Cell, 2010. 21(15): p. 2746-55.

96. Fouraux, M.A., et al., Rabip4' is an effector of rab5 and rab4 and regulates transport through early endosomes. Mol Biol Cell, 2004. 15(2): p. 611-24.

97. Ivan, V., et al., AP-3 and Rabip4' coordinately regulate spatial distribution of lysosomes. PLoS One, 2012. 7(10): p. e48142.

98. Cao, L., et al., A novel putative protein-tyrosine phosphatase contains a BRO1-like domain and suppresses Ha-ras-mediated transformation. J Biol Chem, 1998. 273(33): p. 21077-83.

99. Toyooka, S., et al., HD-PTP: A novel protein tyrosine phosphatase gene on human chromosome 3p21.3. Biochem Biophys Res Commun, 2000. 278(3): p. 671-8.

100. Gingras, M.C., et al., HD-PTP is a catalytically inactive tyrosine phosphatase due to a conserved divergence in its phosphatase domain. PLoS One, 2009. 4(4): p. e5105.

101. Castiglioni, S., J.A. Maier, and M. Mariotti, The tyrosine phosphatase HDPTP: A novel player in endothelial migration. Biochem Biophys Res Commun, 2007. 364(3): p. 534-9.

102. Mariotti, M., et al., The tyrosine phosphatase HD-PTP is regulated by FGF-2 through proteasome degradation. Front Biosci, 2006. 11: p. 213843.

103. Mariotti, M., et al., HD-PTP inhibits endothelial migration through its interaction with Src. Int J Biochem Cell Biol, 2009. 41(3): p. 687-93.

104. Mariotti, M., S. Castiglioni, and J.A. Maier, Inhibition of T24 human bladder carcinoma cell migration by RNA interference suppressing the expression of HD-PTP. Cancer Lett, 2009. 273(1): p. 155-63.

105. Gahloth, D., et al., Structural Basis for Specific Interaction of TGFbeta Signaling Regulators SARA/Endofin with HD-PTP. Structure, 2017. 25(7): p. 1011-1024.e4.

106. Lee, J., et al., Structural Study of the HD-PTP Bro1 Domain in a Complex with the Core Region of STAM2, a Subunit of ESCRT-0. PLoS One, 2016. 11(2): p. e0149113.

107. Ali, N., et al., Recruitment of UBPY and ESCRT exchange drive HD-PTPdependent sorting of EGFR to the MVB. Curr Biol, 2013. 23(6): p. 453-61.

108. Mairhofer, M., et al., Stomatin-like protein-1 interacts with stomatin and is targeted to late endosomes. J Biol Chem, 2009. 284(42): p. 29218-29.

109. Zhang, L., et al., Stomatin-like protein 2 is overexpressed in cancer and involved in regulating cell growth and cell adhesion in human esophageal squamous cell carcinoma. Clin Cancer Res, 2006. 12(5): p. 1639-46.

110. Song, L., et al., Knockdown of stomatin-like protein 2 (STOML2) reduces the invasive ability of glioma cells through inhibition of the NFkappaB/MMP-9 pathway. J Pathol, 2012. 226(3): p. 534-43. 
111. Cao, W., et al., High-level SLP-2 expression and HER-2/neu protein expression are associated with decreased breast cancer patient survival. Am J Clin Pathol, 2007. 128(3): p. 430-6.

112. Sun, F., et al., Stomatin-like protein 2 is overexpressed in epithelial ovarian cancer and predicts poor patient survival. BMC Cancer, 2015. 15: p. 746.

113. Xiao, B., et al., Stomatin-like protein 2 expression is associated with clinical survival in patients with cervical cancer. Int J Clin Exp Pathol, 2015. 8(2): p. 1804-9.

114. Miura, G.I., et al., Myopic acts in the endocytic pathway to enhance signaling by the Drosophila EGF receptor. Development, 2008. 135(11): p. 1913-22.

115. Vukmirica, J., et al., The Rab4A effector protein Rabip4 is involved in migration of NIH 3T3 fibroblasts. J Biol Chem, 2006. 281(47): p. 36360-8.

116. Cao, W., et al., Expression of SLP-2 was associated with invasion of esophageal squamous cell carcinoma. PLoS One, 2013. 8(5): p. e63890.

117. Elmore, S., Apoptosis: a review of programmed cell death. Toxicol Pathol, 2007. 35(4): p. 495-516.

118. Gosney, J.A., et al., Proteomics reveals novel Protein associations with early endosomes in an Epidermal Growth Factor-dependent manner. Journal of Biological Chemistry, 2018.

119. Guo, S., et al., Tyrosine kinase ETK/BMX is up-regulated in bladder cancer and predicts poor prognosis in patients with cystectomy. PLoS One, 2011. 6(3): p. e17778.

120. Zhuang, J., et al., The expression and role of tyrosine kinase ETK/BMX in renal cell carcinoma. J Exp Clin Cancer Res, 2014. 33: p. 25.

121. Holopainen, T., et al., Deletion of the endothelial Bmx tyrosine kinase decreases tumor angiogenesis and growth. Cancer Res, 2012. 72(14): $p$. 3512-21.

122. Wang, Q., et al., Etk Interaction with PFKFB4 Modulates Chemoresistance of Small-cell Lung Cancer by Regulating Autophagy. Clin Cancer Res, 2018. 24(4): p. 950-962. 


\section{CURRICULUM VITAE}

Julie A. Gosney, M.S.

University of Louisville School of Medicine

Department of Pharmacology and Toxicology

505 S. Hancock St. Rm 352F

Louisville, KY 40202

jagosn03@louisville.edu

Work: (502) 852-2115

\section{EDUCATION}

University of Louisville, Louisville, KY

$2014-2018$

M.S. in Pharmacology and Toxicology

Anderson University, Anderson, IN

$2008-2012$

B.A. in Biology \& Psychology (double major)

\section{HONORS}

\begin{tabular}{lr}
\hline University of Louisville & \\
IPIBS Fellowship & $2014-2016$ \\
Pharmacology \& Toxicology Department Class President & $2017-2018$ \\
Elected Class Representative & $2015-2018$ \\
Recipient of Graduate Student Council Travel Award & 2015,2017 \\
Elected Graduate Student Ambassador & $2016-2018$ \\
Anderson University & \\
Dean's List (>3.5 GPA, 4 semesters) & $2008-2012$ \\
Distinguished Student Scholarship & $2008-2012$ \\
Dean's Scholarship & 2011 \\
Geneveive \& Harold Smith Scholarship & $2011-2012$ \\
Indiana Higher Education Award & $2009-2010$ \\
Mary Mustin Endowed Scholarship & $2009-2010$ \\
Paris \& Edith Capron Endowed Scholarship & $2009-2010$ \\
T. Moore \& R. Brunt Scholarship & $2009-2010$
\end{tabular}

\section{PUBLICATIONS}

Gosney JA, Wilkey D, Merchant M, Ceresa BP (2018): Proteomics Reveals Novel Protein Associations with Early Endosomes in an EGF-Dependent Manner. Journal of Biological Chemistry (doi:10.1074/jbc.RA117.000632).

Gosney JA, Ceresa BP (2017): Using Percoll Gradient Fractionation to Study the Endocytic Trafficking of the EGFR. Methods in Molecular Biology 1652:145-158. PMID: 2879164. 
Kurlawala Z, Dunaway R, Shah PP, Gosney J, Siskind LJ, Ceresa BP, Beverly LJ (2017) Regulation of Insulin-like Growth Factor Receptors by Ubiquilin1. Biochemical Journal 474(24):4105-4118. PMID: 29054976.

Ceresa BP, Gosney JA, Jackson NM, Rush JS (2018) Epidermal Growth Factor Receptor. In: Choi S. (eds) Encyclopedia of Signaling Molecules. Springer, Cham

\section{ABSTRACTS}

Gosney JA, Ceresa BP (2015). A non-invasive strategy for enriching early endosomes to examine EGFR signaling. Research!Louisville, GRM-9.

Gosney JA, Ceresa BP (2015). A non-invasive strategy for enriching early endosomes to examine EGFR signaling. Mol. Biol. Cell 26, P351.

Gosney JA, Ceresa BP (2016). A non-invasive strategy for enriching early endosomes to examine EGFR signaling. Research!Louisville, GRD-14.

Kurlawala Z, Shah P, Gosney J, Ceresa B, Beverly L (2017). Novel regulation of IGF1R by Ubiquilin1. The American Society for Pharmacology and Experimental Therapeutics (ASPET)/Experimental Biology.

Gosney JA, Wilkey D, Merchant M, Ceresa BP (2017). Proteomics reveals novel protein associations with early endosomes in an EGF-dependent manner. Research!Louisville.

Gosney JA, Wilkey D, Merchant M, Ceresa BP (2017). Proteomics reveals novel protein associations with early endosomes in an EGF-dependent manner. American Society for Cell Biology.

Gosney JA, Wilkey D, Merchant M, Ceresa BP (2018). Proteomics reveals novel protein associations with early endosomes in an EGF-dependent manner. University of Louisville Graduate Student Research Conference.

\section{PRESENTATIONS}

\section{Oral Presentations}

EGFR Signaling from the Early Endosome. University of Louisville, Department of Pharmacology and Toxicology Seminar. March 19, 2015.

EGFR:Effector Communication from the Early Endosome. University of Louisville, Department of Pharmacology and Toxicology Seminar. June 14, 2016.

Isolating Early Endosomes to Study EGFR Trafficking and Signaling. University of Louisville, James Graham Brown Cancer Center Colloquia. September 28, 2016.

\section{Poster Presentations}

A Non-Invasive Strategy for Enriching Early Endosomes to Examine EGFR Signaling. University of Louisville, Research!Louisville Conference. October 27, 2015.

A Non-Invasive Strategy for Enriching Early Endosomes to Examine EGFR Signaling. American Society of Cell Biology National Meeting. December 13, 2015.

A Non-Invasive Strategy for Enriching Early Endosomes to Examine EGFR 
Signaling. University of Louisville, Research!Louisville Conference. October 11, 2016.

A Non-Invasive Strategy for Enriching Early Endosomes to Examine EGFR Signaling. Purdue University, Third Midwest Membrane Trafficking and Signaling Symposium. November 4, 2016.

Proteomics Reveals Novel Protein Associations with Early Endosomes in an EGF-Dependent Manner. University of Louisville, Research!Louisville Conference. September 12, 2017.

Proteomics Reveals Novel Protein Associations with Early Endosomes in an EGF-Dependent Manner. American Society for Cell Biology National Meeting. December 3, 2017.

Proteomics Reveals Novel Protein Associations with Early Endosomes in an EGF-Dependent Manner. University of Louisville, Graduate Student Research Conference. March 3, 2018.

\section{RESEARCH EXPERIENCE}

\section{University of Louisville, Louisville, KY}

Graduate Fellow

08/2014 - 06/2018

- Study the endocytic trafficking and signaling of the epidermal growth factor receptor (EGFR) using various techniques including immunoblotting, indirect immunofluorescence, fluorescence/confocal microscopy, differential and isopycnic centrifugation, immunoprecipitation, LC/MS-MS, electron microscopy, and siRNA transfection \& knock-down, ${ }^{125}$-EGF radioligand degradation assay

- Thesis work focused on developing a method to enrich and purify early endosomes in order to study how the spatial regulation of EGFR affects interactions with signaling effectors

- Tissue culture of HeLa, hTCEpi, A549, H1650, and CHO cells

- Dissertation work involved monitoring the trafficking, biochemistry, and signaling of EGFR in KD cell lines

PGXL Laboratories, Louisville, KY Clinical Laboratory Technician

$12 / 2012-07 / 2014$

- DNA isolation, quantification, and Real Time PCR analysis of genes directly involved in drug metabolisms including SNPs, RFLPs, and CNVs

- Wrote protocols and SOPs for training new employees

- Independently operated machines involved in liquid handling, DNA isolation, and Real Time PCR

- Researched genes including COMT, MLH1, MSH2, and PMS2 for new assay development

- Attended seminars and participated in training for NextGen Sequencing

- Assisted in preparations for CAP certification of the laboratory

- Completed continuing education courses as required each year by HIPAA

Anderson University, Anderson, IN 
- Independently assisted Dr. Kimberly Lyle-Ippolito in studying the impact of high and low-fat diets on gut microbiota in mice

- Responsibilities included caring for 100+ mice, weighing and observing mice, charting differences in weights, collecting samples and isolating bacterial DNA, and analyzing DNA samples using gel electrophoresis and PCR

\section{LEADERSHIP/TEACHING EXPERIENCE}

\section{University of Louisville}

Volunteer Judge for DuPont Manual High School Science Fair March 2017

Elected Pharmacology and Toxicology class representative

$2015-2018$

Elected Graduate Student Ambassador for the University of Louisville School of

Interdisciplinary Graduate Studies

$2016-2018$

Taught pharmacogenetics lecture to $1^{\text {st }}$ year graduate students

2015

\section{Anderson University}

Lab assistant for undergraduate Biology courses: Introduction to Biology, Microbes and Diseases, and Microbiology

$2010-2012$

Tutor for undergraduate Biology courses

$2009-2012$

Elected fundraising officer in women's service sorority

$2011-2012$

\section{SKILLS}

Technical skills: immunoblotting, tissue culture, centrifugation, immunofluorescence, PCR, real-time qPCR, DNA isolation, flow cytometry, spectrophotometry, restriction digests, LC/MS-MS, ASPE, radioligand degradation, confocal microscopy, electron microscopy, siRNA knockdown, etc. Computer skills: Microsoft Word, Excel, PowerPoint, proficient typist, ImageJ, EndNote bibliography software, GraphPad/Prism, Adobe photoshop, SPSS statistical software

Other applicable skills: interpersonal relationships training, excellent verbal and written communication skills, critical thinking, problem-solving, conflict resolution, flexibility and adaptability, detail-oriented, punctual, time-management, creative thinking, short term and long term planning, dependable, extensive experience working as part of a team, able to work well in a team and independently

\section{GRANTS/FELLOWSHIPS}

\section{Submitted}

NIH (F31) 1F31GM122256-01

Gosney (PI) Project Period:

09/01/2016-TBD

Title: EGFR:Effector Communication from the Early Endosome

Goal: To characterize the effects of EGFR spatial regulation on downstream signaling via the endocytic pathway.

\section{MEMBERSHIPS}

American Association for the Advancement of Science (AAAS)

American Society for Cell Biology (ASCB) 


\section{VOLUNTEER WORK}

Forward Church in New Albany, IN—monthly childcare volunteer 2016 - 2018

Serve as Class Representative at University of Louisville 2015 - 2018

Eastside Christian Church in Jeffersonville, IN_monthly greeter 2014 - 2015

Completed 100+ hours volunteer work with women's service sorority at Anderson

University

$2009-2012$

Served on mission trip to Kampala, Uganda

2012

Served on mission trip to Santo Domingo, Dominican Republic

2010

Served on mission trip to Toronto, Canada

2009 